\title{
Are Architecture Principles Effective?
}

Citation for published version (APA):

Borgers, M. A. C. (2021). Are Architecture Principles Effective? A study in Dutch governmental organizations. [Doctoral Thesis, Maastricht University]. Maastricht University. https://doi.org/10.26481/dis.20210709mb

Document status and date:

Published: 01/01/2021

DOI:

10.26481/dis.20210709mb

Document Version:

Publisher's PDF, also known as Version of record

\section{Please check the document version of this publication:}

- A submitted manuscript is the version of the article upon submission and before peer-review. There can be important differences between the submitted version and the official published version of record.

People interested in the research are advised to contact the author for the final version of the publication, or visit the DOI to the publisher's website.

- The final author version and the galley proof are versions of the publication after peer review.

- The final published version features the final layout of the paper including the volume, issue and page numbers.

Link to publication

\footnotetext{
General rights rights.

- You may freely distribute the URL identifying the publication in the public portal. please follow below link for the End User Agreement:

www.umlib.nl/taverne-license

Take down policy

If you believe that this document breaches copyright please contact us at:

repository@maastrichtuniversity.nl

providing details and we will investigate your claim.
}

Copyright and moral rights for the publications made accessible in the public portal are retained by the authors and/or other copyright owners and it is a condition of accessing publications that users recognise and abide by the legal requirements associated with these

- Users may download and print one copy of any publication from the public portal for the purpose of private study or research.

- You may not further distribute the material or use it for any profit-making activity or commercial gain

If the publication is distributed under the terms of Article $25 \mathrm{fa}$ of the Dutch Copyright Act, indicated by the "Taverne" license above, 


\section{Are Architecture Principles}

Effective?

A study in Dutch governmental organizations

Michiel Borgers

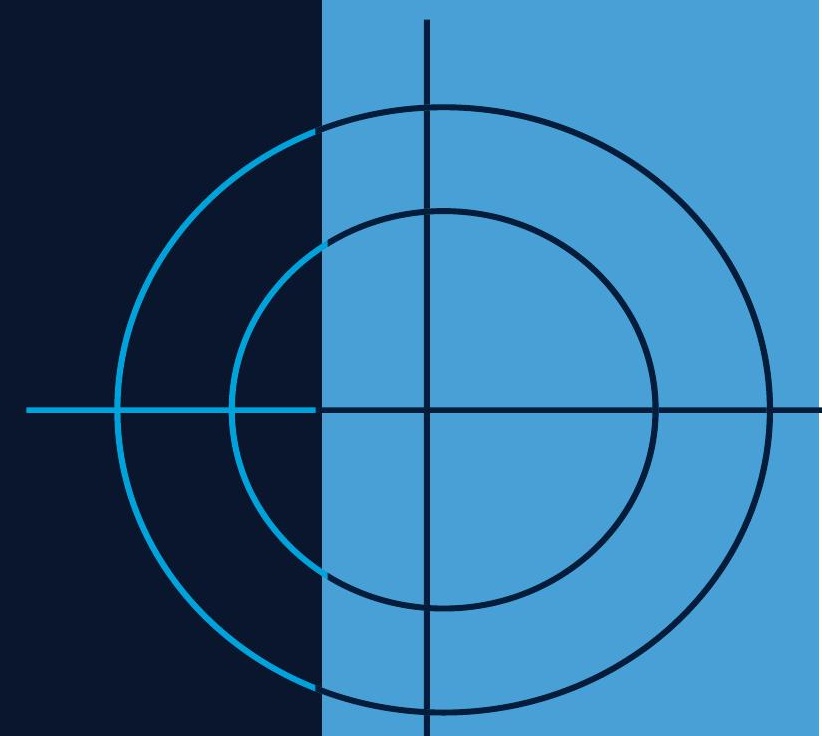


Are Architecture Principles Effective?

A study in Dutch governmental organizations 



\title{
Are Architecture Principles Effective? A study in Dutch governmental organizations
}

\author{
Dissertation
}

to obtain the degree of Doctor at Maastricht University, on the authority of the

Rector Magnificus Prof.dr. Rianne M. Letschert in accordance with the decision of the Board of Deans, to be defended in public on

Friday $9^{\text {th }}$ of July 2021 at 14:00 hours

by

Michiel Antonius Christianus Borgers

Born on September $5^{\text {th }}, 1972$

in Rotterdam 
Supervisor:

Prof. Dr. Frank Harmsen

Co-supervisor:

Prof. Dr. Henderik A. Proper (Luxembourg Institute of Science and Technology, Luxembourg)

Assessment Committee:

Prof. Dr. Roger Meuwissen (Chairman)

Prof. Alexander Brüggen

Prof. Dr. Hans Mulder, Antwerp Management School, Belgium Prof. Dr. Cokky Hilhorst, Nyenrode Business Universiteit

Dr. Bas van Gils

Maastricht University

ISBN: 978-94-6423-297-4

ORCID: 0000-0002-6394-1209

Printed by: OGC Rotterdam

(C) 2021, Michiel Borgers. All rights reserved. No part of this publication may be reproduced or transmitted in any form or by any means electronically or mechanically, including photocopying, recording, or by an information storage and retrieval system, without prior permission in writing from the author. 
To Jeroen 



\section{CONTENTS}

$\begin{array}{ll}\text { PREFACE } & 12\end{array}$

$\begin{array}{ll}\text { ACKNOWLEDGEMENTS } & 13\end{array}$

$\begin{array}{ll}\text { SUMMARY } & 16\end{array}$

$\begin{array}{lll}1 . & \text { INTRODUCTION } & 18\end{array}$

$\begin{array}{lll}1.1 & \text { RESEARCH PROBLEM } & 18\end{array}$

$\begin{array}{ll}1.2 \text { PROBLEM DEFINITION } & 20\end{array}$

1.3 RESEARCH QUESTION 21

1.4 RESEARCH METHODOLOGY 23

$\begin{array}{ll}1.5 \text { OUTLINE } & 27\end{array}$

2. THE DEFINITION AND MEASUREMENT OF ARCHITECTURE PRINCIPLES IN PRACTICE $\quad 28$

2.1 INTRODUCTION 28

2.2 RESEARCH QUESTIONS 29

2.3 RESEARCH METHODOLOGY 30 
2.4 DEFINING AND DESCRIBING ARCHITECTURE PRINCIPLES

2.5 MEASURING ARCHITECTURE PRINCIPLES

2.6 CASE STUDY

2.7 LIMITATIONS, CONCLUSIONS, AND FURTHER RESEARCH

68

3. THE MEASUREMENT OF IS PROJECT SUCCESS IN PRACTICE 74

3.1 INTRODUCTION 74

3.2 RESEARCH METHODOLOGY 74

3.3 WHAT IS IS PROJECT SUCCESS?

3.4 MEASURING SUCCESSFUL IMPLEMENTATION

3.5 LIMITATIONS, CONCLUSIONS, AND FURTHER RESEARCH 94

4. THE CONTRIBUTION OF ARCHITECTURE PRINCIPLES TO IS PROJECT SUCCESS IN PRACTICE

4.1 INTRODUCTION

4.2 RESEARCH METHODOLOGY

4.3 INDIVIDUAL CASE STUDIES

4.4 INDICATORS OF CONTRIBUTION TO IS PROJECT SUCCESS 133

4.5 LIMITATIONS, CONCLUSIONS, AND NEXT STEPS 
5. LIMITATIONS, CONCLUSIONS, AND FURTHER RESEARCH 146

5.1 INTRODUCTION

5.2 METHODOLOGY AND LIMITATIONS

5.3 CONCLUSIONS

5.4 FURTHER RESEARCH 155

5.5 SCIENTIFIC AND SOCIAL IMPACT 157

REFERENCES 160

SAMENVATTING 170

APPENDICES 
PREFACE 


\section{PREFACE}

Principles. Our life is guided by principles: sometimes wittingly and sometimes unwittingly. Implicitly, people are willing to help other people. But, to become an inclusive society in which every individual is equal, we need to have laws, change programs and all other kinds of initiatives to disseminate the message. With that, principles can be tangible or intangible. In both ways, principles are affecting our lives.

Digitization is affecting our life as well. We are living in a digitized world of mobiles, social networks, portals, back office systems, and so on. Governmental organizations are digitized as well: to manage tax returns, to support processes of complaints and appeals, to build statistics, and to manage financial contributions to care providers. Architecture principles, possibly, helped in this digitization of processes.

As the Chief Architect of the Dutch Tax and Customs Administration I was involved in the digitization of many tax, customs and allowance processes. At one day I was wondering about the added value of the architect. Were we, as architects, effective? What was the effect of new Information Systems (ISs) on the digitization of the organization and with that the impact on users? And, because architects like to work with principles, are architecture principles effective? A good question to start some scientific research on.

This research is the first empirical study into the relationship between architecture principles and IS project success. In this research we tried to answer the question "Are architecture principles effective?". Second, we addressed some interesting findings regarding the use of architecture principles. I hope this research inspires all stakeholders responsible for the digitization, to think about the use of architecture principles in 
their projects. I also hope that scientists will do more scientific research about this interesting subject.

\section{Acknowledgements}

Doing PhD research is not a stand-alone operation. Many, many people supported me during this $\mathrm{PhD}$ research in some way. So, thank you all so much for this support even if you are not mentioned here explicitly, because it helped me continuing this research.

First of all, I want to thank my two employers, Willy Rovers (the Dutch Tax and Customs Administrations) and Nick Bos (Maastricht University) enabling the combination of a daytime job and doing scientific research. I strongly believe that both society and science benefit from each other, and we have to combine practice and theory more often.

This empirical research was possible because of the support of four Dutch governmental organizations. Willy Rovers and Jelco Bosma of the Dutch Tax and Customs Administration enabled the TDi-case. Bert Croese and Ronald Ossendrijver of CBS provided the NEST-case. Mark Crooijmans, Henk Volbeda and Lieke van Bers were supporting the Octopus-case at the City Hall of Amsterdam. And, Wim Sijstermans, Muriel Jansen en Lars Pothast helped this research with Epos-case at NZa. I want to thank you all for these opportunities and your time and support during these case studies.

Special thanks to the group of architects and subject matter experts, helping me with reviewing the publications, joining the research teams in the different case studies, participating in the focus group or helping in any other way: Henk van den Berg, Yvette Hoekstra, Robbert Jan van Meenen, Klaas Brongers, Paul Oude Luttighuis, Art Ligthart, Danny Greefhorst, Saco Bekius, Marlies van Steenbergen, Lotje 
Meijknecht, Martin van den Berg, Jim Johnson and Hans Mulder. I always liked the discussions and highly appreciated your contributions, ideas, time and inspiration.

One master student, Thomas Weerts, helped me both with the literature review on measuring IS project success and in developing the measurement instrument. I want to thank you for all the work.

Special thanks to Frank Harmsen. It was a privilege to have you as supervisor. You reviewed the chapters many times, challenged the research approach, and coached me through this journey. This dissertation is a result of your guidance. I also want to thank Erik Proper, as co-supervisor and guru, for all his sharp comments, reviews and detailed insights.

You need many competencies in doing scientific research and in writing your dissertation. Most of them are shaped in your childhood, becoming who you are. Therefore, I want to thank Jeroen, Marjolein, my parents Harrie and Thea and my parentsin-law Ben $\uparrow$ and Trudi being part of the family.

But most of all, I want to express my biggest gratitude and love to my family: Bente, Jens, Finn and Yfke. Their support, commitment and love helped me in the process of doing my PhD and finishing this book. With this book we end this journey and we can start others. 



\section{SUMMARY}

Although we are living in a digitized world, introducing new Information Systems (ISs) seems to be quite difficult. According to industry-based studies, like Standish Group, PMI, and Gartner, the failure rate of IS projects is between 5 and $19 \%$. In Dutch governmental organizations, there was, as an example, in 2020 an overrun of the initial costs with $37 \%$ (1,855 million euros). Therefore, success in implementing requirements in IS projects is not a certainty.

The aim of architecture, and architecture principles, is to focus on the essential requirements, to ensure that the objectives of an IS will be achieved. Therefore, we asked the question "Are architecture principles effective?"

Theory claims that architecture principles contribute positively to IS project success by guiding the design and implementation of IS requirements. To falsify this theory, we measured both the use of architecture principles and IS project success for each case study and placed the outcome in a matrix. To measure the use of principles and IS project success we developed two measurement instruments based on the literature.

We investigated three case studies in Dutch governmental organizations. We plotted the outcome of those measurements into a matrix and analyzed the research data. In these three individual cases we concluded that architecture principles contributed positively to the IS project success. Because other factors could have more impact on IS project success, we were not able to determine the extent to which architecture principles contributed to the success.

Second, we searched for other indicators of contribution as well. Looking across the different case studies we found 
three indicators that may indicate a contribution to IS project success.

We found in each case some "essential architecture principles" that were related to more of the implemented essential requirements and for which the usage of the principles was above average. Second, as architecture principles can be seen as "social constructs" of people who make specific arrangements to direct the design, principles might have been used more often and have more impact than we are aware of. Last, we also have a first indication of the negative impact of principles, due to the use of opposing principles in former nonsuccessful projects. Besides the indicators of contribution across the three case studies, we also have seen indications of added value of enterprise architecture regarding IS project success in the literature.

To our knowledge, the results of this thesis describe the very first empirical study into the relationship between architecture principles and IS project success. Despite all the caveats we have to take into account, we conclude, based on the results of the case studies, that there are indications that architecture principles do contribute positively to IS project success in Dutch governmental organizations. 


\section{INTRODUCTION}

In this chapter, we describe the research problem from a practical and scientific perspective, the main and subsidiary research questions, and the research methodology. Parts of this chapter have been published in [1].

\subsection{Research problem}

We are living in a digitized world. The enormous impact of Information Systems (IS) on our day-to-day life is addressed in daily newspapers and in professional, such as Gartner's reports [2] and [3], Westerman [4], and many others [5]. However, although we use many Information Systems in our private and work lives, introducing new digital technology seems to be quite difficult.

Implementing new Information Systems is challenging. According to industry-based studies, as conducted by e.g. the Standish Group, the PMI, and Gartner, the failure rate of IS projects is between $5 \%$ and $19 \%$ [6], while the (perceived) IS project success is estimated to be $27 \%$ [7] and $35 \%$ [6]. In between these two extremes, there is a category of projects that are neither failures, nor complete successes. And although there might be doubts about the used methodology [8], definitions or scope, the key message of those reports is quite clear: there is room for improvement. This is also acknowledged by the Dutch government, facing the problem of unsuccessful Information System implementations [9]-[11].

Many scientific publications are also addressing the issue of IS project success and failure [12]-[16]. Looking at this research we have to be aware that researchers use the term 'Information System' in different ways. Some of them focus on the technical elements of the system, such as hardware, 
software and data, also referring to the term 'Information Technology' or 'IT'. Other researchers use the terms 'IS' and 'IT' interchangeably [17]. We state that the use of information is more than technology and the successful implementation of digital technology is not a technical challenge only [11], [16]. Therefore we use the definition of an Information System as "a combination of hardware, software, data, people and processes to collect, process, store, and distribute information [18], [19]." As a consequence, IT is a subset of the Information Systems.

In this research, we defined an IS project as being "the design and implementation of an Information System's requirements, so that the Information System will be fit for purpose." In this definition, requirements are key, which is the reason why we defined a requirement as "a property that (a part of) the Information System must possess", consistent with Greefhorst [20] and IEEE [21].

In literature we were also aware that definitions of 'IS project failures' and 'IS project success' may differ [16]. In the past, IS project success was defined with the triangle of "On time", "On budget", "On target", but in the last years there is a shift to a broader view on 'IS project success' [11], [22]. So, in this research we had to define 'IS project success', and with that the opposite 'IS project failure', as we describe in Chapter 3. But in either case, issues with delivering the right requirements is one of the reasons for failures in IS implementations [12], [15], [16], [23].

The aim of architecture is to focus on the essential requirements to ensure that the Information System fits for purpose [20], [24], [25]. To achieve this goal, the meaning of architecture is to restrict the design freedom [20], [27]. Key concepts in architecture are concerns, architecture principles, models, views and frameworks, such as a logical business model, the security view, and the The Open Group's 
Architecture Framework [28]. In this set of instruments, architecture principles are considered to play a key role [20], [29]-[31] in guiding the design and implementation of Information System requirements [32]. Examples of architecture principles are "a fact is stored only once" or "Reuse, before Buy, before Build." After an explorative case study research [33], we concluded that both the definition and description of architecture principles were not sufficiently distinctive to measure them. So, in Chapter 2 we describe and define the architecture principle in detail.

\subsection{Problem definition}

Research has considered the value of architecture in general. For example, Slot [34] concludes "that there are clear indications that enterprise architecture plays a pivotal role in improving the effectiveness of the use of IT and improves IT impact on business performance", including the findings in Table 1. And, Van den Berg [35] investigated the impact of enterprise architecture on IT decision making. Both Kurek [36] and Chaos-report [6] indicates the added value of enterprise architecture regarding the success of IT projects in general (see Table 2). However, all this research only partially addresses the value of architecture principles in particular.

Table 1: Use of solution architecture correlated with project success variables Raymond Slot [34].

\footnotetext{
(a) $19 \%$ decrease in project budget overrun

(b) Increased predictability of project budget planning, which decreases the percentage of projects with large budget overruns from $38 \%$ to $13 \%$

(c) $\quad 40 \%$ decrease in project time overrun

(d) Increased customer satisfaction, with 0.5 to 1 point - on a scale of 1 to 5

(e) $10 \%$ increase of results delivered

(f) Increased technical fit of the project results
} 
Table 2: Resolution by Enterprise Architecture - Chaos 2020 [6].

With Enterprise Architecture

Succesful

Challenged

Failed
54

51

42
Without Enterprise

Architecture

46

49

58

Architecture principles have been studied since the early 1990s, as we have seen in our explorative research [1]. Although much theory has been published concerning the usefulness of architecture principles, there was no scientifically based, empirical evidence of any contribution of architecture principles to the successful implementation of Information System requirements [33]. Therefore, the question is: "Are architecture principles effective?" Do they make a contribution to IS project success?

\subsection{Research question}

Our research involved an investigation into the practical value of architecture principles: are architecture principles effective? In more accurate terms,

\section{Do architecture principles contribute to IS project success?}

To answer this overarching question, we considered the use of architecture principles in the implementation of IS's requirements. We measured both the use of architecture principles and IS project success, to determine if there is a positive or negative contribution in presence of possible other 
success factors. To do so, we needed to answer two subsidiary research questions (see Figure 1).

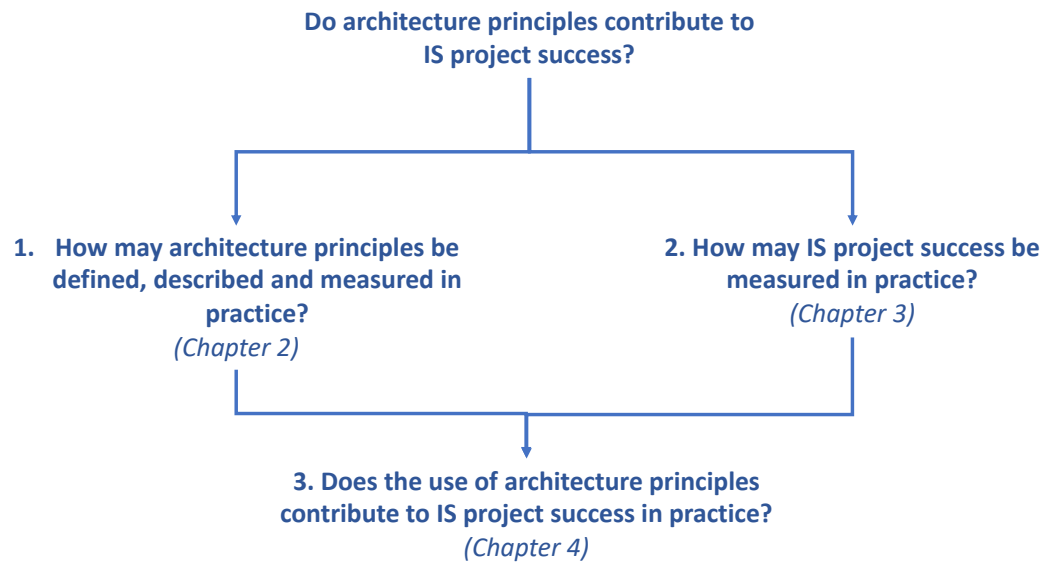

Figure 1: Structure of research questions.

To be able to determine the impact of the use of architecture principles on the successful implementation of the requirements, we first needed to identify and characterize them. When we were able to define and describe architecture principles, we could use this to measure the use of architecture principles in practice. Therefore, the first research question was

\section{How may architecture principles be defined, described and measured in practice?}

Secondly, to determine a connection between the use of architecture principles and the successful implementation of requirements, we also needed to measure IS project success. We defined the second research question as follows: 


\section{How may IS project success be measured in practice?}

Using the answers to both research questions, we could search for a relationship between the use of architecture principles and IS project success. By investigating this relationship, we were able to search for the positive or negative contributions of using architecture principles in practice. Our third research question, therefore, was

\section{Does the use of architecture principles contribute to IS project success in practice?}

\subsection{Research methodology}

Theory claims that architecture principles play a key role in guiding the design and implementation of an IS's requirements and make a positive contribution to the implementation of those requirements as a result. Our aim was to challenge this theory. With Popper [37] in mind, we conducted practical experiments to try to falsify this theory, using real IS projects as case studies. In an extreme case, we could say that if the implementation of requirements is successful without the use of architecture principles, they have no added value and therefore they cannot make a positive contribution.

However, we knew that this research field is contextrelated; the context in which architecture principles are used is also important, in particular for the effect of a principle [20], [30], [38]-[40]. In addition, many other success factors, such as sponsorship and the project team or architecture controls like models or frameworks as described in Section 1.1 [28], may play a role in the implementation of requirements [6]. 
Therefore, we took a more thoughtful approach to falsify the theory, using three possible outcomes (see Figure 2):

1. Negative or no contribution: Other factors were more significant in the failure of the project, or architecture principles made no contribution or a negative contribution to the success of the IS project, or both.

2. A possible positive contribution: Architecture principles did contribute to the extent of an IS project's success unless other factors were more significant in their contribution to the success of the project.

3. No or limited contribution: The IS project was a success with no or limited contribution from architecture principles.

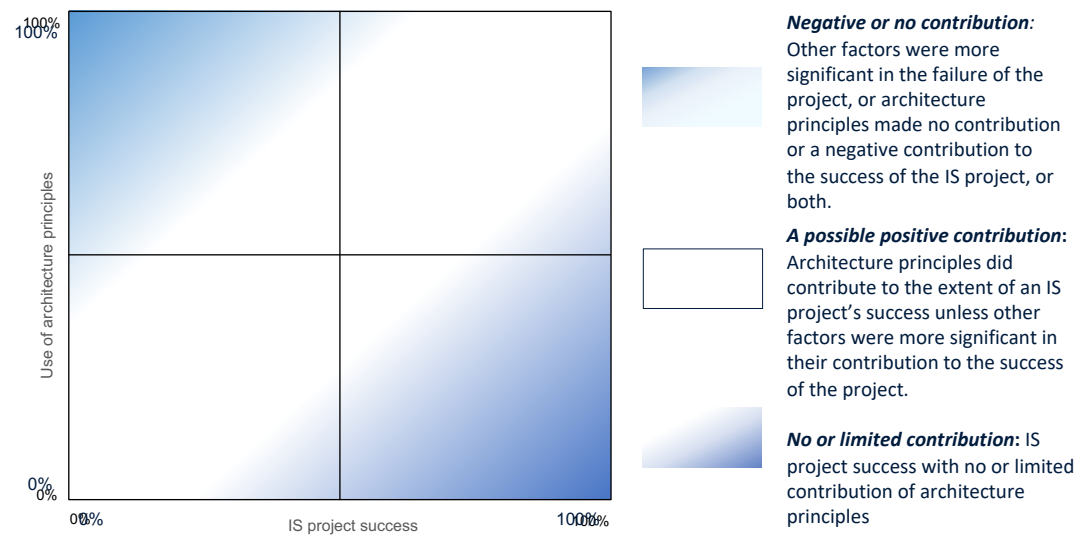

Figure 2: Possible research outcomes.

And, because in practice the use of architecture principles or the IS project success will almost never be fully present or totally absent, we measured the individual case studies on a scale of 0 to $100 \%$ and placed the outcomes in a matrix. There was no research data about the correlation between the use of 
architecture principles and IS project success. So, when analyzing the case studies, we assumed that this correlation is linear. The validation of this assumption was, however, outside the scope of our research. Therefore, although the visualization of the outcome in a matrix helps in drawing conclusions, we were aware of the fact that the positioning of the areas is only indicative.

\section{Research approach}

In this research we chose the use of in-depth case studies as our primary approach. The reason for this is explained below. There are, in general, two reasons for using a case study approach:

1. Early phases of research. Case studies are useful "in early phases of research where there may be no prior hypotheses or previous work of guidance" according to Steenhuis [41] and Eisenhardt [42].

2. Context-related. If a phenomenon is strongly related to its context, case-study research "is used to investigate a specific phenomenon through an in-depth limited-scope study" [42]. Yin states that case studies are necessary "when the boundaries between phenomenon and context are not clearly evident" [43].

As we have described in Section 1.1 there is a lack of research concerning the practical use of architecture principles. In addition, although there is a scientific basis, we liked to challenge its adequacy because it has 'little empirical substantiation' to use Eisenhardt's term [42].

The second reason to choose the case-study approach also applies to our situation. In our literature review, as we describe 
in Section 2.2, we found several authors who have suggested that "the context in which the architecture principles are used, is important as well, in particular for the effect of a principle" [32]. Therefore, architecture principles are conceptual instruments used by people in the context of the design and implementation process.

As the phenomenon of architecture principles is contextrelated, and the fact that there is a lack of empirical research, the use of case studies is justified.

We were aware that by choosing the case study approach, we accepted some limitations. First, the number of case studies was limited and therefore the likelihood of finding a case to falsify the theory was also limited. Second, researchers might be biased in their opinion regarding the specific contribution of architecture principles. Therefore, we needed research protocols to eliminate such opinions as much as possible. Finally, because there are currently no other empirical research results, we were not able to compare the outcome of this research with others.

In this research, we considered whether architecture principles contribute to IS project success or not. Due to the complexity of the research subject, we did not answer, in this stage of research, the question of why architecture principles contribute to IS project success. Therefore, we used a blackbox approach and searched for input and output factors rather than criteria useful for root-cause analysis.

In our black box approach (see Figure 3) we analyzed inputs and outputs of IS projects. The requirements and architecture principles are inputs of the project, and the IS project success is the output. We analyzed these three variables (requirements, architecture principles, and IS project success) and their relationships after the IS project had been finished. We "took a 
picture" of the end state, and we did not investigate what happened with the three variables during IS project execution.

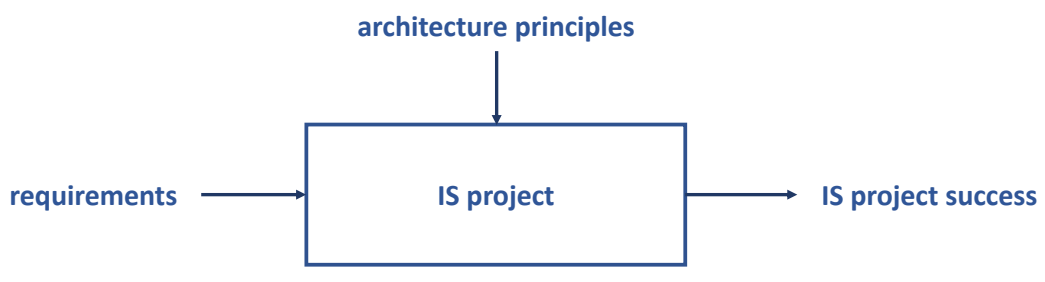

Figure 3: The black-box approach.

In answering the first and second research question, we used a literature study alongside the case-study approach. We used the literature study to develop two measurement instruments necessary to analyze the real-life case studies.

The research results had to be valid and reliable [44]. Therefore, to verify the research outcome, we used the focusgroup method [45] to challenge the results of the case studies and to discuss the overall outcome of this research.

\subsection{Outline}

The outline of this thesis reflects the research questions raised. Therefore, in Chapter 2 we describe how architecture principles are measured. In Chapter 3 we address the measurement of IS project success. Chapter 4 describes the connection between the use of architecture principles and IS project success. We end this thesis, in the conclusion chapter, by answering the overall research question, whether or not architecture principles contribute to IS project success. We also include suggestions for future research. 


\section{THE DEFINITION AND MEASUREMENT OF ARCHITECTURE PRINCIPLES IN PRACTICE}

In this chapter, we describe an instrument for measuring architecture principles that is challenged by a case study at the Dutch Tax and Customs Administration. Sections of this chapter have been published in [32], [33], [46], [47].

\subsection{Introduction}

As described in Chapter 1, architecture principles play, in theory, a key role in guiding the design and the implementation of IS requirements [1], [20], [32]. Because there was no empirical evidence of any contribution that architecture principles make to IS project success [1], [29], [48], we asked the question: "do they have a contribution to IS project success, and if so, is this contribution positive?" To answer this overarching question of our research, we investigated the use of architecture principles in IS projects. After our explorative case study research [33], we concluded that both the definition and description of architecture principles was not sufficiently distinctive to measure them.

This chapter is the result of creating, from theory, an instrument to measure the use of architecture principles, which was challenged in a case study. To create the instrument, we started by defining the research methodology, as described in Section 2.2. In Section 2.3, we formulate a definition and a framework for identifying and describing architecture principles. Section 2.4 provides an architecture principle measurement instrument, based on the definition and framework. The validation results for the measurement instrument, which were based on a real-life case study, are described in Section 2.5. 
We end this chapter with limitations, conclusions, and suggestions for further research.

\subsection{Research questions}

To be able to determine the contribution of architecture principles to IS project success, we first needed to identify and characterize the architecture principles. Second, having a descriptive framework, we were able to measure architecture principles in practice. Therefore, the first research question was

\section{How may architecture principles be defined, described and measured in practice?}

We answered this research question by splitting it into two subsidiary research questions. As we needed to identify and characterize architecture principles, the first subsidiary research question was as follows:

\section{1a. According to the literature, how are architecture principles comprehensively and consistently defined and described?}

For this first subsidiary research question, we addressed two elements: definition and description. A definition is "an explanation of the meaning of a word", while description is "a piece of writing ... that says what something is like" [49]. Definition and description are needed for the identification of architecture principles: What kinds of statements are in scope as architecture principles? To be able to identify architecture principles we needed an exact definition of an architecture principle. Second, we needed a model to describe the 
characteristics of an architecture principle in as exhaustive a manner as possible. Those characteristics describe the architecture principles and are important to be able to measure them.

After answering question 1a, we needed to challenge the outcome in practice. Are the definition and description of the principles useful in a real-life situation, and can we use them to measure architecture principles in practice? Therefore, we phrased the second subsidiary question as follows:

\section{1b. How may architecture principles be measured in practice?}

To answer this question, we first needed a measurement instrument. This instrument consisted of a model to enable the initial identification of architecture principles. Second, we needed to determine the possible values of the characteristics of the principles in practice. In determining the characteristics, it is important that the description is coherent and complete. Nevertheless, a measurement model alone is not enough. We also needed a method to collect and to analyze the data.

To answer research questions $1 \mathrm{a}$ and $1 \mathrm{~b}$, we used the approach described below.

\subsection{Research methodology}

Obviously, we chose to use a literature study to answer question 1a. For question 1b, we used a case-study approach, as described in Section 1.4. 


\section{Literature review}

We concluded in a explorative case study research [33] that both the definition and description of architecture principles was not sufficiently distinctive to measure them. Therefore, we chose to do a comprehensive literature review to describe and define the architecture principle in detail. For the literature review, we used a six-step approach, based on the literaturereview method described by Webster and Watson [50]. This method was also used by Stelzer [38] and Haki [48]. Therefore, we have consensus regarding the process for this area of the research. The six steps were as follows:

1. Defining the boundaries of the literature review

2. Compiling a decomposition model and a framework to analyze and structure the results of the literature review

3. Identifying and selecting relevant literature

4. Reviewing the results of the literature review using our models

5. Answering the subsidiary research questions based on the results of the literature analysis

6. Addressing the limitations, discussing the results, incorporating the response from senior experts on the draft results and presenting final results and implications for further research

- Boundaries of research

Our research focused on architecture principles to be used to implement IS requirements. At the initiation of the literature review, however, we discovered that there is a lack of architecture principle literature related specifically to IS. There is, however, literature on enterprise architecture principles and software architecture principles. IS architecture is part of 
enterprise architecture [28], and therefore it is possible to confine the literature review to enterprise, which we did. Therefore, all conclusions related to principles used in enterprise architecture can also be applied to principles for IS architecture. Consequently, we set the scope of our literature search on architecture principles to consider "Enterprise," "Information System," or "IT."

In addition, as mentioned in Section 2.2, the context in which architecture principles are used is relevant. We narrowed the research scope by focusing on Dutch governmental organizations, resulting in more comparable research results.

- Model and framework for analysis

In step 2, we compiled a decomposition model and a framework to analyze and structure the results that we found in the selected publications. Our aim was to have an instrument to help to decompose the definitions found. This decomposition helps to identify all elements relevant for describing the essence of the term "architecture principle" and to determine which additional elements are not distinctive.

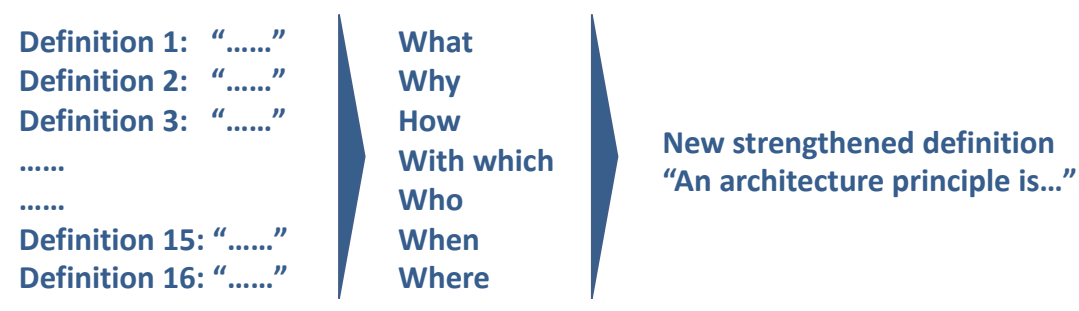

Figure 4: Decomposing architecture principle definitions with $\mathrm{WH}-$ questions.

To determine the essence of a subject, the interrogative "WHquestions" [51] are helpful. We used the seven most-used WH- 
questions ("what," "why," "how," "with which," "who," "when," and "where") to decompose the definitions (see Figure 4). Each element of a definition is attached to one of the questions. After the decomposition of all definitions, we analyzed the similarities and differences in phrasing by question. Based on the analysis, we formulated a new phrasing for a strengthened definition.

We used the framework in UML such as depicted in Figure 5 , to describe the architecture principle. In this framework, in accordance with Fischer and Aier [40], [52], we distinguished the relevant entities and relationships in our research, such as architecture principle, characteristics, and artifacts like design and strategy.

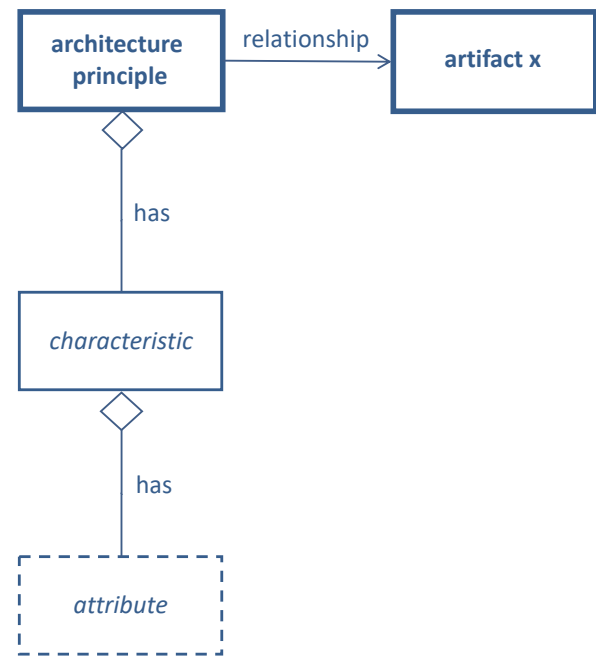

Figure 5: Framework for modelling the characteristics of an architecture principle.

An entity has characteristics, defined as features "belonging typically to an architecture principle and serving to identify it." A characteristic, in turn, has one or more attributes, each of which is "an inherent part of the characteristic." We also addressed 
the relationships between entities and between an entity and its characteristics.

While conducting the literature review, we listed each new characteristic or entity we found in a table, including the definition, attributes, and relationship. When we found a synonym, we added it to the earlier entry. In the end, this resulted in a list of unique characteristics, entities and relationships. As a final step, we designed a model describing the architecture principle, using the framework.

- Identifying and selecting

In step 3, we used various well-known databases, journals, and search mechanisms (EBSCO, Google Scholar, AISeL, and Research Gate) to find relevant literature. In selecting the right publications, we used the following inclusion and exclusion criteria. The first criterion was the selection of English publications only. Second, the title or abstract had to contain at least the combination of terms <architecture principle> AND (<Enterprise $>$ OR $<\mid S>$ OR $<\mid T>$ ).

Because of the large amount of results, we started analyzing the first 60 publications marked as most relevant by the systems. We analyzed the abstracts of those publications and selected those addressing the definition or description of architecture principles in general. We excluded all other literature covering specific fields of application of architecture principles. We stopped searching when publications were addressing only the application of architecture principles. The final list of publications can be found in Table 3. Each of the selected publications was read and analyzed extensively and all relevant information in the publication was structured for analysis.

In some publications, we also found citations of prior literature. When those publications addressed specific 
elements of architecture principles, we added them to our list of publications. In those cases, these publications did not satisfy all selection criteria as described above, because they were addressing another (related) subjects.

\section{Case-study approach}

To answer subsidiary research question $1 \mathrm{~b}$ we chose to use the case-study approach. For the case-study approach we looked at the steps defined by Eisenhardt [53]. Eisenhardt based her steps on literature from other authors, such as Yin, Strauss and Miles [27], [40]-[42], and the experiences of authors who have conducted case studies [57]-[59]. We grouped Eisenhardt's steps into the following three phases:

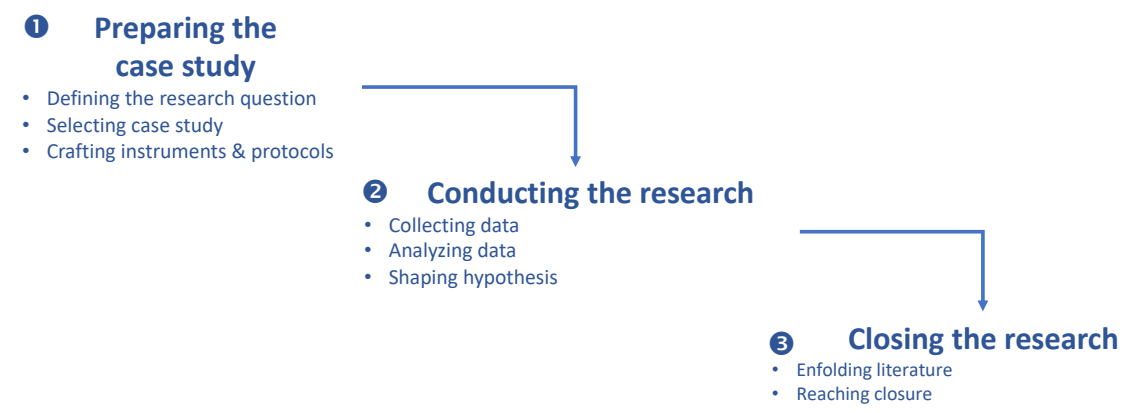

Figure 6: The case-study approach.

1. Preparing the case study

In this phase, we first defined the research question: 'How may architecture principles be measured in practice?' We wanted to answer this question by testing the architecture principle measurement instrument as we describe in Section 2.3 and 2.4 in a case. The test was successful when the 
outcome was complete and coherent and the process was reliable and valid [44].

Second, we selected a case. As our overall research program focuses on Dutch governmental organizations, we chose a case from the Dutch Tax and Customs Administration. Additional reasons to choose this case, were:

- $\quad$ The project used architecture principles

- $\quad$ The project was completed, so that we could determine the actual use of the principles

- $\quad$ The required documents and employees were available to find all relevant data

We started challenging our measurement instrument with one case study only. Because case study research is time consuming, we first wanted to test to what extent the instrument was useful in practice. Depending on the outcome of the first case study, we could decide how to continue. If there was a serious misfit with the instrument itself, we would focus on improving the instrument. If the instrument was performing well in practice, we could continue our research project and optimize the measurement instrument with new case studies where necessary.

We built our measurement instrument and method as described in Section 2.4. We also staffed our research team of subject-matter experts with two independent architects and defined a short survey for the first data collection.

\section{Conducting the research}

This was the iterative phase of data collection, analysis, and theory building. We collected the data from documents, survey, interviews, and a site visit. Based on the results of our desk research and survey, we targeted specific elements of the framework during our interviews. We used an 
extensive spreadsheet containing our measurement instrument to collect all relevant data. During this phase, we refined our measurement instrument, adding new characteristics and attributes as we describe in Section 2.5. After all data were collected, the research team evaluated both the measurement model and the method and made suggestions for improvement.

3. Closing the research

In the last phase we compared the results of the case study with our framework based on the existing literature described in Section 2.3. We decided to close the case study because there were no new data sources to investigate. We ended the case study after evaluating all possible data sources in our spreadsheet and the evaluation of the instrument and method. We reported the results of the case study to the Dutch Tax and Customs Administration. We closed the research by answering the research question as we describe in Section 2.6.

We used these steps to optimize the reliability and validity of the research approach, as well as the objectivity of the data found in the case-study [44].

\subsection{Defining and describing architecture principles}

The analysis of the literature review leads to the answer of research question $1 \mathrm{a}$. We start with the general research results, and we provide the definition and description of the architecture principles, respectively, in the two following subsections. 


\title{
General literature study results
}

\begin{abstract}
After the publication search and selection, using the selection criteria defined in step 3 of the literature review literature (Section 2.2), we found 33 publications for defining and describing architecture principles (see Table 3). These publications cover the years 1990 - 2020.
\end{abstract}

Table 3. Relevant publications related to defining and describing architecture principles.

\begin{tabular}{|c|c|c|c|}
\hline $\begin{array}{l}\mathrm{Nr} . \\
1\end{array}$ & $\begin{array}{l}\text { Title of publication } \\
\text { A Principles-Based Enterprise Architecture: } \\
\text { Lessons from Texaco and Star Enterprise }\end{array}$ & $\begin{array}{l}\text { Author } \\
\text { G.L. Richardson, et al. }\end{array}$ & $\begin{array}{l}\text { YoP } \\
1990\end{array}$ \\
\hline 2 & A Big-Picture Look at Enterprise Architectures & F.J. Armour, et al. & 1999 \\
\hline 3 & $\begin{array}{l}\text { Enterprise Architecture: Enabling Integration, } \\
\text { Agility and Change }\end{array}$ & J. Hoogervorst & 2004 \\
\hline 4 & $\begin{array}{l}\text { Enterprise Architectures - Review on Concepts, } \\
\text { Principles and Approaches }\end{array}$ & D. Chen, et al. & 2004 \\
\hline 5 & $\begin{array}{l}\text { Giving Meaning to Enterprise Architectures - } \\
\text { Architecture Principles with ORM and ORC }\end{array}$ & P. van Bommel, et al. & 2006 \\
\hline 6 & $\begin{array}{l}\text { On the Syntax and Semantics of Architectural } \\
\text { Principles }\end{array}$ & Ä. Lindström & 2006 \\
\hline 7 & Impact of principles on Enterprise Engineering & $\begin{array}{l}\text { Martin Op 't Land, Erik } \\
\text { Proper }\end{array}$ & 2007 \\
\hline 8 & $\begin{array}{l}\text { Architecture principles - A regulative } \\
\text { perspective on enterprise architecture }\end{array}$ & Van Bommel, et al. & 2007 \\
\hline 9,10 & $\begin{array}{l}\text { The Open Group Architecture Framework } \\
\text { TOGAF }^{\mathrm{TM}}\end{array}$ & The Open Group & $\begin{array}{l}2007 \\
2011\end{array}$ \\
\hline 11 & $\begin{array}{l}\text { Enterprise Architecture Principles: Literature } \\
\text { Review and Research Directions }\end{array}$ & Dirk Stelzer & 2009 \\
\hline 12 & $\begin{array}{l}\text { The Roles of Principles in Enterprise } \\
\text { Architecture }\end{array}$ & $\begin{array}{l}\text { Erik Proper, Danny } \\
\text { Greefhorst }\end{array}$ & 2010 \\
\hline 13 & What Is an Enterprise Architecture Principle? & $\begin{array}{l}\text { Christian Fischer, Robert } \\
\text { Winter, Stephan Aier }\end{array}$ & 2010 \\
\hline 14 & $\begin{array}{l}\text { A Conceptual Framework for Enterprise } \\
\text { Architecture Design }\end{array}$ & Sabine Buckl & 2010 \\
\hline 15 & $\begin{array}{l}\text { Enterprise Architecture Principles and their } \\
\text { impact on the Management of IT Investments }\end{array}$ & Kalevi Pessi, et al. & 2010 \\
\hline 16 & $\begin{array}{l}\text { How are Enterprise Architecture Design } \\
\text { Principles Used? }\end{array}$ & $\begin{array}{l}\text { Robert Winter, Stephan } \\
\text { Aier }\end{array}$ & 2011 \\
\hline 17 & $\begin{array}{l}\text { Construction and Evaluation of a Meta-Model } \\
\text { for Enterprise Architecture Design Principles }\end{array}$ & $\begin{array}{l}\text { Stephan Aier, Christian } \\
\text { Fischer, Robert Winter }\end{array}$ & 2011 \\
\hline
\end{tabular}


19 New Avenues for Theoretical Contributions in Enterprise Architecture Principles - a Literature Review

20 The Dutch State of the Practice of Architecture Principles

$21 \quad$ Enterprise Architecture Principles. In Research And Practice: Insights From An Exploratory Analysis

22 A Principle-based Goal-oriented Requirements Language (GRL) for Enterprise Architecture

23 Alignment of Enterprise Architecture Principles: A Case Study

$24 \quad$ Measuring and Managing the Design Restriction of Enterprise Architecture (EA) Principles on EA Models

25 The nature and a Process for Development of Enterprise Architecture Principles system's requirements realisation?

27 Case report of identifying and measuring IT architecture principles in the Dutch Tax Agency Formalizing and Modeling Enterprise

Proper

Mohammad Kazem Haki,

Christine Legner

Danny Greefhorst, Erik

Proper, Georgios

Plataniotis

Mohammad Kazem Haki,

Christine Legner

Diana Marosin, Sepideh

Ghanavati, Dirk van der

Linden

Christer Tallberg, Kalevi

Pessi, et al.

Diana Marosin, Sepideh

Ghanavati

Kurt Sandkuhl, Daniel

Simon, Matthias

Wissotzki, Christoph

Starke

Michiel Borgers

Michiel Borgers,

Frank Harmsen

Diana Marosin, Marc van

Zee, Sepideh Ghanavati

Requirements Language (GRL)

29 A semi-formal evaluation of architecture design based on architecture principles

Diana Marosin, Sepideh

Ghanavati

Omer Uludag, Erik

Proper, ea. principles for supporting large-scale agile transformations

$31 \quad$ Understanding architecture principles as working mechanisms

Mark Paauwe
Mark Paauwe
Kazem Haki, Christine
Legner

2012

2013

2013

2014

2015

2015

2015

To define and describe architecture principles, all selected publications use the literature review as research method. Some of those literature reviews are comprehensive literature studies, like Stelzer [38], Aier [52] and Haki [48], [29], others are referring to previous publications, such as Marosin [60] and 
TOGAF [24]. Some of the publications introduce new definitions and descriptions; others strengthen existing ones. Many publications confirm and use the conclusions of previous publications. Three publications use surveys as research method as well, but only one for investigating the specification of architecture principles [31].

All authors confirm the importance of architecture principles for the architecture and design of systems. Architects state that architecture principles have added value, not only from a theoretical perspective, but in practice, according to some limited, indicative surveys [29]-[31].

Most of the publications describe architecture principles in general, calling them enterprise architecture (EA) principles. Only a few are related to a specific layer of the architecture, such as the business, IS, application, or IT [20], [61], [62]. There are nine authors using the general term 'architecture principles' in their publications [20], [31], [63]-[70]. Therefore, as discussed in Section 2.2, we used the more general yet still applicable literature on EA principles as well.

Our research shows that, in general, there has been consensus concerning architecture principle definitions and characteristics over the last decades. Only Paauwe recently claimed that "the principle of a concept (a concept principle) is the enforced way a concept works, producing results" and should always be true, as a law of nature [68], [69]. In other words, as Haki says, it is a scientific principle [70]. If a principle is always true, and therefore it is also true in the current situation, will it help to direct a change to a new situation? If the idea is considered more closely, the author is suggesting using a format for describing a principle including the necessary preconditions. In that sense, it could be argued that this type of principle is still a normative principle, standing that the preconditions should be fulfilled. 
Therefore, we stated that architecture principles are normative principles, as they are declarative statements [67], [70] and we concluded there is consensus about defining and describing architecture principles. Nevertheless, we did find some inaccuracy or incompleteness in the publications, which we elaborate in the next two sections to strengthen the definition and description of an architecture principle.

\section{Definition of an architecture principle}

To define architecture principles, we first listed all definitions found in the literature in a table (see Table 1 in appendix A for an overview of all definitions). In this overview, it is interesting to see that the definitions in later publications are a consolidation of previous definitions and are evolving to become more comprehensive. In Fischer [40] and Haki [29], the elaboration of the definitions is quite detailed, making them, in our terms, descriptions rather than definitions. It is noteworthy to see that there were no significantly deviating definitions or remarks on prior publications.

To provide insight into the similarities and differences between the definitions, we decomposed the definitions using $\mathrm{WH}$-questions. During the analysis, we focused on the essence of an architecture principle. The definition, also, should be comprehensive and consistent. Here, we address the similarities and differences by WH-question (see Table 4).

In describing the determining elements of an architecture principle, most authors agree that an architecture principle is a statement or a type of design principle. In accordance with Haki et al. [29] and Fischer et al. [40], we stated that an architecture principle should be "based on business and IT strategy" because with architecture we wanted to focus on the essential 


\section{requirements. Although many authors do agree that an architecture principle is a type of design principle, we omited this because we address the design element later in the definition.}

\section{Table 4. Decomposition and consolidation of an architecture principle definition.}

\begin{tabular}{|c|c|c|c|}
\hline $\begin{array}{l}\text { Interrogative } \\
\text { question }\end{array}$ & Explanation & Definitions in literature & $\begin{array}{l}\text { Consolidated } \\
\text { description for } \\
\text { architecture } \\
\text { principle }\end{array}$ \\
\hline What & $\begin{array}{l}\text { What is an } \\
\text { architecture } \\
\text { principle? } \\
\text { Describing the } \\
\text { determining } \\
\text { elements. }\end{array}$ & $\begin{array}{l}\text { are organization's basic } \\
\text { philosophies [71], are simple, } \\
\text { direct statements [72], are design } \\
\text { principles [61], are rules [73], } \\
\text { defines the underlying general } \\
\text { rules and guidelines [63], are } \\
\text { fundamental propositions [38], is } \\
\text { based on business and IT } \\
\text { strategy [40], a declarative } \\
\text { statement [20], should be based } \\
\text { on business and IT strategies } \\
\text { [29], have been defined as } \\
\text { guidelines and rationales [74], } \\
\text { can be seen as 'rules of conduct' } \\
\text { [74], is described in a principal } \\
\text { statement [29], an enterprise- } \\
\text { specific and abstract, yet simple } \\
\text { collection of statements [75], } \\
\text { which generally provide a } \\
\text { framework [75], Resulting [68] }\end{array}$ & $\begin{array}{l}\text { is a declarative } \\
\text { statement, as a } \\
\text { specific type of } \\
\text { design principle, } \\
\text { based on } \\
\text { business and IT } \\
\text { strategy. }\end{array}$ \\
\hline How & $\begin{array}{l}\text { How does the } \\
\text { principle work? } \\
\text { Describing the } \\
\text { manner of the } \\
\text { principle. }\end{array}$ & $\begin{array}{l}\text { establish a context for } \\
\text { architecture design decisions by } \\
\text { translating business criteria into } \\
\text { language and specifications [72], } \\
\text { put boundaries around decisions } \\
\text { about system architecture [72], } \\
\text { can be attributed to different } \\
\text { layers [29], that normatively } \\
\text { prescribes a property of the } \\
\text { design of an artifact [20], can be } \\
\text { attributed to different architectural } \\
\text { layers [40], refer to the } \\
\text { construction of an organization } \\
\text { [29], can be made more precise }\end{array}$ & $\begin{array}{l}\text { It normatively } \\
\text { describes a } \\
\text { property of the } \\
\text { design of an IS, }\end{array}$ \\
\hline
\end{tabular}




\begin{tabular}{|c|c|c|c|}
\hline Why & $\begin{array}{l}\text { Why is the } \\
\text { architecture } \\
\text { principle } \\
\text { described? } \\
\text { Describing the } \\
\text { reason(s) or } \\
\text { objectives to } \\
\text { achieve. }\end{array}$ & $\begin{array}{l}\text { that guide the development of the } \\
\text { architecture [71], for the constant } \\
\text { examination and re-evaluation of } \\
\text { technology plans [71], how an } \\
\text { enterprise wants to use IT [72], } \\
\text { for the use and deployment of all } \\
\text { IT resources and assets across } \\
\text { the enterprise [63], that guide the } \\
\text { description, construction, and } \\
\text { evaluation of enterprise } \\
\text { architectures [38], saying what to } \\
\text { improve [40], reaching a } \\
\text { predefined goal [20], that should } \\
\text { be met by the architecture [24], to } \\
\text { ensure the artifact meets its } \\
\text { essential requirements [20], why } \\
\text { this principle is helpful in attaining } \\
\text { a predetermined goal [29], for the } \\
\text { design and evolution of } \\
\text { technology plans [74], for } \\
\text { decision making and thus support } \\
\text { of the transformation process of } \\
\text { an enterprise from a current to a } \\
\text { target EA [75], resulting [68] }\end{array}$ & $\begin{array}{l}\text { which is } \\
\text { necessary to } \\
\text { ensure the IS } \\
\text { meeting its } \\
\text { essential } \\
\text { requirements. }\end{array}$ \\
\hline Which & $\begin{array}{l}\text { With which } \\
\text { elements is an } \\
\text { architecture } \\
\text { principle } \\
\text { included? } \\
\text { Describing the } \\
\text { elementary } \\
\text { components of } \\
\text { an architecture } \\
\text { principle. }\end{array}$ & $\begin{array}{l}\text { provide guidelines and rationales } \\
\text { [71], a rationale is formulated } \\
\text { explaining why the principle is } \\
\text { meant to help [40], concrete } \\
\text { implications or key actions are } \\
\text { described [40], measurement is a } \\
\text { key issue of EA principles..it } \\
\text { should be defined how to } \\
\text { determine its fulfillment [40], } \\
\text { should be described in a principle } \\
\text { statement, along with a } \\
\text { rationale...., as well as } \\
\text { implications [29], metrics should } \\
\text { be identified for each principle to } \\
\text { measure its fulfilment [29] }\end{array}$ & [Not relevant] \\
\hline Who & $\begin{array}{l}\text { Who is using } \\
\text { the architecture } \\
\text { principle? } \\
\text { Describing the } \\
\text { personal } \\
\text { related to the } \\
\text { architecture } \\
\text { principle. }\end{array}$ & $\begin{array}{l}\text { that technology managers can } \\
\text { understand and use [72] }\end{array}$ & [Not relevant] \\
\hline
\end{tabular}

and operational by formalization [74], by [68]

that guide the development of the architecture [71], for the constant examination and re-evaluation of description, construction, and valuation of enterprise improve [40], reaching a predefined goal [20], that should be met by the architecture [24], to decision making and thus support of the transformation process of an enterprise from a current to a target EA [75], resulting [68] guidelines and ration [71], a rationale is formulated explaining why the principle is meant to help [40], concrete mplications or key actions are key issue of EA principles..it should be defined how to determine its fulfillment [40] should be described in a principle statement, along with a rationale...., as well as be identified for each principle to measure its fulfilment [29] that technology managers can the architecture understand and use [72] principle? Describing the personal principle. 


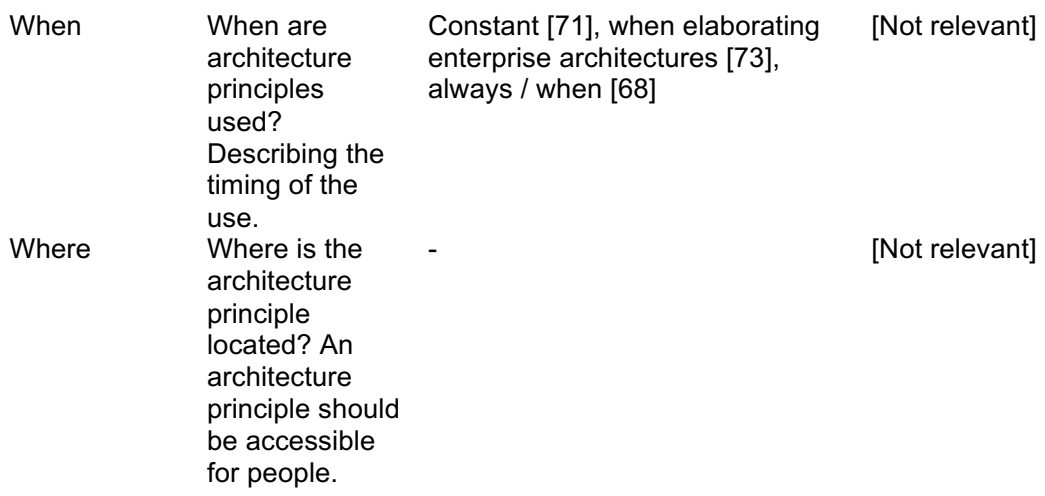

Although defined in many different ways, the purpose of the architecture principle can be summarized as describing restrictions to the design. This is consistently formulated by Greefhorst and Proper [20]: the architecture principle "normatively describes a property of the design of an artefact." In our case, the artifact is the IS.

In many definitions, the objective of the architecture principle is described with phrases such as "should be met by the architecture" or "justification for decision making throughout an EA." However, the objective of an architecture is that a system meets its essential requirements. Furthermore, because architecture focuses on the "essential" requirements, we would like to address this in the definition: it is the element which distinguishes between design and architecture principles.

In searching for additional elements to describe the essence of an architecture principle, we did not find significantly distinctive elements. In our analysis of the remaining $\mathrm{WH}$ questions, we only identified elements that we could link to elements in our definition. For example, "a rationale is formulated" can be linked to the elements "is based on business and IT strategy" and "its essential requirements." This does not mean that these elements are irrelevant: they need to be 
incorporated into the description of the architecture principle, as indicated above. This hypothesis is strengthened by the fact that only four authors addressed one or more of the remaining $\mathrm{WH}$-questions in their definition.

By combining all these findings, we defined an architecture principle for ISs as follows:

"An architecture principle is a declarative statement based on, at least, business and IT strategy. It normatively describes a property of the design of an information system that is necessary to ensure that the information system meets its essential requirements."

From this analysis, we concluded that there is consensus in the literature concerning the definition of an architecture principle. The differences in the definitions found are related to the use of undefined terms or the use of synonyms. Furthermore, we found incomplete or excessive definitions that did not capture the essence of an architecture principle.

\section{Description of architecture principles}

To be able to measure the use of architecture principle in practice, we have to describe them as well, as explained in Section 2.2. Therefore, we needed to answer the following questions: "Which characteristics of architecture principles can be described?" and "How are architecture principles related to their environment?" To answer these questions, we started investigating the different types of principles.

For many years, there were, in general, two types of architecture principle: design principles and representation 
principles [30], [38], [48]. The latter type refers to the way architectures are represented; the first directs the design of a system itself. In the literature, they were described as having different characteristics and serving different objectives.

Recently, Lumor et al. [76] introduced a third type of principle, namely architecture-management principles. These architecture-management principles reflect the view that EA is also a process. The idea behind this third type of principles is the fact that, in general, architecture and its principles might be a product, a process, a result, and so on [20], [34], [75], [76]. An architecture principle should also address the process view. See Table 5 for an overview of the different type of principles.

Table 5: Overview of type of principles.

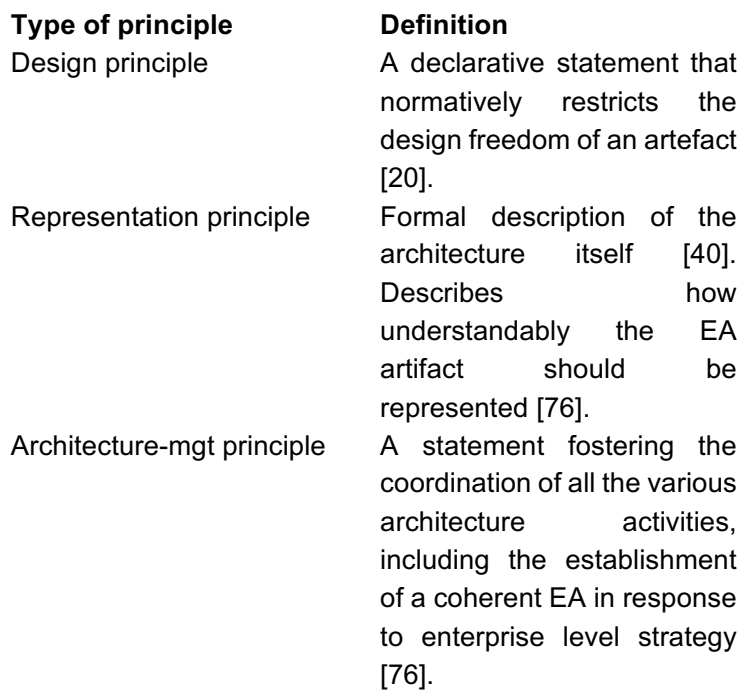

\section{Example}

"Data should be stored once and used many times."

"Architecture principles should have a statement, a rationale, and implications."

"The High-Level Design should be approved by the Architecture Board."

In this literature review, we took the view that all these different types are different perspectives on the same type of architecture principles. This is in accordance with Lindström 
[63], who distinguishes syntactic and semantic characteristics. Syntactic characteristics describe the elements and interrelationships of a principle. Semantic characteristics describe the quality elements of the principle. Haki suggested, in [48], that this differentiation is the same kind of subdivision as the differentiation between design and representation principles. Therefore, depending on perspective, the architecture principle has more or less specific characteristics.

We understood that, with this choice, we would have to collect all types of characteristics, which may also be related to each other. We already encountered this consequence in our previous case-study research [33].

In describing architecture principles, we distinguished the characteristics of the architecture principle itself on the one hand and its relationship with entities in its environment on the other. This breakdown is comparable with the definition by Richardson and Aier et al. in its core definition and basic extensions, and it is helpful in providing more transparency in the description of the architecture principle [30], [40], [71]. In the literature, we found all types of characteristics and entities described. Using our framework, we listed all these characteristics (see Figure 7 and Table 6).

- Characteristics

We started with the "specification" characteristic. There is consensus that an architecture principle can be specified by the attributes "statement," "rationale," and "implications." All authors name these three attributes as inherent parts of an architecture principle. We grouped these three attributes together as one characteristic because together they specify the architecture principle.

The second characteristic of an architecture principle is called "measure." This characteristic describes the level of 
fulfilment of the principle. To some authors, such as [23], [34] and [56], this is a typical characteristic of an architecture principle as it can be compared with "compliance" (with a principle).

Hoogervorst, in [48] and [58], endorsed by Winter, Aier and Greefhorst [20], [30], [52], introduced the characteristic "key action" as a guideline for implementing the principle. Marosin [74] added the characteristic "precondition," which has to be fulfilled by key actions before a principle can be applied. As these elements are strongly related to each other, we consider them as attributes of one characteristic called the "prerequisites" on which the principles depend.

We also introduced the "meta data" characteristic. This characteristic typifies the architecture principle, so the principle can be managed. Attributes such as name, assurance, version number, status, visualization, and generic information are in the scope of this characteristic. Many of these attributes are defined by Greefhorst and Proper [20], but until now there has been no exhaustive overview of this type of attribute.

Finally, there are all types of quality, or semantic, attribute defined in the literature, which an architecture principle should meet. The Open Group Architecture Framework [24], Van Bommel [78], Lindström [63], Marosin [74], and Greefhorst [20] all have their own lists of quality attributes. A detailed comparison shows that they are simply using different terms for the same type of attributes or using a slightly different definition of the quality attribute. Therefore, we chose the quality attributes used by Van Bommel [78] and Greefhorst [20]: "specific," "measurable," "achievable," "relevant," and "timeframed" (SMART). The reasons for choosing this list of quality attributes are that they are defined in some detail in [20] and that they are easy to remember because of the re-use of the SMART criteria for objectives. 
Table 6. Characteristics and attributes of architecture principles.

\begin{tabular}{|c|c|c|}
\hline \multirow{4}{*}{$\begin{array}{l}\text { Characteristic } \\
\text { Specification }\end{array}$} & Attribute & Definition \\
\hline & Statement & Statement \\
\hline & Rationale & $\begin{array}{l}\text { Highlights the business benefits of adhering } \\
\text { to the principle }\end{array}$ \\
\hline & Implications & $\begin{array}{l}\text { Highlights the requirements for carrying out } \\
\text { the principle }\end{array}$ \\
\hline Measure & & Level of the fulfilment of the principle \\
\hline \multicolumn{3}{|l|}{ Prerequisites } \\
\hline & Precondition & $\begin{array}{l}\text { Preconditions and requirements to be fulfilled } \\
\text { before the principle can be applied }\end{array}$ \\
\hline & Key action & $\begin{array}{l}\text { Guidelines for implementing the principle, } \\
\text { giving the preconditions }\end{array}$ \\
\hline Meta data & Several & $\begin{array}{l}\text { Specifications to be able to govern the } \\
\text { principle, like version number, owner, status, } \\
\text { visualization, etc. }\end{array}$ \\
\hline \multicolumn{3}{|r|}{ (1) } \\
\hline & Specific & $\begin{array}{l}\text { The user can understand its intention and its } \\
\text { effects to use it in his work }\end{array}$ \\
\hline & Measurable & $\begin{array}{l}\text { Possible to determine whether or not a given } \\
\text { behavior is in line with architecture principle }\end{array}$ \\
\hline & Achievable & $\begin{array}{l}\text { The implications of it can all be performed by } \\
\text { or adhered to by all those affected }\end{array}$ \\
\hline & Relevant & $\begin{array}{l}\text { The principle should lead to a improvement of } \\
\text { the system meeting the essential requirement }\end{array}$ \\
\hline & Time framed & Principle should be stable in context and time \\
\hline
\end{tabular}

\section{- Entities in their environments}

In addition to their characteristics, listed above, the context in which architecture principles are used is important [20], [38][40], [52], especially when considering the effect of a principle. The key context of an architecture principle, according to the literature, consists of the "design," "requirements," "IS architecture," "business \& IT strategy," and "architecture principle set." We described these relationships one by one, and they are-based on our framework in Figure 5-visualized in Figure 7. 
The most direct relationship an architecture principle has is with the "design." Architecture, and therefore also architecture principles, restricts the design freedom of a system [20], [27], [61], [77], [79]. As we have already seen in the definition of the architecture principle, that restriction is necessary "to ensure the IS meets its essential requirements." Therefore, the architecture principle should ensure through the design that the IS satisfies the "requirements."

Design principles, (design) patterns, standards, and guidelines are other artifacts in the development process. They are also part of the "design of IS," and definitions of these artifacts can be found in Appendix I.

In addition, an architecture principle is, most of the time, part of a set of principles. Although in most literature the focus is on individual architecture principles, a principle is only effective if it is part of a set [20], [38], [63], [74], [80]. As we are interested in the contribution of architecture principles, we needed to also describe "the architecture principle set." We defined an architecture principle set as "a group of architecture principles defined and presented as a collection." Since a set of principles is an entity in itself, it also has characteristics and attributes. Based on Greefhorst and Proper [20], we defined three types of characteristic: "classification," "meta data," and "quality" (see Table 7).

Table 7. Characteristics of architecture principle set.

$\begin{array}{lll}\begin{array}{l}\text { Characteristic } \\ \text { Classification }\end{array} & \text { Attribute } & \text { Definition } \\ \text { Type } & \begin{array}{l}\text { The principles in the set are related to one of } \\ \text { the architecture layers. }\end{array} \\ \text { Scope } & \begin{array}{l}\text { Organizational level of use of the principle. } \\ \text { Seta data }\end{array} & \begin{array}{l}\text { Specifications to be able to govern the principle } \\ \text { set, like version number, owner, status, } \\ \text { visualization, etc. }\end{array}\end{array}$




$\begin{array}{ll}\text { Representative } & \text { The set covers all relevant requirements in a } \\ \text { specific problem domain. } \\ \text { Accessible } & \begin{array}{l}\text { Users can find and retrieve the set of principles } \\ \text { and they can comprehend the principles. }\end{array} \\ \text { Consistent } & \begin{array}{l}\text { No contradictions between the architecture } \\ \text { principles in the set. }\end{array}\end{array}$

First, architecture principles are grouped together based on a "classification." This "classification" is based on the type or scope of the architecture principles. The type is related to the architecture layers of an architecture model. There are many definitions of architecture layers in use, such as those by TOGAF [24], Zachman [81], and Integrated Architecture Framework [82]. In our research, we considered the "information system" layer and, within this layer, the subdivisions "application" and "infrastructure." Architecture principles can also be classified based on the (organizational) level of use, such as for a "part of the target organization," "full target organization," or "more than the target organization."

Second, an architecture principle set can be typified by "meta data" to manage the principle set, such as "name," "release number," "amount of architecture principles in the set," and so on. Some authors address the point that the number of principles in the set should be as small as possible [63], [64], [78]. Many attributes may be added to the characteristic "meta data," and for now there is no complete list available.

Third, as with individual architecture principles, an architecture principle set meets quality standards, the "quality of the set." In the case of a set of principles, we distinguished the attributes "representative," "accessible," and "consistent."

Returning to the framework and looking at the entities related to an architecture principle, we have two remaining entities: 'IS architecture' and 'business \& IT strategy'. We considered the 
architecture principle set as part of the 'IS architecture', whereas the 'business \& IT strategy' guides the 'IS architecture'. We added "...based on business and IT strategy" as a characteristic of the architecture principle directly, as addressed by Fischer [40] and Haki [29] in their statements and because Lindström [63] and Armour [72] address this characteristic as well in their publication.

\section{- Framework}

Based on our analysis, we developed the final model for describing an architecture principle, including its environment (see Figure 7). As discussed in our analysis above, this model diverges slightly from the meta-model of Aier, et al. [40], [52].

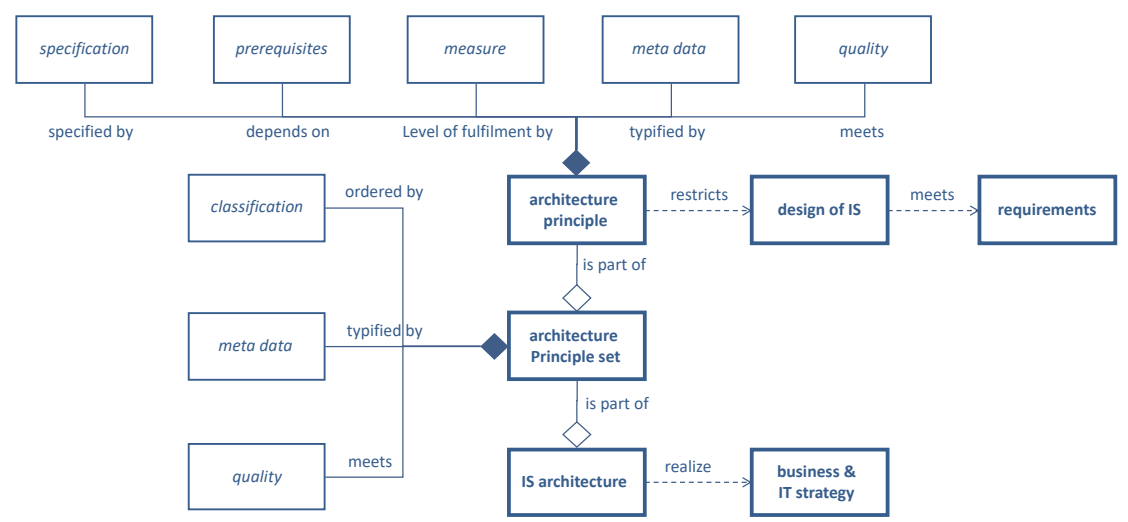

Figure 7: Framework for describing an architecture principle and set.

In our literature review, we also discovered a consensus regarding characteristics. Although we have the opinion that the different types of architecture principles are different perspectives on the same types of principles, we did not find any contradictions. We added and reorganized various characteristic and attributes. As already addressed by a previous case-study research [33], some characteristics were 
defined rather subjectively in the literature, using terms such as "significant," "easy," or "obvious." We have strengthened the definitions where possible, although we are aware that architecture principles are semi-structured, informal, and written in natural language [28], [60], [74], [80], [83]. Furthermore, we have also described the characteristics and attributes of an architecture principle set because the contribution of an architecture principle is only effective in a set.

\subsection{Measuring architecture principles}

After the identification and characterization of architecture principles, we needed both a measurement model and a corresponding method to be able to measure principles in practice. We challenged this measurement instrument, including the definition and framework, in a real-life situation as described in Section 2.5.

Measurement model

To measure architecture principles and related architecture principle sets in practice we needed a well-defined measurement instrument. This measurement instrument should be capable of the following:

1. Identify the architecture principles and the architecture principle sets related to them, so we can distinguish the architecture principle from other kinds of statements used in practice.

2. Describe the values of the characteristics and attributes of the architecture principles and the architecture principle 
sets, so we can measure the use of the architecture principles.

\section{- Identification}

To identify an architecture principle and an architecture principle set we formulated their definitions, based on the literature review described in Section 2.3, as follows:

"An architecture principle is a declarative statement based on, at least, business and IT strategy. It normatively describes a property of the design of an information system that is necessary to ensure that the information system meets its essential requirements."

and

"A group of architecture principles defined and presented as a collection."

The researchers use these definitions to identify principles and sets, by checking whether or not an architecture principle (set) fulfills all elements of the definition. Therefore, we designed a definition check in the measurement instrument for the elements "declarative statement," "based on business and IT strategy," "normatively," "describes a property of the design," and "necessary to meet its essential requirements." For an architecture principle, each of these elements must be present, including explanatory facts. The outcome of this step is reported in terms of a spreadsheet (Appendix C, Table 26). For an architecture principle set, the researchers view every group of architecture principles described together as a set because the definition of an architecture principle set is more generic. 


\section{- Description}

To describe both the individual architecture principles and the sets of architecture principles, we developed the framework of characteristics and related attributes as described in Section 2.3 (see Figure 7). Using this framework, the researchers list all characteristics and attributes in our measurement instrument, including their definitions (see Table $6 \& 7$ ).

For each architecture principle, the reseachers collect all data related to its characteristics and attributes. In a spreadsheet, the researchers record all relevant data for each principle, categorized by source. The researchers used the same approach to describe architecture principle sets (see Appendix C, Table 27).

\section{Measurement method}

To be able to use the measurement instrument, we also needed a reliable and valid measurement method to measure the use of architecture principles. The measurement method helps with collecting and analyzing the right data and then with measuring the architecture principles. The measurement method is an iterative, three-step approach (see Figure 8).

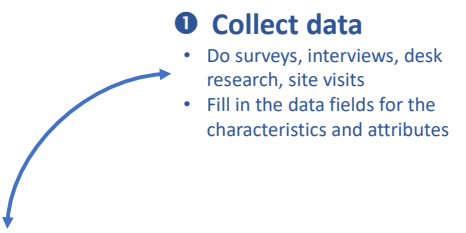

3 Measure the principle

- Evaluate exceptions \& trends

- Draw conclusions

- Describe the architecture principles \& sets

2 Analyze data

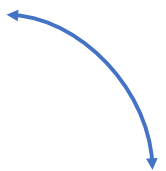

- Check precision and accuracy of collected data

- Verify the architecture principle in accordance with the definition

- Analyze the qualitative data on exceptions

- Quantify the data and find specific trends

Figure 8: The measurement method. 


\section{Collect data}

The objective of this step is to collect data about architecture principles and the architecture principle set (see Figure 9). Therefore, data about the related artifacts, as described in the framework (See Section 2.3, Figure 7), is also relevant: IS architectures, IS designs, requirements, and business and IT strategies. A combination of data collection methods is used: desk research, surveys, interviews, and site visit. The interviews start after the surveys and desk research, and the data collection ends with a site visit. In the interviews new documents can be addressed, so after some interviews extra desk research might be necessary.

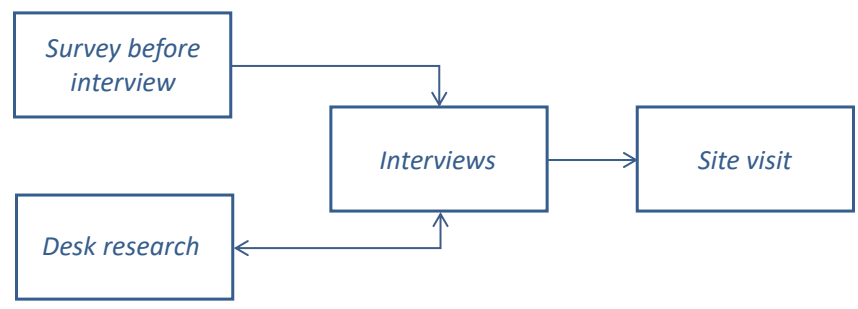

Figure 9: The data collection methods.

For the desk research, all types of documents related to architecture principles can be useful, such as project plans, strategy documents, architecture descriptions, requirements specifications, or test reports. All these address elements of the architecture principles or the related artifacts or both.

The survey (see Appendix C: survey before interview) has been used to collect data before the interview sessions. This enabled the researchers to focus on specific items during the interviews. Basically, for each of the eight characteristics of the framework one question is added to the survey. Besides there is an open question to list all principles 
used in the project and to add some remarks about the use of the architecture principles. For the first case, in which we tested the measurement instrument, the survey in Appendix $\mathrm{C}$ is used without the 'Success of the project'-section, because in this case study the measurement of the IS project success was out of scope.

The case study has to be conducted with a research team of at least two researchers, being subject-matter experts to interpret all data. The researchers can check with each other the data collected during interviews and are able to challenge each other in drawing conclusions.

All interviews are recorded, and the minutes of the interviews are sent to the interviewees for feedback. The interviewees are architects, software engineers, the test manager, the project leader, and the system owner, being the roles that use architecture principles or related artifacts. Site visits are useful to see the IS in daily operation and to consider to what extent the essential requirements are implemented.

All relevant data per architecture principle and per source have to be recorded in order to collect different facts about the same characteristic or attribute (see Table 27 in Appendix C). This is useful for the data analysis when differences or even conflicts in the data about a specific characteristic or attribute occur.

\section{Analyze data}

In this step, the research team analyzes the data to check its precision and accuracy and to find exceptions and trends. For all data collected, the team checks for inconsistencies between sources. If these are found, the team needs to return to data collection to find correct or new data. If, afterwards, data conflicts remains, the team has to explain the differences or decides not to use the data. 
Second, the team checks whether or not so-called architecture principles are in accordance with the architecture principle definition. The team determines if each principle satisfies each element of the definition and notes the reasoning in a spreadsheet (see Table 26 in Appendix C). If a principle does not satisfy all elements of the definition, the so-called architecture principle is declared to be out of scope.

The team then analyzes the qualitative data on exceptions. It is necessary to perform the analysis per principle, but also between different principles. The team considers remarkable differences between attributes or characteristics of a principle or between principles. For instance, the description of a key action does not match with the prerequisite to be fulfilled. Or some architecture principle is fulfilled completely, while a corresponding principle is not fulfilled.

The final action is to quantify the values of the characteristics to find specific trends. The team quantifies the data per principle and per set as follows:

- $\quad$ For each attribute, the team uses a three-level code scheme [44]: " $0 \%$ " is no fulfilment, " $50 \%$ " is partial fulfilment, and " $100 \%$ " is complete fulfilment. This score is a substantiated and documented expert opinion. With expert opinions in context-related research only some level of accuracy can be achieved, so the team uses a three-level code scheme only. The team calculates the score of the characteristic by taking the average scores of the corresponding attributes.

- $\quad$ For the "classification" characteristic of the principle set only, the team uses an alternative score: the scores used referres to the specific values the attribute can 
have. See Table 25 in Appendix B for all attribute values of the "classification" characteristic.

- The team also calculates the average score of each characteristic over all principles and sets.

- Finally, the team calculates the average use of architecture principle by taking the average score of all six characteristics of all individual architecture principles and the "prerequisites", "meta data", and "quality" of the sets of architecture principles. The team defines "100\%" as a full use of the principles, " $50 \%$ " as partly use and " $0 \%$ " no use.

The team is now able to perform cross-section analyses, to create graphics, and to search for trends.

\section{Measure the principle}

This final step is intended to evaluate the exceptions and trends. The team describes the architecture principles and the architecture principle sets, including overall conclusions about their use.

Based on the qualitative and quantified analyses, the team evaluates the exceptions and trends. The team explaines these exceptions and trends and draw conclusions as subject-matter experts. Needless to say, the team adds evidence supporting those conclusions.

Finally, the team describes the architecture principles and the architecture principle sets by describing their characteristics and attributes. To this description, the team adds the qualitative and quantified analyses, including the conclusions. 


\subsection{Case study}

As we have seen in Section 2.2, architecture principles are conceptual instruments used by people in the context of the design and implementation process. We first describe the context of the project, followed by the measurement of the architecture principles.

We used the "Teruggaaf dividendbelasting" (TDi), the "dividend tax return" in English, of the Dutch Tax and Customs Administration as the case study for our research. The TDi is an IS supporting the return of tax on dividends payed to legal entities. The project started in 2014 and we investigated this project until the sprint of release 2017.12. According to most stakeholders the TDi-project was a success.

The project was staffed with approximately six people. In correspondence with the measurement method, we interviewed the business owner, project manager, two project architects, software developer responsible for the software architecture, and the tester \& scrum master. The project used an Agile approach. Project members were used to work with different kinds of architecture artifacts.

For this case study, we asked for all documents related to architecture principles as described in the measurement method. We received parts of the backlog items and all architecture documents such as the "reference architecture Declaration Tax", "a high-level design TDi", the "ICT start architecture TDi" and advice "IT ondersteuning Inhoudingsvrijstelling". During the site visit we saw the TDiapplication in operation.

We conducted this case study with a research team of three subject-matter experts. For each architecture principle we could find at least three different data sources. Although the team discovered subjectivity regarding some of the facts, the 
researchers could draw unambiguous conclusions. So, at the end there was an unambiguous picture of the used architecture principles and sets.

Architecture principles of the TDi case

In the TDi case 55 statements were found that might be architecture principles. According to our definition (see Section 2.3), only 36 architecture principles could be identified as such (Appendix G, Table 29). The other statements were development process artefacts, like design principles such as "separation of concerns", technical standards ("use the Java platform") or guidelines.

The average score for all characteristics was $74 \%$. In Figure 10, we see the level of fulfilment of these 36 architecture principles and sets combined; the individual scores may differ between the principles.

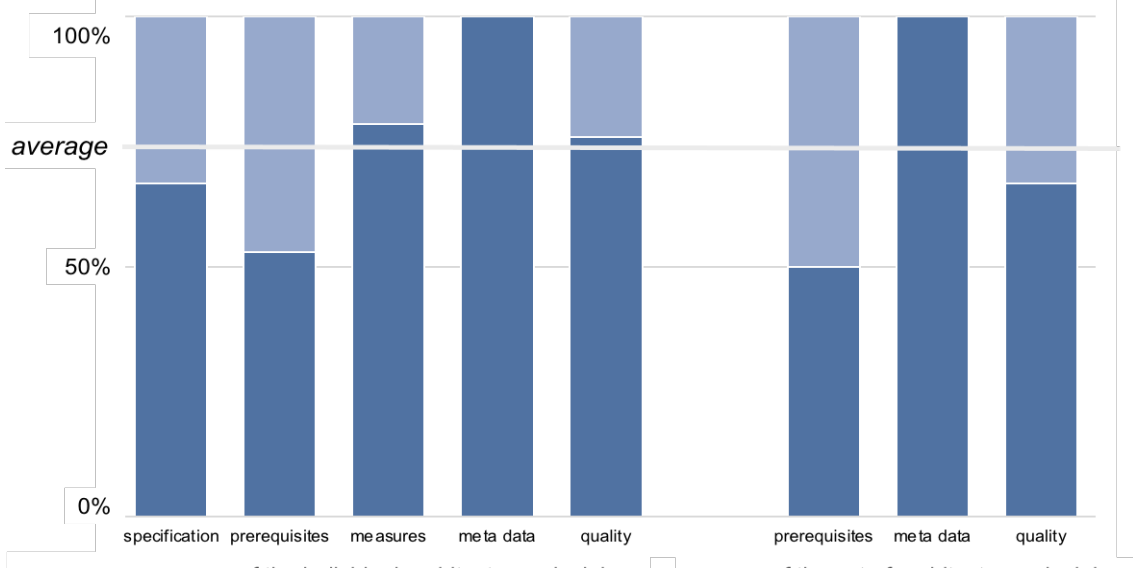

score of the individual architecture principles

score of the set of architecture principles

Figure 10: Level of completeness of the 36 architecture principles and the sets. 
Looking at the specification characteristics of the architecture principles, we recognized that none of the principles included a rationale, while the statement and implications were appropriately determined. A reference to the rationale as described in other architecture documents was also missing.

Figure 11 shows that $80 \%$ of the principles were fulfilled partially $(36 \%)$ or fully (44\%). Only one principle was not followed ("from object-based to subject-based working"), and in $17 \%$ of cases we could not determine whether or not the principles had been fulfilled because of

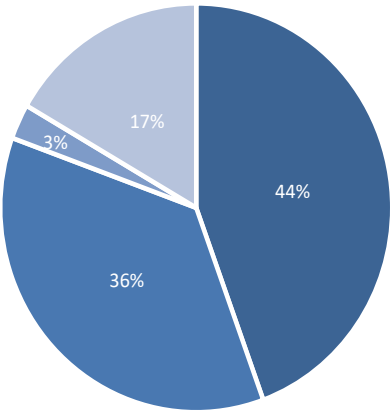

- completely - partly - not I- unknown

Figure 11: Level of fulfilment of the architecture principles.

missing resource data. Interestingly, the developers did not respect some of the principles as intended and chose to implement parts of the systems using alternative directions. This was without the approval of the project architects or other stakeholders in the project. The project manager concluded: "the degree of acceptance to comply with some of the principles was not that high." The two architects confirmed this.

With respect to the prerequisites, specific preconditions were defined for seven principles, and various overall preconditions were defined for all principles. Not all of the preconditions were (completely) fulfilled at the start of the project or during it, such as "B/CAO building blocks available." So, they could not comply with this principle. The architects 
explained this by stating, that they had to choose for the principle 'building block' without having a building block, so they had to build one in the project. Therefore, not all principles could be fulfilled, as we saw. Surprisingly, there were no "key actions" identified to fulfill the preconditions.

All meta data was in place, so managing the architecture principles was unproblematic; information about the author, status, version, users, and much more was easy to find.

The architecture principles also met the quality attributes. The main reason why the overall quality score was not $100 \%$ was that the rationale was missing. Therefore, we were not able to determine the principles' intentions and relevance, as described in the "specific" and "relevant" attribute. All architecture principles, even those imposed from outside the project, were translated to the TDi context.

The architecture principles originated from two documents: a high-level design (HLD) and a project start architecture (PSA). The HLD described the process, application, and technical infrastructure of the TDI system, while the PSA focused on the application and technical infrastructure only. In the HLD, 12 architecture principles were defined explicitly, but most principles were only addressed by referring to other architecture documents. One reference was to the "reference architecture Declaration Tax". In that document there was a separate section concerning prerequisites and basic assumptions. So, prerequisites may not only be related to individual principles.

In the PSA, nine IT principles were described, including directives for use in the implementation of the TDi system. In both documents, many meta data attributes could be found, such as author, administrator, status, and target audience. Given the many architecture principles mentioned in both sets, we concluded that the sets were not representative for meeting 
the essential requirements. There were too many architecture principles adopted from the overall architectures, resulting in overlap. These principles were not translated to a single principle specific to the TDi system. Although there were many overlapping architecture principles, there were no contradictory principles in the sets. The accessibility of the sets was good because they were managed by the architects of the TDi project. As the sets referred to other documents, the accessibility of the original sets of principles was less evident.

\section{Evaluation of the measurement model}

To evaluate the measurement model, we needed to test in practice whether both the definition and framework of the architecture principles were complete and coherent. Regarding the definition of the architecture principle, there are four findings:

1. To start identifying the architecture principles, the model was helpful in determining which of the 55 statements fulfilled the elements of the definition. As a result, 19 of the so-called architecture principles did not pass verification and were other types of development process artifacts (see Appendix I). Besides, we did not find any other statements that were not explicitly called architecture principles but that did fulfil the elements of the definition.

2. The definition of the architecture principle set did not provide sufficient differentiation. There are many ways to present a group of principles. In our case, we analyzed the different types of sets to understand the interrelationships between those sets. In this case study, we found that the presentation of the architecture principles was related to 
other architecture documents that were already in place. Therefore, the method of presenting the principles was not necessarily related to the system itself but was influenced by external factors. Consequently, our case study resulted in a changed definition of the architecture principle set: "a group of architecture principles defined and presented as a collection based on a similar type or scope of architecture principles."

3. Although we might state that, in this case, the identification of all individual principles was achieved, we also learned that the identification is also related to the essential requirements. In our case study, the essential requirements were defined at a high level, for example, "the system has to be future-proof," so it was quite easy to link architecture principles to the essential requirements. In future case studies, therefore, more in-depth research into the essential requirements will be necessary.

4. The coherence of the definition of architecture principles has already been theoretically explained in our literature review, using the $\mathrm{WH}$-questions approach [32]. During the case study, we did not find any inconsistencies between the elements that might suggest that the elements of the definitions are incorrect.

The second part of the measurement model describes the architecture principles. In the evaluation of the characterization of the principle, we had four findings:

1. Looking at the completeness of the model, we found all but two of the attributes defined in the model in the case study. The "rationale" attribute was defined in other documents and although no "key actions" were defined, in 
some interviews necessary key actions were presented. Therefore, none of the attributes is irrelevant.

2. In our case study, we detected some omissions in the model. The attribute "degree of acceptance" must be added to the "measure" characteristic because this element was addressed by several sources in our case study. It describes an aspect relevant to the fulfilment of the principle and is defined as the "level of acceptance of the principle by all of its users." The attribute "preconditions fulfilled," which is related to the "prerequisites" characteristic, is another relevant addition. We explicitly saw in the case study that when preconditions were set, it was also relevant to know whether the preconditions were fulfilled. The definition of this attribute can be described as "the level of fulfilment of the preconditions defined."

3. For the architecture principle set, we have added an extra characteristic: "prerequisites." We discovered in the case study that some prerequisites were not related to a specific principle, but to a group of principles. In addition to the "precondition" attribute, "basic assumptions" were described for some sets. Basic assumptions are "relevant criteria for successful use of the principle."

4. In this case study, we did not find any inconsistencies in the coherence of the description model. Some of the relationships as described in the model, such as "depends on" or "level of fulfilment," were described explicitly in the documents or mentioned during the interviews. The amount of information, though, was insufficient to make fact-based statements about the consistency or the coherence. In this case study, it was clear that there are interrelationships between attributes, for example, the missing rationale and therefore a lower score for quality, 
as described in [33]. More research data is necessary to make clear statements about the coherence.

\section{Evaluation of the measurement method}

We evaluated the measurement method by discussing the reliability and validity of the case study's results. There were three findings in the evaluation of the reliability and validity:

1. To challenge the reliability of the results, we wanted to know to what extent the results would be consistent when repeating the case-study research. In the measurement method, different protocols were defined to assure the reliability of the outcome: using different methods of data collections, working with a research team, minutes including feedback, and so on. All these mechanisms are important because this case study demonstrated the subjectivity of the facts collected. Two architects, for example, were working closely together during the TDi project but had different opinions about the fulfilment of some of the architecture principles. The research team could, based on all different sources, make an expert judgement about the fulfilment.

2. Although we used different methods to collect data, in this case study we were lacking some in-depth information about the essential requirements. As a result, it was difficult to determine to what extent architecture principles were adding value in meeting the essential requirements. Additional sources related to the essential requirements, such as interviewing more business owners, would help to bridge this gap. 
3. In evaluating the validity of the measurement method, we concluded that the description of the architecture principles reflected the real situation of TDi. In this case study, we were not always able to consider the details of specific architecture principles; as the case used a considerable number of principles, 36 in total, it was difficult to address all individual principles. Therefore, in future case studies, we need mechanisms to acquire more in-depth information about the individual principles.

\subsection{Limitations, conclusions, and further research}

\section{Limitations}

- Literature study limitations

With regard to the literature study, there are two threats to the completeness and coherence of our results. The first limitation we have identified is the interpretation of the words used in the definitions and the characteristics. Although the semantics of natural language are always an issue in a literature study, we encountered descriptions that were rather vague and therefore subject to (personal) interpretation and possible wrong conclusions in several papers. As many publications confirmed and used the conclusions of previous publications, we judged the risk of misinterpretation to be low.

The other limitation is the rather broad scope of the literature search, which considered architecture principles in the enterprise domain instead of architecture principles in the IS domain. In certain cases, we translated architecture principle characteristics to specific IS ones without knowing whether to do so would be valid in practice. This is a topic for further 
research. As architecture principles can affect multiple architecture domains [20], we considered this a low risk.

To discuss the results of our literature review, we also sent our draft paper to a small group of senior experts in this research area. We used their responses to eliminate vagueness in the draft paper. In addition, the experts made some specific remarks related to the paper.

Several experts mentioned that formulating architecture principles is important, but that the use of architecture principles is the real issue in practice. The description of architecture principles is a precondition, necessary to determine their use and effectiveness.

The second remark was related to the ordering of the characteristics. As addressed in Section 2.3, we have chosen not to order the characteristics in our research, although there are different perspectives on architecture principles. Two experts suggested ordering the characteristics using a framework, for example, the dimensions framework defined in Greeforst and Proper [20]. Such frameworks may also help in evaluating the relationships between different characteristics.

The last remark was related to the definition of an architecture principle. The original definition suggested that architecture principles are based on business and IT strategy only. We agree with the experts that business and IT strategy are merely two (important) sources for formulating architecture principles. Therefore, we reframed the definition by adding "at least" to the phrasing.

- Case study limitations

Although the arguments for using the case-study approach remain valid, there are some limitations that it is important to address in this case study. 
We are aware that one case cannot prove the completeness of the measurement instrument. As discussed in Section 2.4, the objective of this research is to test to what extent the instrument is useful in practice. For an extended test of the completeness and coherence of the measurement instrument, we need extra iterations with new cases.

A second limitation could be that the researchers were biased in searching for characteristics and attributes, despite all the protocols that were defined. The moment we introduced a model as a description of our research object, we saw architecture principles through this model. We tried to avoid this prejudice by avoiding naming attributes during the survey and interviews. The fact that we identified new attributes and characteristics shows that we were also receptive to new elements.

Finally, we can also note that there is currently no other instrument that measures architectural principles, so we cannot compare this instrument with other instruments. Studies have been conducted on the added value of architecture in general and we could apply that approach to the same case to assess whether comparable results are achieved.

\section{Conclusions}

\section{- Defining and describing principles}

In the most relevant publications, we found 16 different definitions of architecture principles and a large set of characteristics. Since 1990, the definition of an architecture principle has been consolidated. In addition, there is consensus about many characteristics. Nevertheless, we did find some inaccuracy or incompleteness in definitions and descriptions, as we addressed in this paper. 
First, we found all types of definitions in the literature, most of which were incomplete or failed to identify the essentials of an architecture principle. By decomposing and rephrasing the elements of these definitions, we achieved a more comprehensive and consistent definition.

With our framework consisting of all kinds of characteristics, we were able to describe architecture principles. We grouped together the rationale, statement, and implication into one characteristic: "specification." In addition, we distinguished "key action" and "preconditions" as two separate attributes, combined in the characteristic "prerequisites." We also considered "meta data" and "quality" as explicit characteristics of an architecture principle, which has not always been the case in the past literature. Where possible, we tried to define the characteristics more objectively, despite the fact that in natural language, interpretations of words are always possible. Altogether, there were no contradictions found in the past literature, but we have extended the description of architecture principles to include new characteristics.

Analyzing the contribution of individual architecture principles without considering the set of principles is unproductive. An architecture principle is only effective in combination with other architecture principles. We therefore also described the characteristics of the architecture principle set: "classification," "quality," and "meta data." We described the characteristics of both an architecture principle and an architecture principle set in a framework that also related to entities in the context of an architecture principle.

- Measuring principles

To answer research question $1 \mathrm{~b}$, we first needed to investigate what the essential elements of an instrument for measuring architecture principles were. Based on a theoretical framework, 
we described a measurement instrument tested in a real-life case study. We can conclude, based on these practical experiences, that the measurement instrument is fit for purpose, although the instrument should be extended with extra characteristics and attributes. These extensions are "degree of acceptance" and "preconditions fulfilled" for describing the individual principles and the characteristic "prerequisites," including the attributes "precondition" and "basic assumptions," for the architecture principle sets. Although we tested the instrument with only one case study, we are beyond doubt that with these additions the model has added value in measuring architecture principles and in measuring related architecture principle sets.

Second, we needed to determine how to use this measurement instrument in practice. We defined a three-step method to collect, analyze, and measure the architecture principles. We applied this measurement method in our case study, with a description of the architecture principles and principle sets for the TDi case as a result. We believe that the method yields reliable and valid results, although we discovered in this case study that more information on the requirements and individual principles would strengthen the results.

\section{Further research}

In summary, the conclusions and limitations confirm that it is feasible to use the architecture principle measurement instrument with more case studies. Doing more iterations, we would be able to strengthen the definition and description and test the instrument's ability to compare architecture principles and principle sets between case studies. 
First, when carrying out new case studies, we would prefer the number of cases to be as large as possible. However, substantially increasing the number of case studies would require automatic processing of the data. In our opinion, this is only possible to a limited extent, as compliance with architecture principles always requires human interpretation.

Second, we can use the new case studies to test the completeness and coherence of the measurement instrument and method. We need to investigate how we can elaborate on the essential requirements. Therefore, new case studies will provide new insights into the use of the instrument and method and help to optimize both. 


\section{THE MEASUREMENT OF IS PROJECT SUCCESS IN PRACTICE}

In this chapter, we describe an instrument for measuring IS project success.

\subsection{Introduction}

We wanted to determine the contribution of architecture principles to the success of IS projects in practice. In Chapter 2, we described a way to measure the use of architecture principles. However, to determine the usefulness of architecture principles, we also needed to measure IS project success. In literature we saw different definitions of 'IS project success' [16] and a change to a broader view on 'IS project success' [11], [22], as described in Chapter 1. So, we needed to define and describe IS project success first. After having a descriptive framework for IS project success, we were able to describe a way to measure IS project success in practice.

We start this chapter with the research methodology in Section 3.2. In the third section, we provide a definition of IS project success and describe its characteristics. An instrument for measuring IS project success is described in Section 3.4. We end this chapter with conclusions, limitations, and suggestions for further research.

\subsection{Research methodology}

Research question

In this chapter, we answer the second research question of our research project to determine IS project success in practice: 


\section{How may IS project success be measured in practice?}

To be able to answer this question, we first had to define and describe IS project success. We needed to understand the meaning of "IS project success" and have characteristics to describe successful IS projects in a complete and coherent way. Therefore, subsidiary question 2 a was as follows:

\section{2a. What is IS project success?}

Second, based on the definition and description, we needed a way to measure IS project success in practice. Consequently, we needed a measurement instrument, consisting of a measurement model and a method. To summarize, subsidiary question $2 b$ in this research was as follows:

\section{2b. How may IS project success be measured in practice?}

\section{Research process}

Given that much research is available regarding IS project success in general and measuring IS project success in particular, we conducted a concise literature study to answer the research question [22], [84]-[88]. We expected to find a comprehensive measurement instrument in the literature that had been challenged in practice many times, so testing the measurement was out of scope. For the literature study we employed the same six-step approach as in Chapter 2 [50]. 
1. Defining the boundaries of the literature review

2. Using a model to analyze the results of the literature review

3. Identifying and selecting relevant literature

4. Reviewing the results of the literature review

5. Answering the two research questions based on the results of the analysis

6. Addressing the limitations, discussing the results, and presenting implications for further research

- Boundaries of research

In our search, we did not make a distinction between IT projects and IS projects. As described in Chapter 1 we chose for the scope of IS projects, knowing that IT projects are a subset of IS projects. As will be discussed in Section 3.3, we did not confine the definition of an IS project to a process perspective or results perspective only. Both perspectives are relevant in determining the success of an IS project.

\section{- Model for analysis}

We used a simple model to help us analyze the results in the selected publications. This model, visualized in UML, describes IS project success using characteristics and attributes (see Figure 12). IS project success consists of some characteristics and, in turn, characteristics have one or more attributes. While a characteristic is defined as "a feature belonging typically to IS project success and serving to identify it," an attribute is defined as "an inherent part of the characteristic."

As we discuss in Section 3.3, we used the definition of IS project success to order the characteristics in two dimensions. For each dimension, we defined three characteristics in accordance with the definition of the dimension. For each 
characteristic, we defined a set of attributes that together create a complete and coherent description of the characteristic [44].

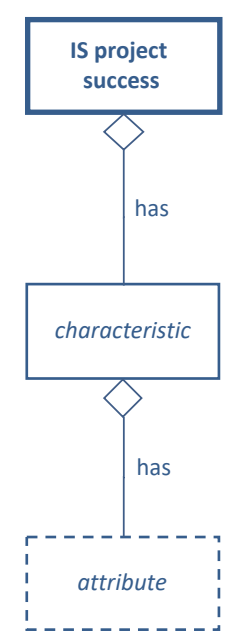

Figure 12: Model to describe IS project success with characteristics and attributes.

- Identification and selection

To identify and select relevant literature, we used various wellknown databases, journals, and search mechanisms: EBSCO, AISeL, Google Scholar, and Research Gate. We started searching for English publications from 2015 onwards because there has been much recent research. We selected publications with the terms $(<I S>$ OR $<|T\rangle)$ AND $<$ project success $>$ AND $<$ measure $>$ AND <literature review $>$ in the title or abstract when searching for definitions for IS project success. Those keywords were derived from the research questions $2 a$ and $2 b$, which were formulated based on the results of our initial research [1]. From the resulting list of publications, we excluded all literature 
addressing specific fields of application. We also used citations to prior literature to find other relevant publications. When searching for literature regarding a specific characteristic, we used the terms <"characteristic" $>$ AND $(<\mid S>$ OT $<|T\rangle)$. After the identification and selection of literature, we started to review the results, answered the two research questions, and addressed limitations and suggestions for further research.

\subsection{What is IS project success?}

To be able to define IS project success, we needed to understand the concept of IS projects. An IS project is "the design and implementation of an information system's requirements, so that the information system will be fit for purpose." This definition is important because success is, according to the Cambridge dictionary [89], "wanted or hoped for." Therefore, success is related to the defined requirements and objectives that the stakeholders would like to achieve.

In addition, success is related to different stakeholders with different points of view. Therefore, capturing all viewpoints relevant for determining IS project success is challenging. According to Thomas, "there is no one best method for defining and measuring success," though there are characteristics that help to measure IS project success [88]. So, in contrast to the suggestions of some publications in past years [84], [90], [91], there is a common line to recognize in defining criteria to define and measure success [92].

In determining IS project success, a distinction can be made between project management success (PMS) and project product success (PPS) (see Figure 13) [22], [84]-[88]. 


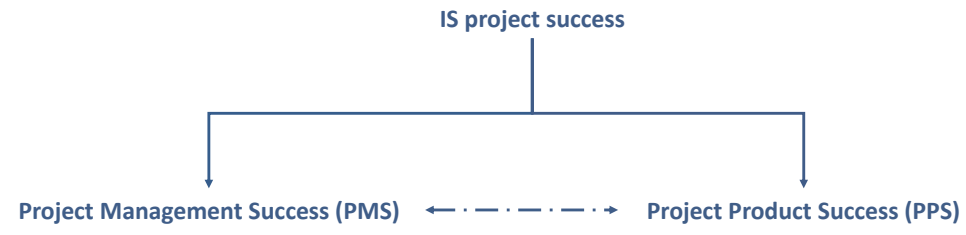

Figure 13: IS project success defined.

Project management success focuses on the best possible execution of the project, and PPS focuses on the effects of the product after implementation. There is a relationship between these two dimensions; however, there are differing opinions on whether there is a precisely sequential relationship [93], or there is hardly any dependency [87], or the relationship is something in between [22], [84], [85], [94].

\section{Project Management Success}

Three success criteria are relevant for determining PMS, as defined by [13], [95], [96], and many others: "On time," "On budget," and "On target."

On time: A project is on time if the IS is live at the end of or within the approved timeline. The timeline is the duration between the start and finish of the project.

On budget: We declared a project to be on budget when the IS is implemented on or within the approved project costs. Project costs are all costs necessary for the IS to become live, including both personnel and out-of-pocket costs. 
On target: The IS is delivered on target if it meets all approved requirements. These requirements should be approved by the steering board. In some publications, synonyms for "target," such as "functionality," "scope," and "quality," are used [97], [98].

Managing these three criteria is difficult in practice because of changing circumstances within and around the project [11], [13], [22], [99]. This is one of the reasons why managing IS project success with these criteria alone is insufficient.

\section{Project Product Success}

The DeLone \& McLean (D\&M) IS success model [22], [84], [87] is used to measure PPS. DeLone and McLean developed and updated this model in the past few years [100], [101]. The D\&M IS success model describes six dimensions that together determine IS success (see Figure 14).

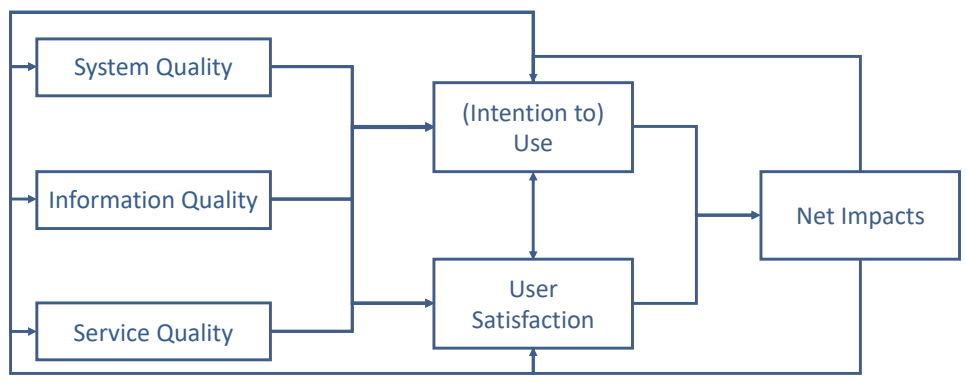

Figure 14: Updated DeLone \& Mclean IS success model (modified version) [101].

In agreement with Van der Westhuizen [87], we saw the dimensions "information quality," "system quality," and "service 
quality" in the D\&M model as detailed descriptions of the "on target" element of PMS; these terms are another way of structuring the functional and Quality-of-Service requirements. Therefore, we have focused on the remaining three dimensions.

If we would like to measure "use," "user satisfaction," and "net impacts," we must be aware that these three characteristics can be viewed from different stakeholder perspectives [92], [100], [102]: individual, organizational, industrial, and even global. As an example, the web has individual users, but is also used by organizations and globally. The same can be applied to "user satisfaction" and "net impacts."

Use: We defined "use" as "the extent to which an IS is incorporated into the stakeholders' business processes." This definition is derived from Cuellar [103]. As there may be a difference in the usage of an IS immediately after going live (early use) and its future use [104], real usage is when the IS is incorporated into day-to-day work.

User Satisfaction: We defined "user satisfaction" as "the level of contentment of all (individual and groups of) stakeholders concerning the IS and related services." In measuring "user satisfaction," we aim to measure the user's satisfaction with both the IS product itself and with related services, such as operations, development, and support [105], [106]. We endorsed the statement of Ives and Vaezi that a user does not make a sharp distinction between the IS and the related service. Consequently, this definition is an expansion of the scope of the DeLone definition [100].

Net Impacts: Ultimately, an IS should provide added value. This added value can be both financial [107] and non-financial [100], [108]. For governmental organizations, for example, the public 
or social value may be more important [108]. Furthermore, the net impacts can be both positive and negative. If the (non-) financial investments are higher than the outcome, the contribution of the IS is negative. Therefore, in accordance with DeLone [100] we defined "net impacts" as "the extent to which information systems are contributing (or not contributing) to the success of all kinds of stakeholders."

IS project success

As IS project success is the combination of both PMS and PPS, it can be visualized in this framework (see Figure 15):

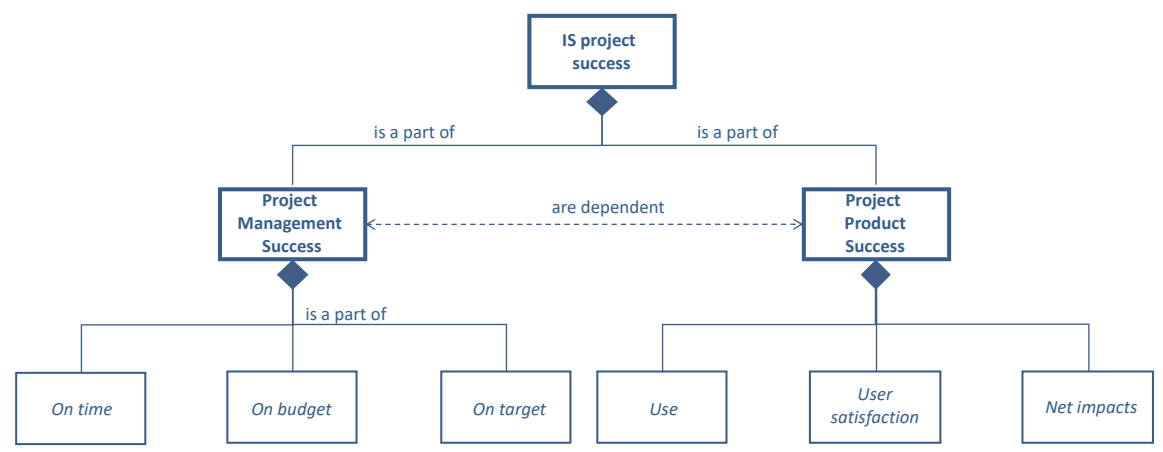

Figure 15: Description of IS project success (adaption of the Van der Westhuizen and Fitzgerald-model [87]).

With this framework, we have described IS project success: it is the combination of the six characteristics. Up until now, there have been no explicit statements that particular characteristics in the model are more important than others.

Furthermore, although DeLone and McLean [88] state that net impacts "address the ultimate impact of a system, and therefore represent the most important category of success 
management," there still remains the question of whether an IS project is successful if it exceeds its timeline or budget.

Summarizing, we determined that the outcome of IS project success is not a binary 'yes' or 'no' [11], [13], [109], [110]. The level of IS project success is defined by the outcome of the six characteristics. With that, stating that IS project failure is the opposite of IS project success, IS project failure can be defined as the inverse of IS project success. In this research we only use the definition of IS project success.

\subsection{Measuring successful implementation}

After describing IS project success, we could answer research question 2b: "How may IS project success be measured in practice?" To measure IS project success (and therefore the PMS and PPS characteristics), we needed a measurement model and a related measurement method.

\section{Measurement model}

To measure IS project success, we needed a well-defined measurement model. This measurement model had to describe the six characteristics of the IS project success framework in a complete and coherent way [44].

To describe the characteristics, we searched in the literature for specific attributes for each characteristic. These attributes should together describe the characteristic completely and overlap as little as possible. In this research, we were interested in the outcome of IS project success; it was not our intention to perform a root-cause analysis. Therefore, we were looking for only a limited number of attributes. 
Furthermore, the measurement of all attributes had to result in an objective value, whether qualitative or quantitative.

In choosing the attributes, we aimed to build on previous research as far as possible. By applying existing, validated attributes, it is easier to reuse research outcomes [13], [101], [105], [111], although we must remember that researchers may use slightly different definitions in their research [106]. Based on these prerequisites, we defined the following attributes for each characteristic.

\section{- On time}

Given the definition for a project to be "On time," three attributes were relevant. The first attribute was the "Initial timeline" of the project. At the start of the project, the timeline is approved by the steering board, with a start and end date. The "Actual timeline" is the true start and end date of the project. According to the literature changes might happen during the project's execution which affects the duration of the project positively or negatively and have to take into account in calculating the approved timeline of the project [8], [11], [112]. In our definition we state that we calculate only the necessary time to implement the approved changes. So, "Change requests" is the third attribute. The project is "On time" when the actual timelines correspond to or are within the initially approved timeline, including the project's lead-time as defined in the change requests (see Figure 16 and Table 8 ).

Table 8: Attributes for measuring "On time."

Characteristic On time

Attribute
Definition

The information system is live at the end of or within the approved timeline.

The originally planned and approved duration between the start and finish of the project. 
Actual timeline

Change requests
The factual duration between the start and finish of the project.

Necessary project lead-time to implement approved change requests.
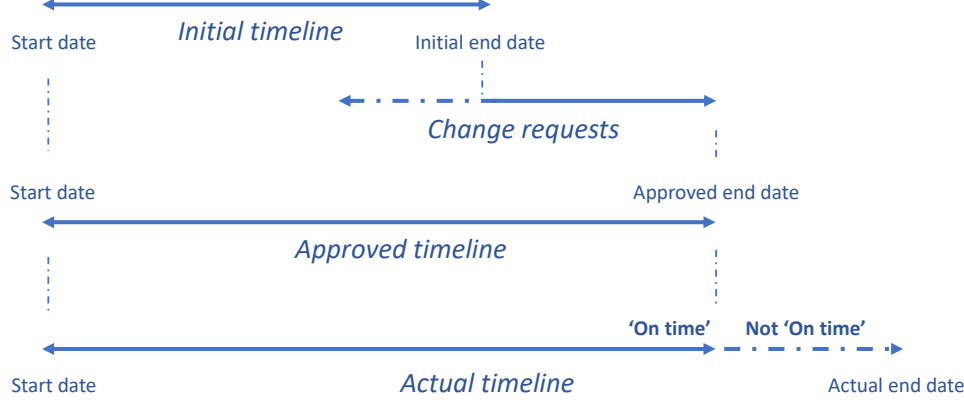

Figure 16: relationship between the different attributes to measure "On time."

- On budget

As with "On time," we used three attributes to describe the characteristic "On budget" in accordance with its definition. The "Initial budget" is the expected project costs, both personnel and out-of-pocket costs, approved by the steering board at the start of the project. The "Actual costs" are the total cost of the project. As addressed in the description of "On time," changes might happen during the project's execution, which also could affect costs positively or negatively [8], [11], [112]. So, in approved change requests positive or negative necessary "Supplementary budgets" could be addressed. The project is "On budget" when the actual costs are at or within the initial budget, including the supplementary budgets (see Figure 17 and Table 9). 


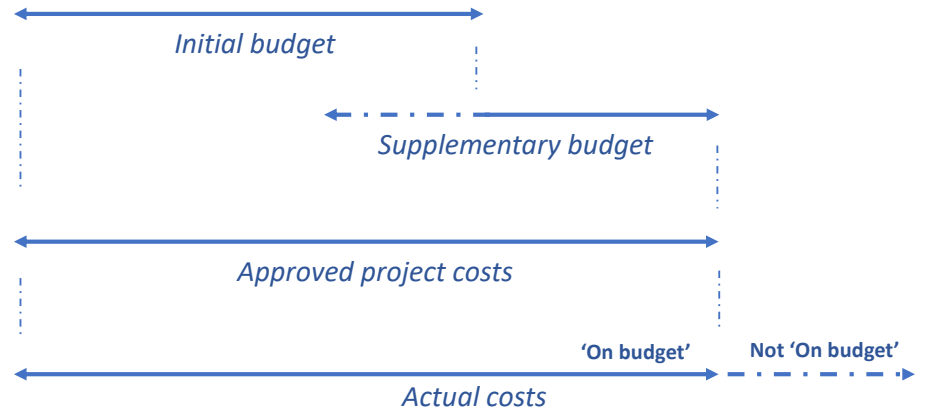

Figure 17: relationship between the different attributes to measure "On budget."

Table 9: Attributes for measuring "On budget."

$\begin{array}{lll}\begin{array}{l}\text { Characteristic } \\ \text { On budget }\end{array} & \text { Attribute } & \begin{array}{l}\text { Definition } \\ \text { The information system is implemented on } \\ \text { or within the approved project costs. }\end{array} \\ \text { Initial budget } & \begin{array}{l}\text { Expected and approved costs at the start } \\ \text { of the project. } \\ \text { Actual costs }\end{array} & \begin{array}{l}\text { The total cost of the project. } \\ \text { Supplementary budget }\end{array} \\ \begin{array}{l}\text { Positive or negative extra necessary } \\ \text { budget allocated based on approved } \\ \text { change requests. }\end{array}\end{array}$

\section{- On target}

To determine whether an IS meets all approved requirements, we had to define requirements in more detail. We distinguished "functional requirements" and "Quality-of-Service requirements." "Functional requirements" are the required functions that an IS needs to be able to perform [113]. "Qualityof-Service requirements," strangely also known as nonfunctional requirements in our field of study, describe the performance, the quality, and the constraints of an IS [114]. 
As we would like to measure IS project success related to the use of architecture principles in our research, we focused on the essential (functional and Quality-of-Service) requirements only (See Table 10).

Table 10: Attributes for measuring "On target."

$\begin{array}{ll}\begin{array}{l}\text { Characteristic } \\ \text { On target }\end{array} & \text { Attribute } \\ & \text { Functional requirements } \\ & \begin{array}{l}\text { Quality-of-Service } \\ \text { requirements }\end{array}\end{array}$

Characteristic

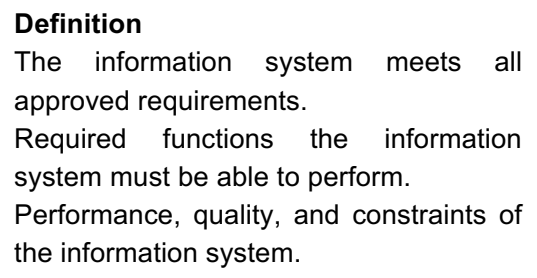

- Use

Although it may seem to be easy to measure system usage, many elements influence the level of usage. Therefore, it is a delicate issue to determine those attributes which together give a complete and coherent description of system usage. Many methods are available to measure system usage, such as those suggested by Cuealler [103], Straub [115], Doll [116], and DeLone [100]. We chose Cuealler's method for measuring usage because it describes usage in a complete and coherent way, using a small number of attributes (See Table 11).

Table 11: Attributes for measuring "Use."

$\begin{array}{ll}\text { Characteristic Attribute } & \text { Definition } \\ \text { Use } & \text { The extent to which an information system } \\ & \text { is incorporated into the stakeholder's } \\ & \text { business processes. } \\ \text { Extent } & \text { The proportion of available functions used } \\ & \text { in the business process. }\end{array}$




$\begin{array}{ll}\text { Frequency } & \begin{array}{l}\text { The number of times that the functions are } \\ \text { used compared to the total amount of time } \\ \text { that the functions could be used. } \\ \text { Whether, when a function is used in a } \\ \text { business process, the maximum potential } \\ \text { use is made of it. }\end{array} \\ \text { Attitude towards use } & \begin{array}{l}\text { The extent to which users truly } \\ \text { incorporate the information system in their } \\ \text { business process. }\end{array}\end{array}$

We had to take into account that perspectives on use may differ between stakeholders.

\section{- User satisfaction}

To measure the contentment of the stakeholders, we aimed to measure the users' satisfaction both with the IS as a product and with related services, such as operations, development, and support [105], [106]. This is because we believed that a user does not make a sharp distinction between an IS and a related service.

In the literature, we discovered that the number of attributes to measure "user satisfaction" differs from measuring a single item [100] to two items [117], five items [118], 39 items [105], or even more [106], [119]. In analyzing all the literature, we identified that most attributes are related to Brown's [117] "ease of use" or the "usefulness" of the IS. User satisfaction with IS support can be categorized by the type of service delivered or by the way the service is delivered (See Table 12).

Table 12: Attributes for measuring "User satisfaction."

$\begin{array}{lll}\begin{array}{l}\text { Characteristic } \\ \text { User satisfaction }\end{array} & \text { Attribute } & \begin{array}{l}\text { Definition } \\ \text { The level of contentment of all (individual and groups } \\ \text { of) stakeholders concerning the information system } \\ \text { and related services. }\end{array} \\ & \text { The level of appropriateness for specific activities. }\end{array}$




$\begin{array}{ll}\text { Ease of use } & \begin{array}{l}\text { The convenience of the information system's } \\ \text { operation. }\end{array} \\ \text { Service portfolio } & \begin{array}{l}\text { The type of services offered with regard to the } \\ \text { information system. }\end{array} \\ \text { Service delivery } & \text { The way the service is delivered. }\end{array}$

Naturally, user satisfaction may differ between stakeholders. Therefore, "user satisfaction" have to be measurend among all stakeholders, noting that the weights of the results may differ, so it is nog possible to simply add the different outcomes [118].

\section{- Net impacts}

With the "net impacts" characteristic, we aimed to measure the contribution of the IS to the success of the different stakeholders. This contribution is not a one-dimensional "inputoutput accounting method," as Martinsons says [120]. In addition, in most cases that contribution differs for the different stakeholders.

In the literature, we saw different methods to describe the net impacts of an IS. For example, Doll's key approach is to focus on the objective of the IS by ordening the type of IS [116], Mirani describes the benefits in an organizational context [121], and Scott et al. focus on the user perspective, in particular that of the citizen [108], [122].

We chose the four-dimensional approach of Martinsons, using Kaplan and Norton's "Balanced Score Card," translated for the IS context [120]. This approach is more comprehensive than others and the balanced score card is also a common method in practice. Therefore, we used the following attributes to describe the "net impacts" of an IS (See Table 13): 
Table 13: Attributes for measuring "Net impacts."

$\begin{array}{lll}\begin{array}{l}\text { Characteristic Attribute } \\ \text { Net impacts }\end{array} & \begin{array}{l}\text { Definition } \\ \text { The contribution of the information system to } \\ \text { the success of the different stakeholders. } \\ \text { The contribution of the information system to } \\ \text { the value of the business. } \\ \text { User orientation }\end{array} \\ \text { Internal processes } & \begin{array}{l}\text { The information system delivers value-adding } \\ \text { services to end-users. } \\ \text { The information system and related services } \\ \text { Future-readiness }\end{array} & \begin{array}{l}\text { The information system is continuously } \\ \text { improving and prepared for future changes. }\end{array}\end{array}$

\section{Measurement method}

To measure IS project success, we needed a reliable and valid measurement method [44]. We need to collect and analyze data for the characteristics and attributes to be able to draw conclusions. We used the iterative three-step approach for measuring the architecture principles, as described in Chapter 2 , to have a simple and unambiguous method for the research (see Figure 18).

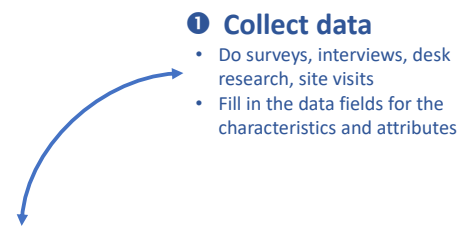

(3) Measure IS project success

2 Analyze data

- Evaluate scores \& exceptions

- Draw conclusions

Check precision and accuracy of collected data

- Analyze the qualitative and quantitative data on exceptions

- Quantify the data and find specific trends

Figure 18: The measurement method. 


\section{Collect data}

The objective of this step is to collect data regarding the six characteristics and its attributes of IS project success (See Section 3.3, Figure 15). A combination of data collection methods have to be used: desk research, surveys, interviews, and site visit. The interviews start after a first survey and the desk research, and the data collection ends with a specific survey and a site visit (See Figure 19). In the interviews new documents can be addressed, so after some interviews extra desk research may be necessary. Documents, such as project-initiation documents, project plans, progress reports, planning schedules, and change requests, are of interest for the desk research.

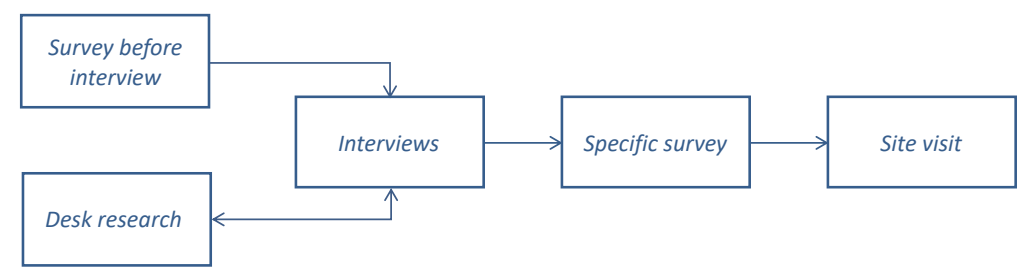

Figure 19: The data collection methods.

Two surveys are used. Before the interview sessions, a survey is sent to the interviewees to collect overall information regarding the six characteristics (see Appendix C: survey before interview). This enables the reachers to focus on specific items during the interviews. Basically, for each of the characteristics of IS project success one question is added to the survey. Besides there is an open question to add some remarks about the success of the project.

The second survey is sent to all users of the IS and addresses the "use" and "user satisfaction" characteristics. This survey has the intention to measure the perceived 
usage and user satisfaction [115], [118] and is one way to measure these characteristics.

The case study is conducted with a research team of two researchers, being subject-matter experts to interpret all data. The researchers can check with each other the data collected during interviews and are able to challenge each other in drawing conclusions.

All interviews are recorded, and the minutes of the interviews are sent to the interviewees for feedback. The interviewees are architects, software engineers, business analists, the test manager, the project leader, the system owner, and those with comparable positions being the roles that steer on requirements and IS project success. The site visit is useful to see the IS in daily operation and to consider to what extent the essential requirements are implemented.

\section{Analyze data}

The objective of the second step is to analyze the data. First, the research team has to verify the precision and accuracy of the data. Inconsistencies are resolved with new data collection, need to be clarified, or the research data concerned are out of scope. Second, the team determines the value of each attribute of the framework, based on all data collected. This might be a quantitative value, such as for "timeline" or "costs," or a qualitative value, such as for "attitude towards use." The third step is to quantify the outcome of the characteristics, as follows:

- The team defines a project as fully "on time" when the actual timeline is at most $10 \%$ more than the planned duration (the initial timeline including the change requests). A project is partially "on time" when the actual timeline is between $10 \%$ and $50 \%$ more than the planned duration. A project is not "on time" when there 
is an overrun of more than $50 \%$. The team uses these three levels because in practice this is not a binary discussion about successes and failures only [11], [13], [109], [110].

- The team determines the outcome of the "on budget" characteristic in a similar way, for the same reason. A project is fully "on budget" when the actual costs are within a margin of $10 \%$ of the initial budget plus the supplementary budget. The score is partially "on budget" if there is an overrun between $10 \%$ and $50 \%$ of the approved budget. A project is not "on budget" if the overrun is more than $50 \%$.

- For the other characteristics, the team calculates the score with a three-level code scheme [44]: "0\%" is no fulfilment, " $50 \%$ " is partial fulfilment, and " $100 \%$ " is complete fulfilment. The score for the characteristic is the average of its attribute scores, using the same code scheme, with each score scientifically substantiated.

- The team calculates the average level of IS project success by taking the average score of all six characteristics and define "100\%" as a full IS project success, " $50 \%$ " as partly successful and " $0 \%$ " no success.

The final step is to perform cross-characteristic analyses, to create graphics, and to search for interesting findings.

\section{Measure IS project success}

This final step is to evaluate the scores, exceptions and findings, given the analysis. As subject-matter experts, the team draws conclusions regarding IS project success and adds substantiating facts to those conclusions. The team 
closes the case study by describing IS project success, including the overall conclusions.

\subsection{Limitations, conclusions, and further research}

\section{Limitations}

We checked, given our research approach, whether the definition, description, and measurement model were coherent and complete. We also evaluated the measurement instrument for validity and reliability.

Given the number of research publications available, we selected only a small number of publications, on the premise that our selection criteria would help us to find the most relevant. If we did not find all relevant publications, our research outcome would be less complete or coherent. As we selected recent publications and used literature surveys concerning the success of IS projects, we were confident that our findings are sufficiently complete and coherent for our overall research objective.

Nevertheless, in a literature study, the semantics of natural language is always subject to (personal) interpretation. Although we reused many existing, validated measures, including their definitions, misinterpretation may have been possible. This was a point that required attention, especially during the use of the measurement instrument in the case studies.

The final limitation of this literature study approach was that we did not test the measurement instrument in practice. We expected to find a comprehensive measurement instrument in the literature that had been challenged in practice many times. Since we had to create our own measurement instrument, we 
had not yet evaluated the instrument's validity and reliability in practice.

\section{Conclusions}

The aim of this part of the research was to find a way to measure IS project success in practice. The first step to a measurement instrument was to answer the question "What is IS project success?" We defined IS project success as the combination of PMS and PPS. PMS is the extent of success of the project's execution, while PPS is the level of success of the product's effects, after implementation. To describe both PMS and PPS, we constructed a framework with six characteristics: three characteristics for each dimension (see Figure 15).

Having a description of IS project success, we were ready to answer the second research question: "How may IS project success be measured in practice?" For each of the six characteristics, we first found attributes to use as measures in the literature. These attributes describe the characteristic in a complete and coherent way. Second, we introduced an iterative three-step approach as a valid and reliable measurement method: "collect data," "analyze data," and "measure IS project success." We elaborated each step by describing the specific activities and results. The combination of the measurement model and measurement method is the answer to the second research question.

Theoretically, we now had a way to measure IS project success in practice. The next step was to challenge this measurement instrument in real-life case studies. 


\section{Next steps}

In the next chapter, we describe the application of the measurement instrument to three real-life case studies. In combination with the instrument for measuring architecture principles, we were able to investigate the contribution of architecture principles to IS project success.

In the future, follow-up research on IS project success might be interesting. We have defined IS project success as the combination of PMS and PPS, but what are the interdependencies? Is one dimension, or characteristic, more important than the others [112]? How do the characteristics of each dimension influence each other, and what are the success factors that influence the characteristics positively? Although these questions are of clear interest, they were outside the scope of our research program. 



\section{THE CONTRIBUTION OF ARCHITECTURE PRINCIPLES TO IS PROJECT SUCCESS IN PRACTICE}

In this chapter, we describe the contribution of architecture principles to IS project success in three case studies.

\subsection{Introduction}

In our research, we aimed to answer the question whether the use of architecture principles contributes to the success of IS projects in practice. In theory, architecture principles play a key role in guiding the design and the implementation of IS requirements [1], [20], [32]. But are architecture principles effective in practice?

Now that we have described the instruments to measure both architecture principles and IS project success, we are able to start answering the third research question of this research: "Does the use of architecture principles contribute to IS project success in practice?" In this chapter, we describe the contribution of architecture principles to IS project success in three real-life case studies and determine indicators of contributions across different cases.

We start this chapter with the research methodology in Section 4.2. In the third section, we describe the three individual case studies of Dutch governmental organizations. Indicators of contributions are described in Section 4.4. We finish this chapter with conclusions, limitations, and next steps. 


\subsection{Research methodology}

Research question

In Chapter 1 we described there was no scientifically based, empirical evidence of any contribution of architecture principles to IS project success [33]. Now we have instruments in place to measure both architecture principles and IS project success as described in Chapter 2 and 3, we are able to start answering the third research question of this research:

\section{Does the use of architecture principles contribute to IS project success in practice?}

As mentioned in the first section, we considered real-life case studies to see if we could find any contribution by architecture principles. Therefore, the first subsidiary research question was as follows:

\section{3a. Does the use of architecture principles contribute to IS project success in a specific case?}

However, we must also consider other, maybe more significant, factors that play a role in the failure or success of IS projects. As many of these success and failure factors have been defined over the years [6], [9], [10], [12]-[14], and some are more or less related to architecture principles, we took another approach. We focused on indicators of contribution to IS project success by the use of architecture principles. Such indicators can draw attention to positive or negative contribution and should be 
present across different case studies. The second subsidiary question, therefore, was as follows:

\section{3b. Are there indicators of contribution to IS project success by the use of architecture principles, across the different cases?}

\section{Case-study approach}

The case-study approach was our key research approach, as described comprehensively in previous chapters. As our research focused on a practical, context-related subject, the case-study approach was the best method to use [41]-[43]. To do so, our research steps were as follows: prepare the case study, conduct the research, and close the research (see Figure 20) [32].

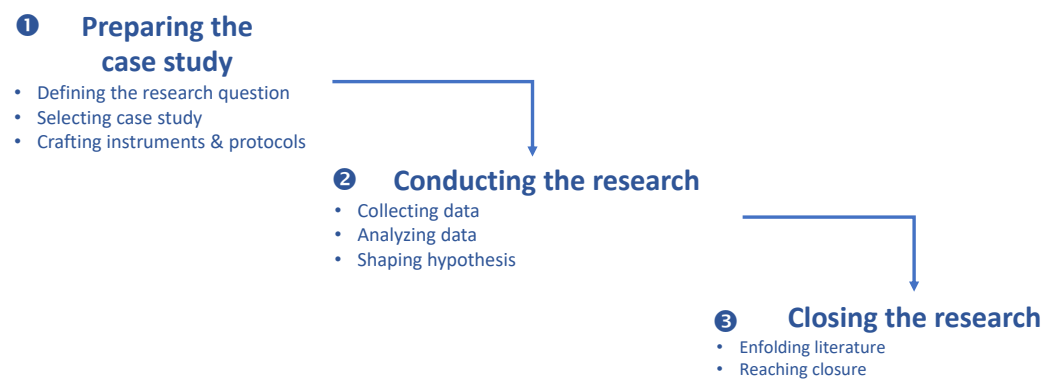

Figure 20: Case study approach.

1. Preparing the case study

In this phase, we first defined for each case the research question: "Does the use of architecture principles contribute to IS project success in the case of project X?" With the 
answer to this question, we could answer research question $3 a$.

We selected three case studies. The case studies had to meet three selection criteria: the project should have been conducted in a Dutch governmental organization, it should be finished, and sufficient information about the project should be available for investigation. Since we could expect three different outcomes, we allowed cases that did or did not use architecture principles and projects that were successful or unsuccessful.

We built our measurement instrument and method for both architecture principles and IS project success as described in Section 2.4 and 3.4. We also staffed per case our research team of subject-matter experts with two independent IS specialists and defined surveys for the data collection.

\section{Conducting the research}

In this phase, we conducted the three case studies, using the two measurement instruments described comprehensively in Chapters 2 and 3 . In an iterative process of data collection, analysis, and measuring the principles and IS project success, we conducted each case study. We collected the data from documents, survey, interviews, and a site-visit. Based on the results of our desk research and survey, we targeted specific elements of the framework during our interviews. We filled in our spreadsheet containing our measurement instrument with all relevant collected data.

We ended the individual case studies after evaluating all possible data sources in our spreadsheet, drawing conclusions per case study and reporting the results. The results of each case were reported using the STARR framework [123]. STARR is the acronym of "Situation", 
"Transition", "Analysis", "Results", and "Reflection". An important part of the results of the individual case studies was the outcome of the architecture principles' contribution. That outcome was the result of the scores of the two measurement instruments, based on facts collected.

\section{Closing the research}

The last phase of this research was to analyze the outcomes of the different case studies individually and to explore those indicators of contribution to IS project success.

Part of the analysis was to ask a group of seven subjectmatter experts to discuss the two subsidiary research questions. We used a nominal focus-group method to guide this discussion [45]. We saw the focus-group method as appropriate because we were investigating an unexplored phenomenon on one hand and using the unique knowledge of case experts on the other.

When there were no more new data sources to investigate regarding the individual cases, we decided to complete the research. After incorporating the outcome of the focus-group session in our research outcome, we found no more new indicators for contribution. We reported the final results of the case studies to the concerning organizations. We closed the research by answering our two research questions, as stated above.

\section{Boundaries of research}

In the literature, different kinds of architecture principles are named and defined. In this research, we used the following definition of an architecture principle: "An architecture principle is a declarative statement based on, at least, business and IT 
strategy. It normatively describes a property of the design of an information system that is necessary to ensure that the information system meets its essential requirements." Therefore, all types of principles-enterprise or software, semantic or syntactic, design or representation or management-meet this definition.

As this research field is context-related, we had to impose boundaries on our research to achieve comparable results. As mentioned in Chapter 2, we first narrowed the scope to Dutch governmental organizations. Second, we also narrowed the scope by looking for specific types of IS projects. IS projects can be classified in many ways, such as by the size of the project, the type of IS, the industry, or the delivery method [6]. In this research, we looked for medium-sized, custom-built, finished IS projects in Dutch governmental organizations.

\subsection{Individual case studies}

To answer the first subsidiary question, we explored three case studies. In this section, we summarize the results of those case studies, which were conducted in different Dutch governmental organizations. In Appendix D, E, and F detailed results can be found of each of the three cases.

\section{NEST case}

- Situation

Related to the theme of "Energy," Statistics Netherlands (CBS) delivers statistics related to levels and streams of energy in the Netherlands, such as "Use of energy," "Petroleum resources 
and products," and "Renewable energy." CBS has encountered challenges in delivering these energy statistics. First, as IS reached its end-of-life, the continuity of energy statistics was jeopardized. Second, the process of producing energy statistics was prone to error.

To solve these issues, CBS started the project "Energievernieuwing" ("Energy Renewal"), which was conducted from July, 2015, to March 24, 2017. A previous project, called JiB, had the same objective, but was abandoned because it was confronted with too many challenges. The project was staffed with approximately seven people to build the NEST-application for 16 users. In correspondence with the measurement method, we interviewed the deputy business owner, information analyst, scrum master and architect, software architect, and the tester. The project used an Agile approach. Project members were used to work with some architecture artifacts, but not explicitly with architecture principles.

For this case study, we received for documents related to architecture principles and IS project success, like the Project Initiation Document, Business Analysis, User Satisfaction Survey results, Software Architecture Document, and a Request for Change. During the site visit we saw the NESTapplication in operation.

We conducted this case study with a research team of two subject-matter experts.

\section{- Transition}

The main objectives of the project were as follows:

- $\quad$ To secure the continuity of the IS for energy statistics and, with that, the continuity of the energy statistics process. 
- To mitigate the risks of errors and inconsistencies between energy figures.

In this transition, the modules "ZZ-system" and "NEH-system" had to be rebuilt into a "NEST-A" and "NEST-B" system. In addition, the implementation of a standard statistics process had to be accomplished. The objectives were translated into 12 essential requirements to be fulfilled by the process and the system (See Appendix D). At the end of the transition, the new process and system needed to guarantee the fulfilment of reporting obligations to the EU and ministerial agreements with the International Energy Agency.

- Analysis

In this section, we describe the main results of our measurements, which we made using our instruments. The success of the IS project and the use of architecture principles were measured.

Success of the project

The success of the IS project "Energy Renewal" was $75 \%$ on average, so it can be defined as more-thanpartially successful. The average score was calculated on the basis of the individual scores for the IS project success characteristics (see Figure 21). For

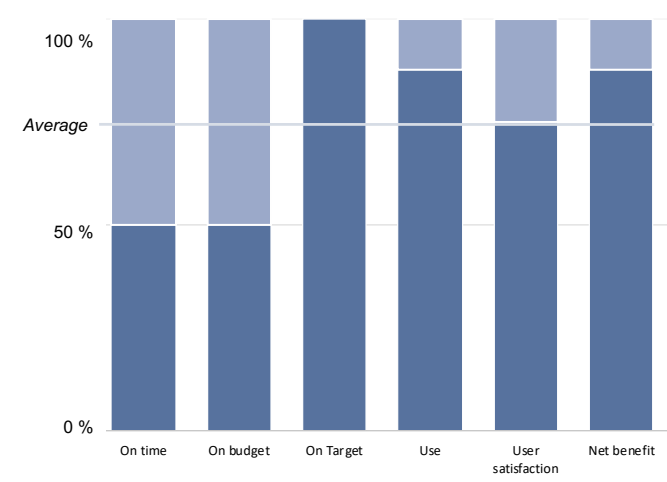

Figure 21: Scores of NEST's IS project success characteristics. 
each characteristic, we determined the individual score by using our measurement instrument.

On time: With a $10.8 \%$ delay on the necessary project leadtime, the "Energy Renewal" project was partially on time. The threshold of "on time" is a delay of $10.0 \%$. Besides the initial timeline of 15.5 months, 3.0 months were necessary to build extra functionality to achieve the overall objectives. Another 1.5 months was needed due to a delay caused by missing resources, so that time was not necessary to build the extra functionality (See Table 14).

Table 14: the values for the "On time" attributes for project NEST.

$\begin{array}{llll}\text { Initial timeline } & \text { Change requests } & \text { Actual timeline } & \% \text { delay } \\ 15.5 & 4.5 \text { (of which } 3.0 \text { necessary) } & 20.5 & 10.8\end{array}$

Figures in months.

On budget: The "Energy Renewal" project overran both in hours and in euros, by $22.3 \%$ and $24.8 \%$, respectively. Because the overrun of the project was between $10 \%$ and $50 \%$, we defined this project as partially on budget. In this calculation, we included 720 hours that were necessary to implement extra functionality. The other hours were requested to gain on the delay in testing, solving test findings and to optimize documentation (See Table 15).

Table 15: the values for the "On budget" attributes for project NEST.

$\begin{array}{llllc} & \text { Initial budget } & \begin{array}{l}\text { Supplementary } \\ \text { budget }\end{array} & \text { Actual costs } & \text { \% overrun } \\ \text { Hours } & 14,110 & 3,650 & 18,140 & 22.3 \\ & & (720 \text { necessary) } & & \\ \text { Euros } & 8,000 & 27,000 & \text { Unknown }^{*} & \\ \text { Total (euros) } & 974,420 & 277,025 & 1,277,590 & 24.8 \\ \text { * No information was found, so } & \text { we assumed that all the expenses were spent }\end{array}$


On target: The two main objectives of the project were achieved. Moreover, the 12 essential requirements of the NEST system were implemented. Since no Quality-of-Service requirements-such as performance, availability, or securitywere defined, all levels of service were adequate. Overall, the project was delivered on target.

Use: The use of NEST scored highly. Almost every step of the energy statistics process was supported by NEST, and in these steps only the NEST system was being used. The statisticians were using many functions of the NEST system. However, in some cases data needed to be changed manually between two process steps, so a full score on use was not yet available.

User satisfaction: The user satisfaction scores were average. The usefulness of NEST was quite good, and data-matching between different energy statistics was much easier with the new system. Although users were satisfied with NEST, there was one point requiring attention: the performance of the system needed improvement, in particular with regard to extensive calculations. This was interesting, because no official performance requirements were defined.

Net impacts: The error susceptibility of the process was decreased by the more unambiguous data model and by eliminating manual actions. Financial savings were also made possible because of the reduced number of systems and the better process. However, the return on investment was projected to take less time than realized. Future-readiness was improved because of the use of new technologies and the component-based approach. Therefore, the "net impacts" of NEST achieved almost full scores. 


\section{Use of architecture principles}

In this case study, 13 statements were found that were addressed as architecture principles. According to our definition and criteria, nine statements were identified as architecture principles. The others were standards and guidelines for projects. In the bar chart (see Figure 22), there is an overview of the scores for the principles' characteristics. The average score for all characteristics was $48 \%$.

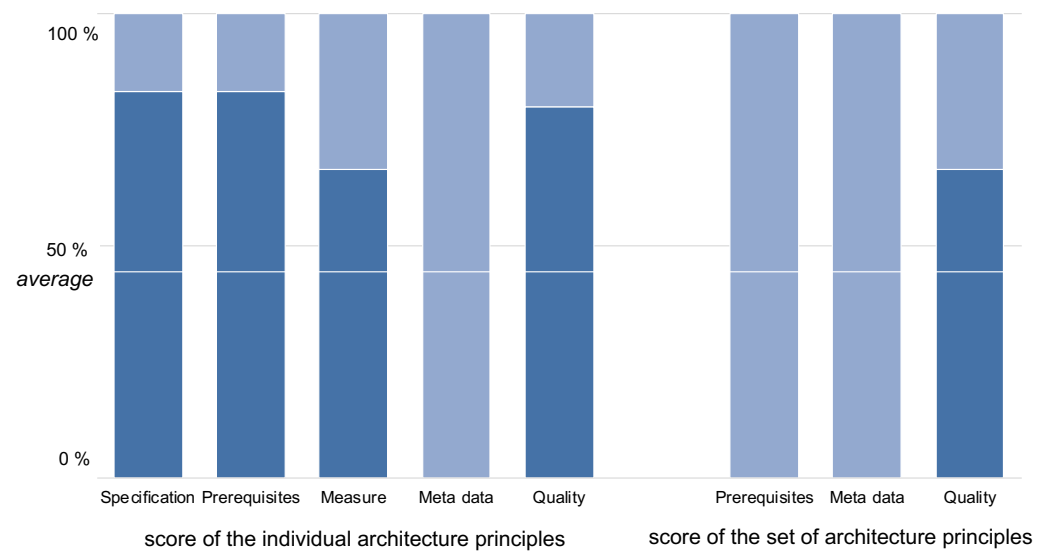

Figure 22: Scores of the architecture principle characteristics of NEST.

Specification: The "statement" and "rationale" were present for all nine architecture principles. The "implications," though, were incomplete, inconsistent between different sources, or lacking.

Prerequisites: The project did not fulfil the prerequisites of two principles sufficiently. As the architects were focused on the technical prerequisites, they overlooked some non-technical prerequisites. Their argument to address only the technical 
prerequisites was: "as architects we were not in the position to set particular categories of prerequisites."

Measure: Five architecture principles were complied with completely, and two principles were complied with only partially. For two principles, we could not determine whether or not the principles had been followed, since we lacked the implications of those principles.

Meta data: The architecture principles were not documented explicitly: "there was no catalog or check list available." Therefore, no meta data regarding the principles was in place. Some information related to the architecture principles was found in the project documentation. Most of the informationsharing took place via oral discussions.

Quality: Five architecture principles (almost) matched all quality attributes. The other four principles had decreased quality for the attributes "specific," "measurable," or "achievable."

Due to the implicit use of the architecture principles, there was also no set of principles present. However, if we consider the group of principles as a set, we can address some facts about the "quality" and the "classification" of the group of principles. As there were no sets, there were no facts to be found regarding the attributes "meta data" and the "prerequisites" of the set.

Classification: All principles but one were generic principles to be used within CBS and not specifically aligned to the NEST system. Six principles were focused on the application, while three principles were related to the IS. 
Quality of the set: The identified principles covered nine of the eleven essential requirements of the NEST system and probably also covered the other two requirements. As the implications of some principles were unclear, we could not connect all essential requirements to the principles. Furthermore, the group of principles did not conflict with each other; some principles were even related to each other or strengthened each other.

\section{- Results}

To answer the question "Does the use of architecture principles make a contribution to IS project success in the NEST case?", we plotted the outcome of our measurement instruments in the matrix (see Figure 23).

As we have seen in the analysis, the level of IS project success was $75 \%$ and the score for the use of architecture principles was $48 \%$. Therefore, the NEST case study may be placed indicatively between the "a possible positive contribution" and the "no or limited contribution" area of the matrix. Because of the implicit use of the architecture principles, three of the nine principle's characteristics scored $0 \%$.

Although there may have been other project success factors as well, such as end-user involvement and the replacement of application software, we determined that there was a relationship between architecture principles on one hand and the essential requirements on the other. We identified links between the architecture principles and design properties of the NEST system, and we were also able to connect the essential requirements to those parts of the design. One of the examples is the architecture principle "Nest is divided in rest points", which 
could be linked to the requirements as "Eliminating of double data management" and "Standardization of the work process."
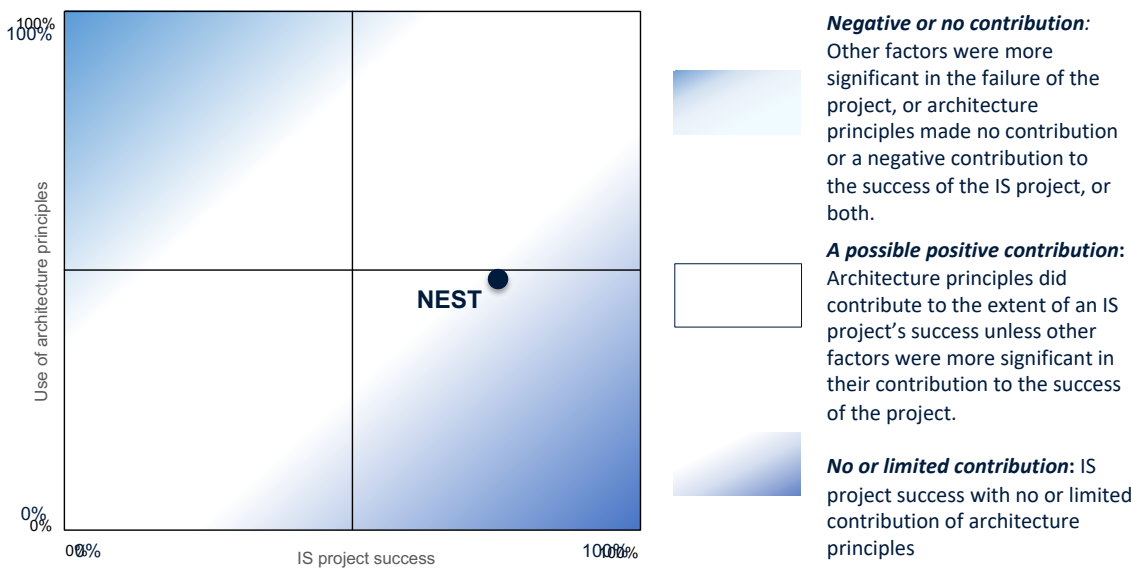

Figure 23: Use of architecture principles and the IS project success of NEST.

Unfortunately, we were not able to determine to what extent the principles contributed to the success of the IS project. The use of architecture principles was $48 \%$ on average, and the impact of the design elements on realizing the essential requirements also could not be determined.

The delay in time and the overrun in budget, were caused by factors that could not be linked to the use or neglect of architecture principles.

Therefore, we conclude that in this case architecture principles made, to some extent, a positive contribution to the "Energy Renewal" project and the implementation of the NEST system. 
- Reflection

If we reflect on this case study, we can identify the following research findings and limitations.

First, one important finding is the implicit use of the architecture principles. Although there were no policies, agreements, or documentation, project members used architecture principles in this project. Some principles were even used by all those involved, although not everyone addressed them as architecture principles.

Second, the architects in the project focused on technical solutions when discussing the prerequisites. This might be an indication that they saw the use of architecture principles as a technical subject.

Regarding IS project success, it is interesting to see that there were no requirements related to the performance of the system, although the lower user satisfaction score was caused by a lack of performance. Therefore, there is a relationship between PMS on one hand and PPS on the other.

Before the project "Energy Renewal," there were other attempts to rebuild the system. This could have had a positive effect on the success of this project, for example, by using other architecture principles.

In engaging in this case study, there were some limitations. Although different sources were used, for a small number of attributes it was hard to find all relevant data. Though, we found at least two different data sources for each characteristic. Overall, there was a consistent and coherent picture of both the architecture principles and IS project success. Given the fact that all the findings strengthened each other, we think our conclusions are robust.

In our case study, we were not able to determine the impact of the principles on the design or to measure the impact of the design elements on the realization of the essential 
requirements. Methods for these issues could be the subject of further research.

\section{Octopus}

- Situation

One of the functions of the City Hall of Amsterdam is to manage complaints and appeals related to decisions made by civil servants. In the City Hall, 14 different ISs were used to support the processes of complaints and appeals. In addition, there were different methods to manage these processes of complaints and appeals. The overall objective of the "Digitization Legal Domain" project was to replace all applications with a single application and to standardize these processes for the approximately 350 users. This program started on April 1, 2016 and continued until April 30, 2018.

The team size of the Octopus project was around seven people. For this case study we interviewed both members of the project team and stakeholders: the business owner, project manager, IT delivery manager, information analyst, enterprise architect, business architect, technical architect, and the test manager. People involved in the Octopus project were used to work with architecture, including architecture principles.

For this case study, we received all kinds of documents related to architecture principles and IS project success, like: the Business Case, the Project Initiation Document, Business Analysis, Project Start and End Architecture, Technical Architecture, Requirements overview, Exception reports, and Project Evaluation.

We conducted this case study with a research team of two subject-matter experts. 


\section{- Transition}

The transition of this program was defined as follows:

"All business units of the City Hall of Amsterdam that manage complaints and appeals related to administrative law must use the same information system, work in a uniform and fully digital manner, and be able to use the system interface with the Administration of Justice ("Rechtspraak"). In addition, a connection with the Administration of Justice will be available for private law."

This transition would be successful if the following objectives were achieved:

- Automated and digitized communication with the Administration of Justice using one IS

- Connection between private law and the "Mijn Rechtspraak" portal

- $\quad$ Rationalized (temporary) IS with optimized processes for complaints, appeals, and preliminary injunctions

- $\quad$ Digital information management (using digital cases)

To achieve those objectives, the IS had to meet eight essential requirements (See Appendix $\mathrm{E}$ ).

\section{- Analysis}

The main outcomes of our measurements, for both IS project success and the use of architecture principles, are described here. 
IS project success

The IS project
success of the
"Digitization Legal

Domain" project was

$67 \%$ on average, so it

can be defined as

more-than-partially

successful.

The

average score was

calculated on the

basis of the individual

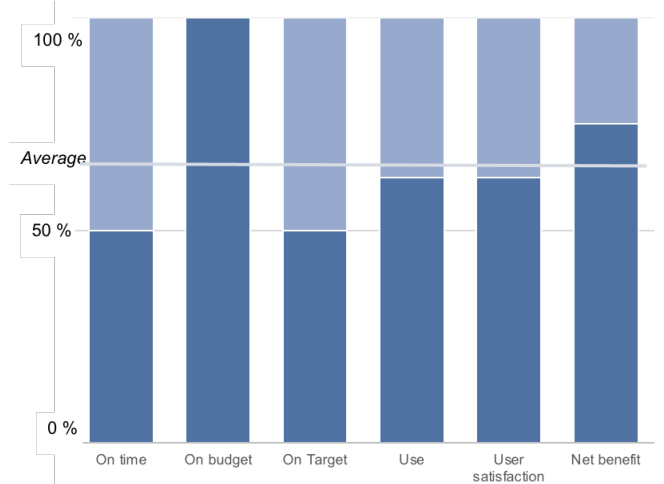

Figure 24: Scores of Octopus's IS project success characteristics. scores of the IS

project success characteristics (see Figure 24). For each characteristic, we determined the individual score by using our measurement instrument.

On time: The necessary initial timeline was planned to be 21 months, but the project ended five months later, with a delay of $23.8 \%$. Therefore, the project was "partially" on time. The connection with the document management system, the lack of resources, and a number of findings during testing were the reasons for the delay. The steering committee approved four scope reductions because of the absence of the Administration of Justice system, but they did not address any implications for the timeline (See Table 16).

Table 16: the values for the "On time" attributes for project Octopus.

$\begin{array}{llll}\text { Initial timeline } & \text { Change requests } & \text { Actual timeline } & \% \text { delay } \\ 21 & 0 & 26 & 23.8\end{array}$

Figures in months. 
On budget: According to the concluding report, the total cost of the project "Digitization Legal Domain" was 530,222 euros, while the initial budget was $1,808,470$ euros. However, the effect of the approved scope reductions, such as the cancelling of the system interface with the Administration of Justice and the delay of the new target application, was a saving of 574,000 euros. Therefore, the project was on budget with actual costs being $43.0 \%$ of the initial budget.

Portions of the costs that were allocated in the initial budget and spent during the project were not charged at the end of project. These were costs for employees' "Informatie Voorziening," communications, facilities, and so on. Therefore, no statement could be made concerning whether the project was "on budget." If we incorporate these (planned) costs in the realization, the actual cost becomes $1,341,032$ euros; that is, an overrun of $8.6 \%$. This is still within the threshold of $10 \%$, and therefore the project is "on budget" (See Table 17).

Table 17: the values for the "On budget" attributes for project Octopus.

$\begin{array}{lllll} & \text { Initial budget } & \begin{array}{l}\text { Supplementary } \\ \text { budget }\end{array} & \text { Actual costs } & \text { \% overrun } \\ \text { Hours } & 51,503 & 0 & \text { Unknown } & - \\ \text { Euros } & 1,808,470 & -547,000 & 530,222 & -43.0 \% \\ \text { Euros (EST) } & 1,808,470 & -547,000 & 1,341,032 & +8.6 \%\end{array}$

* No information available

On target: One of the four main objectives was achieved: rationalization of the ISs and implementation as a harmonized process. All stakeholders considered this objective to be the most important. "The initial reason to start the Octopus project was to rationalize the number of applications in the legal domain." They were aware of the fact that the connection with the Administration of Justice was postponed by others. Of the 
eight essential requirements, three were implemented, two requirements were partially implemented, and three were not implemented. At the start of the project, some Quality-ofService requirements relating to the availability-integritysecurity level (AIS level) were defined. The project had to implement a lower AIS level than originally defined. Given all these results, the project was delivered on target "partially."

Use: The use of the Octopus system was partially successful. The system included all necessary functions to manage complaints and appeals. Employees were required to use Octopus for handling complaints and appeals. However, users were also making shortcuts to work outside the system. Only a small group of users wanted to incorporate the Octopus system extensively in their way of working.

User satisfaction: User satisfaction scored "partially" on our measurement. Although the system supported the activities of the users, it was an old-fashioned system that was not userfriendly. A majority of users was not eager to use the Octopus system and encountered insufficient support from IT staff. The quality of that support, though, scored well.

Net impacts: The business case was positive, because of the rationalization of the 14 ISs and the harmonization of the process. In choosing to implement the current Octopus system, the City Hall of Amsterdam have chosen a temporary solution. This solution is not future-proof, but with the temporary system there is now time to tender for a permanent system.

In the case study, we asked stakeholders which project success factors might have contributed to the success of Octopus. The commitment of all legal business units, and the collaboration 
within the project team and with various stakeholders were addressed as important factors.

\section{Use of architecture principles}

Of the 45 statements found, 39 were identified as architecture principles used in the Octopus project. The bar chart below (see Figure 25) shows the average scores of the principles' characteristics. The average score for all characteristics was $70 \%$.

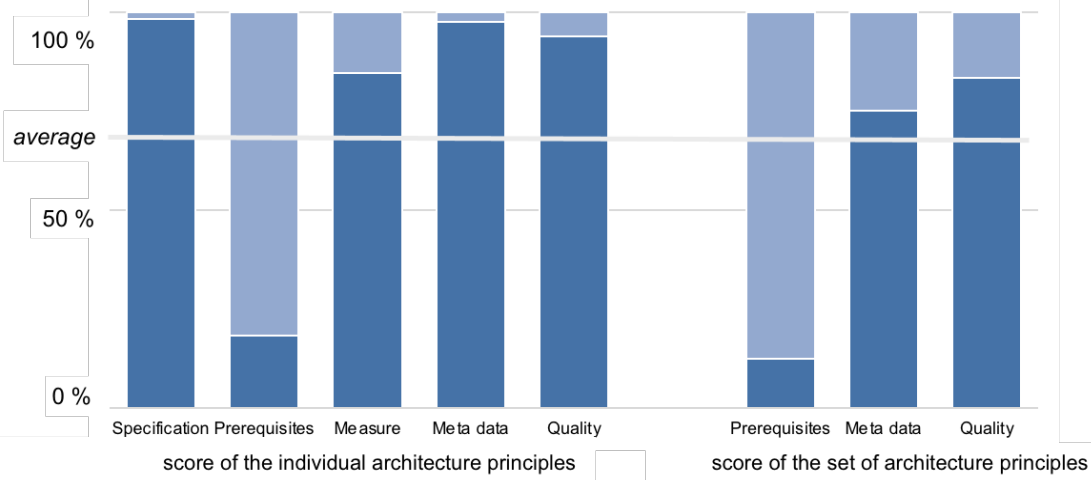

Figure 25: Scores of Octopus's architecture principle characteristics.

Specification: Almost all principles had a "statement," "rationale," and "implications" as they were documented in (architecture) documents. One principle, "Process harmonization", was used implicitly as architecture principle." The business owner disseminated the directive of process harmonization across the organization.

Prerequisites: Of the architecture principles, $28 \%$ had explicitly defined prerequisites. These prerequisites were (partially) 
fulfilled. No prerequisites were defined for the other principles, and they were, at best, implicitly present during the implementation.

Measures: The Octopus system did not comply with $21 \%$ of the principles, and only partially with $20 \%$. Despite the support for all 39 principles, fulfillment of particular architecture principles was difficult because of the lack of the Administration of Justice system and the impossibility of a new technical infrastructure, among other missing prerequisites.

Meta data: Apart from one, all architecture principles were described in one or more (architecture) documents, such as "Project Start Architecture," "Project End Architecture," and "Technical Architecture Octopus." Therefore, the management of the architecture principles, with all meta data, was in place.

Quality: Of the architecture principles, $87 \%$ met (almost) all quality attributes. Most of the others had some shortcomings in the descriptions ("specific") and, related to that, in the measurability or achievability of the principle.

The 39 identified principles were grouped into four sets. We also measured the characteristics of those sets.

Classification: All sets, except for the set "ICT principles," concerned the IS layer; the "ICT principles" set was focused on the application and technical infrastructure. The project "Digitization Legal Domain" was the scope for two sets, while the other two sets were defined for the entire City Hall organization. Because we identified the "Process harmonization" principle as a separate set, we also found out that individual principles could have their own classification. 
Prerequisites: Except for the set "process harmonization," no "preconditions" or "assumptions" were found.

Meta data: The sets, including meta data, were described in different (architecture) documents.

Quality: Two sets were representative, covering the essential requirements within their scope. The other two sets were only partially representative because many of the principles in these sets were related to only a small number of essential requirements. The accessibility of the sets was well established through the documentation and discussions during the projects. Two sets had overlapping principles, and in one set there were some contradictions between principles. Overall, the average score of the "quality" of all sets together was $83 \%$.

- Results

We plotted the outcome of our measurements in the matrix (see Figure 26) to answer the question "does the use of architecture principles make a contribution to the IS project success in the Octopus case?"

With a score of $67 \%$ for the level of IS project success and a score of $70 \%$ for the use of architecture principles, the Octopus case study was placed indicatively in the "a possible positive contribution" area of the matrix.

As described in the analysis section, three objectives were not achieved, including the related essential requirements. The underlying causes for missing these results were the absence of the Administration of Justice system and the lack of resources for the project. These reasons were not related to the use of architecture principles. The failure of the Document Management System (DMS) could be related to the use of an 
architecture principle, but the root cause of the failing DMS has never been found. One interesting element is the partial fulfilment for "use" and "user satisfaction." No architecture principles addressed these elements (in)directly. Besides, no principle encouraged the fulfillment of "the training of users in using the new information system"-requirement. So, the use of architecture principles had no added value on those characteristics.
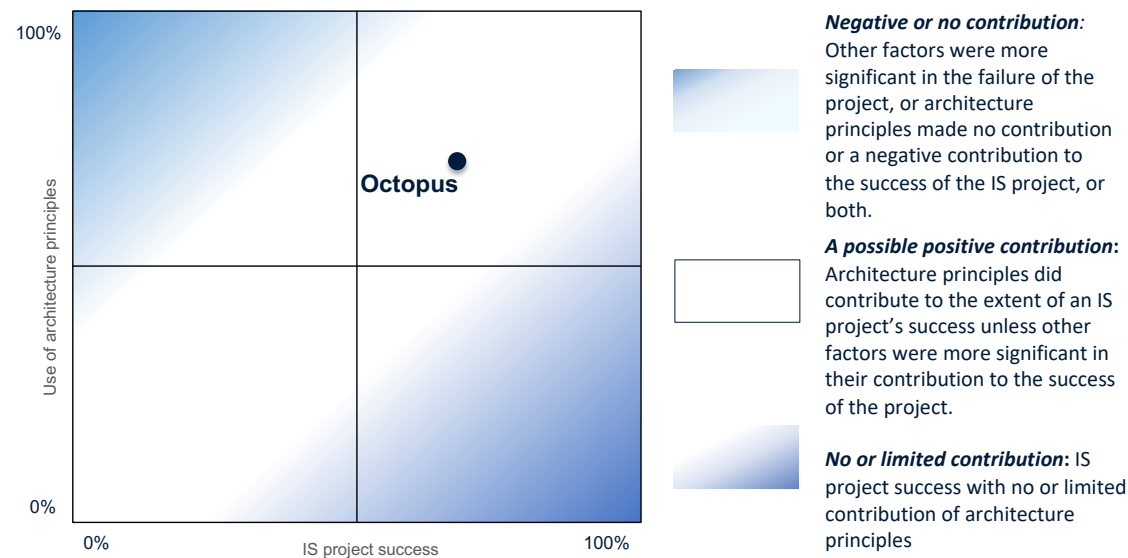

Figure 26: Use of architecture principles and the IS project success of Octopus.

Nevertheless, the success of the harmonization of the process (requirement 2) and the rationalization of the systems (requirement 1) can be related to the design and the related principles, especially the "process harmonization" principle. The essential requirements that were implemented can also be linked directly to the (partial) compliance with 31 architecture principles.

In conclusion, we suggest that the 31 architecture principles made, perhaps in combination with other projectsuccess factors, a positive contribution in the project 
"Digitization Legal Domain" and the implementation of the Octopus system.

\section{- Reflection}

There were some interesting findings in this case study. Although the IS project success scored $67 \%$ with our measurement instrument, all stakeholders were very satisfied with the outcome of the project. They saw the Octopus project as very successful, and they gave more weight to the harmonization and rationalization objective than to the others. Introducing weighting factors in the measurements instrument could help in addressing the importance of characteristics or attributes.

Stakeholders did not identify the principle "process harmonization" as an architecture principle, although everyone considered the "harmonization" principle as key in the implementation of the Octopus system. Architecture-and with it architecture principles-was seen as a technical discipline, a responsibility of IT staff.

Along with the principle "process harmonization," we discovered that the "classification" characteristic of a set can also be applied to a single principle. Therefore, we needed to add the "classification" characteristic to the framework related to the individual principle.

The scope was the complaints and appeals related to administrative law. Therefore, all architectural decisions in the project were made within the defined scope, while a broader scope could also imply other principles and solutions.

In this case study, there were also some limitations. First, although a large amount of project documentation was available, not all relevant data-such as budget data-could be retrieved. Second, because of the outbreak of the COVID-19 
virus, ${ }^{1}$ a return call to the users to ask them to fill in the questionnaire was not feasible. With an estimated response of $23 \%$, the questionnaire gave an indication to help determine the "use" and "user satisfaction," and other data sources were also available to complete the measurements.

The fact that architecture principles were described explicitly in several documents had the effect that not only "meta data" was available, but the scores for "specification" and "quality" were also high. It seems, as already discussed in theory, that there are dependencies between the different characteristics of the framework for measuring architecture principles, by which they strengthen or weaken each other.

\section{Epos}

- Situation

In the Netherlands, everyone must rely on good, timely, and affordable care. Therefore, the "Nederlandse Zorg autoriteit" (NZa) is the Dutch governmental organization that regulates and monitors care providers and care insurers. An important function within the $\mathrm{NZa}$ is to manage the individual ordinances and contributions to care providers and health insurers. In the past, they supported this process with a large number of spreadsheets and later the MeNZa system. The objective of the Epos project was to implement a new IS, including a simplified process. The start of this project was July 1, 2018, and the project ended on May 31, 2020.

Before the Epos project NZa implemented the MeNZasystem in two projects MeNZa Classic and MeNZa 2.0, but the system became much more complex with decreasing

\footnotetext{
1 : the COVID-19 pandemic started in the Netherlands around March $16^{\text {th }}$, and all organizations had to prioritize their business.
} 
performance. NZa started the Epos project with a staff of approximately 6 people, using an Agile approach. Both NZaemployees and people from care providers and care insurers are using the Epos-system.

In correspondence with the measurement method, we interviewed the business owner, two business analysts-testers, lead developer-architect, project manager, and three product owners-business testers. Project members were not used to work with architecture artifacts. Documents we used related to architecture principles and IS project success were, among others: Decision making MeNZa renewal, Analysis Renewal MeNZa, Business Analysis MeNZa, Epos Architecture Review, Scrum Board overview, Go - No Go live Epos, and Planning Epos. Because of the COVID-19 pandemic a site visit was not possible. An instruction video and the link to the Epos portal were some proof of the Epos portal in operation.

We conducted this case study with a research team of two subject-matter experts.

\section{- Transition}

As described in "Besluitvorming Nieuwbouw MeNZa" (decisionmaking new MeNZa), the transition to Epos was as follows:

"The objective is to implement a new, modern, and highperformance renewed version of MeNZa (new MeNZa), with a similar and smarter user functionality and similar end products (among others, PDF appointments), implementing the following requirements:

- Including a business card for the NZa, considering the Look \& Feel and output of the system

- $\quad$ Providing a uniform process and lay-out (using style cards) 
- $\quad$ Offering good performance (state-of-the-art, millisecond response on clicking)

- $\quad$ A system that works intuitively

- $\quad$ Scalable (also, in the long-term, for MijnNZa.nl)

- Compliant with archiving requirements

- Compliant with security and privacy requirements

- Simple to maintain

- $\quad$ Offering a flexible set-up

- $\quad$ Providing a shorter project lead-time and testing time

- Future-proof"

These were the 11 essential requirements for the Epos system. With the implementation of Epos, the optimization and harmonization of processes needed to be accomplished. After the implementation of all required forms in Epos, the MeNZa application needed to be replaced.

- Analysis

The main outcomes of our measurements, for both IS project success and the use of architecture principles, are described here.

IS project success

The IS project success of the "Epos" project was $98 \%$ on average, so it can be defined as fully successful. The average score was calculated based on the individual scores

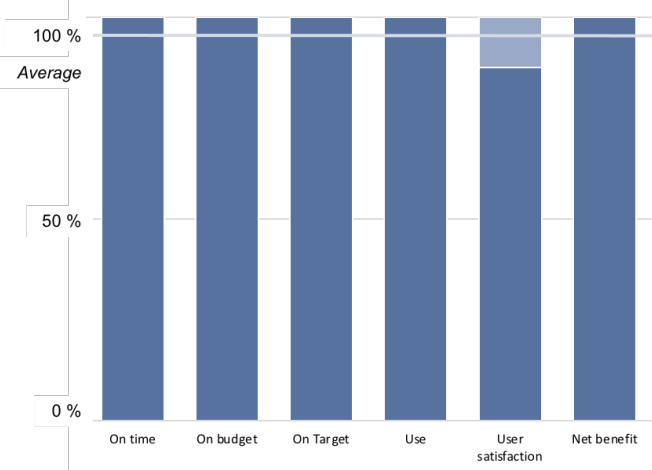

Figure 27: Scores of Epos's IS project success characteristics. 
of the IS project success characteristics (see Figure 27). For each characteristic, we determined the individual score using our measurement instrument.

On time: At the beginning, the project had some difficulties in implementing the forms. The effect was a delay of three months overall; with a necessary timeline of 21 months, the delay was $9.5 \%$. Therefore, because the delay was within the margin of $10 \%$, the project was fully "on time." The exception of three months was necessary to implement three extra forms (See Table 18).

Table 18: the values for the "On time" attributes for project Epos.

$\begin{array}{llll}\text { Initial timeline } & \text { Change requests } & \text { Actual timeline } & \% \text { delay } \\ 18 & 3 & 23 & 9.5\end{array}$

Figures in months.

On budget: The initial budget for the project was 599,434 euros for external costs and 9,030 of internal and external hours. The project requested an additional budget of 91,186 euros (888 hours) to implement the three extra forms. At the end of the project, the actual cost was 709,050 euros. Therefore, with an overrun of $2.7 \%$, the project was on budget (See Table 19).

Table 19: the values for the "On budget" attributes for project Epos.

$\begin{array}{lllll} & \text { Initial budget } & \begin{array}{l}\text { Supplementary } \\ \text { budget }\end{array} & \text { Actual costs } & \text { \% overrun } \\ \text { Hours } & 9,030 & 888^{*} & \text { Unknown } & - \\ \text { Euros } & 599,434 & 91,186 & 709,050 & 2.7 \\ & & & \\ \text { * The only exception request, for the supplier hours } & \\ \text { ** No information available } & & \end{array}$


On target: The Epos project achieved its objective. Only one essential requirement was implemented partially; all the others were implemented fully. The defined Quality-of-Service requirements for performance, availability, and capacity were implemented. Epos also met its generic security requirements.

Use 2: The use of Epos was successful. The Epos system supported all functions for managing requests up to send the disposition. To acquire ordinances or contributions, external users had to use the Epos system. To perform internal functions the users also had to use the Epos system. There was a positive attitude towards the use of Epos: "The system is that great, why wouldn't you use the system?" People at NZa wanted to use Epos for other functions within NZa as well.

User satisfaction": The employees at NZa were satisfied in using the system. According to external users, Epos was a userfriendly and intuitive system. There was a need for some small changes only. In general, users were satisfied with the service support, although there was some room for improvement.

Net impacts: There was a full score for the "net impacts" of Epos. The Epos system supported one of the main functions of $\mathrm{NZa}$ and was one of NZa's core systems. Epos supported the organization efficiently and eliminated many manual activities. In comparison with former systems, Epos accelerated the processing of ordinances and contributions. The Epos system was future-proof for other functions in addition to ordinances and contributions.

\footnotetext{
2: Due to the COVID-19 outbreak, we were not able to send a questionnaire to the different user groups regarding 'use' and 'user satisfaction'.
} 
We also asked for the critical success factors of this project. Key to the success were the lessons learned from former projects: MeNZa Classic and MeNZa 2.0. They learned from these experiences and made different choices in the Epos project. First, an important choice was to change from configuring to modelling the system, with the effect of reducing the complexity of the system. Second, there was a focus by management on project results and financial spending.

\section{Use of architecture principles}

We identified 11 statements as architecture principles. Almost all project members did not recognize statements in the project as architecture principles, because they were not used to work with them. So, there may have been even more principles, which were used implicitly. In the bar chart (see Figure 28), there is an overview of the scores for the principles' characteristics. The average score for all characteristics was $57 \%$.

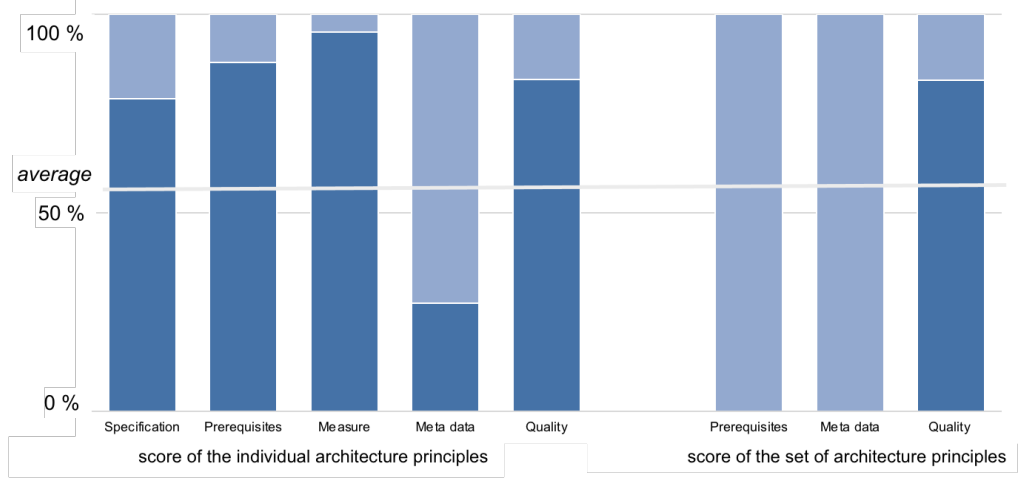

Figure 28: Scores of the architecture principle characteristics for Epos. 
Specification: Despite the lack of descriptions of the architecture principles, parts of principles were specified in documents such as Analysis Renewal MeNZa and Decision making MeNZa renewal, and stakeholders were also able to illuminate particular principles, like "Component Based Development." Six of the architecture principles were well-specified: the "rationale" and "implications" were less clear for the others.

Prerequisites: No explicit prerequisites were defined, which is natural when architecture principles are only used implicitly. The project had already met several prerequisites at the start, such as having the expertise and technology for component-based development. However, the prerequisites were not fulfilled for some other principles, such as "re-use."

Measures: Despite the support for all architecture principles, the Epos system complied fully with nine principles and only partially with two. Principles like "Harmonization", "Modelling", "Business in the lead" and "Agile" could be identified in the implementation of the Epos-system or in the way of working of the project. The fulfillment of the "re-use" principle was difficult, as the re-use of complicated forms required more effort of experts. For some developers, the implications of "KISS" (Keep It Simple Stupid) were not clear, with the effect that there was no explicit separation of presentation, business, and data functions in the Epos system.

Meta data: Although some parts of the architecture principles were described in the project documents, no overview of the principles was presented. Therefore, no meta data related to one or more of the principles was present. 
Quality: Eight of the architecture principles (almost) matched all quality attributes. The other three principles had shortcomings in almost all of the five attributes.

We also analyzed the 11 architecture principles as a set. As the principles were not described as a set, there were no common "prerequisites" or "meta data." We were able to measure the "quality" of the set and analyze the scope and type of the principles.

Classification: Four principles were related to the entire IS, while the other seven principles guided the design of the application. Most of the principles were specifically used to implement the Epos system, while two principles applied to the entire $\mathrm{NZa}$ organization.

Quality: The eleven principles were quite representative, covering almost all essential requirements. Project members discussed most of the principles during the project with the relevant stakeholders and some information could also be found in project documentation. The principles were not inconsistent with each other; on the contrary, some pairs of principles strengthened each other.

\section{- Results}

In Figure 29, we present the outcome of our measurements of the Epos project. With these results, we were able to answer the question: "does the use of architecture principles make a contribution to IS project success in the Epos case?"

In this case study, IS project success scored $98 \%$, and the use of architecture principles scored $57 \%$. With these results, the Epos project was placed indicatively just in the "no or limited contribution" area of the matrix. 


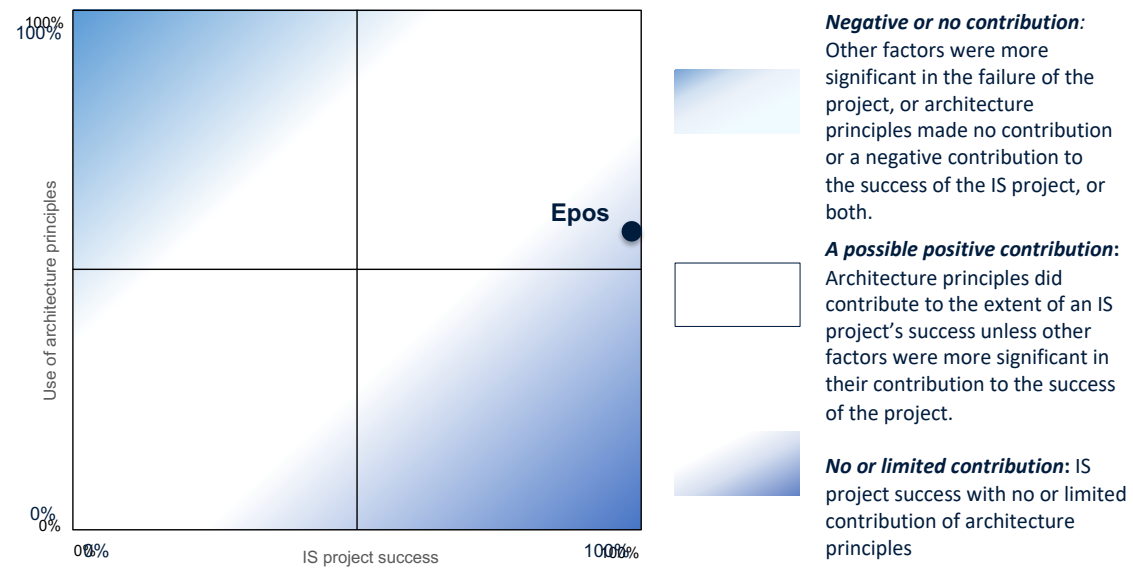

Figure 29: Use of architecture principles and IS project success for Epos.

In this result, it is interesting to see the score for the use of architecture principles. As the project members did not specify the principles explicitly, the average score of the characteristic "meta data" scored below 30\%, and the "prerequisites" and "meta data" of the set scored $0 \%$. These scores affected the average score for the use of the architecture principle negatively.

The Epos system did comply with almost all principles, and those principles could be related to most of the essential requirements. Stakeholders named at least one principle, "modelling," as a critical success factor for the project.

In summary, we conclude that architecture principles did contribute positively to the implementation of the essential requirements and the IS project success of Epos. At least three principles, "component based", "harmonization" and "micro services", had an impact on success, although other success factors may also have been important. 
- Reflection

Reflecting on this case, we can address some limitations and findings relevant for further analysis.

Two elements are relevant for evaluating the results of this case study. Due to the COVID-19 outbreak, we were not able to send a questionnaire to the different user groups regarding "use" and "user satisfaction." As a result, we could only use the information from the interviews.

Some characteristics were related to each other, so their scores augmented each other. Due to the implicit use of principles in this case, it is clear that no "meta data" was available for either the individual principles or the set of principles. This could affect the score of other characteristics as well. Implementing weighting factors into the measurement instrument could be an improvement.

First, one important finding is the measurement of IS project success. The Epos project was successful, with a score of $98 \%$, due to the former projects MeNZa Classic and MeNZa 2.0. The Epos project learned from experience with regard to costs, user expectations, and net impact, among other factors. Therefore, IS project success is relative within a particular scope and context.

Second, stakeholders in the Epos project looked at architecture principles from a technical perspective. The strategic agenda 2018 - 2020 of NZa even described a set of business principles that could have guided the Epos project. If stakeholders do not see this kind of principles as architecture principles, it is difficult to identify all kinds of principles used in a project.

A third finding is related to the more implicit use of the architecture principles. The project organizers had fulfilled several prerequisites at the start of the project and complied with the principles during the implementation of the system. 
Therefore, describing the principles explicitly would have had no extra effect on IS project success.

In MeNZa Classic and MeNZa 2.0, NZa used a different architecture principle than in the Epos project: "configuring" instead of "modelling." The "configuration" principle may have added extra complexity to the MeNZa system, although there was no additional evidence to verify this statement. If this is the case, architecture principles may also can have a negative contribution to IS project success.

\subsection{Indicators of contribution to IS project success}

In this section, we discuss indicators we have seen across the different case studies that may indicate a contribution to IS project success. Thereby, we answer the following question: "Are there indicators of contribution to IS project success by the use of architecture principles, across the different cases?" Before we discuss the five indicators of contribution, we illustrate the process of analysis across the different case studies.

Process of analysis

To answer subsidiary question $3 \mathrm{~b}$ we had to analyze the results across the different use case studies. But, as we have seen in Chapter 1, we had to be aware of the fact that this research subject was context-related, so not all results could be compared with each other straightforward.

In general, the context of the case studies was, to some extent, comparable. The cases were all internal projects within Dutch governmental organizations. The IS projects could be 
categorized as medium-sized, based on budgets and project team size. Besides, all were custom-built, finished IS projects with a duration between 20.5 and 26 months.

Considering the elements of research, we had to be aware that measuring IS project success is relative, because it is depending on the chosen scope and the different perspective on use and user satisfaction between stakeholders (See Section 3.4). The measurement of the use of architecture principles is, to some extent, comparable across the different cases. Independent subject-matter experts determined the values of the characteristics and attributes of the principles.

In finding indicators of contribution, we used qualitative and light scale quantitative data analysis across the case studies. Qualitative data analysis was based on comparable situations across cases and similar type of quotes out of different interviews. Although the case study approach is a qualitative research method, we tried with our measurement method to quantify the research data as much as possible. We used light scale quantitative data analysis searching for trends between principles and characteristics. With calculating averages and percentages, visualized in graphs, we did some cross-case analyses regarding the use of principles and searched for interesting findings.

In Chapter 2 we explained why we chose the case study approach. The case studies, being the first empirical study on architecture principles known to us, are a first step towards a more rigorous and elaborate, and possibly quantitative empirical study into the relationship between architecture principles and project success. As the research domain is still in its infancy, we did not attempt to apply statistical methods to the data, but instead chose to use a more explorative approach.

This was also the reason why we involved the use of a nominal focus-group [45] with experts from practice and 
academia: to judge and discuss the case study results in an explorative manner, and the determine what can be concluded from the results, and what not. The objective of the focus-group method was to obtain insights out of the collected research data helping in answering the research questions. We used a nominal type of session, and so starting with structured brainstorming regarding specific questions, to guarantee equality of participation among members and to collect all possible inputs. We saw the focus-group method as appropriate, because we were investigating an unexplored phenomenon on one hand and using the unique knowledge of case experts on the other [45]. In Appendix $\mathrm{H}$ we added the used procedure of the Focus Group Session.

Based on the outcome of both the data analysis and the focus-group session we formulated five indications of contribution of principles to IS project success as answer on subsidiary research question $3 \mathrm{~b}$.

1. Architecture principles as social constructs

An architecture principle does not have to be described explicitly in a document, as the definition indicates. It can also be an oral agreement made by two or more people. Therefore, an architecture principle can also be seen as a social construct, describing the directive for a design

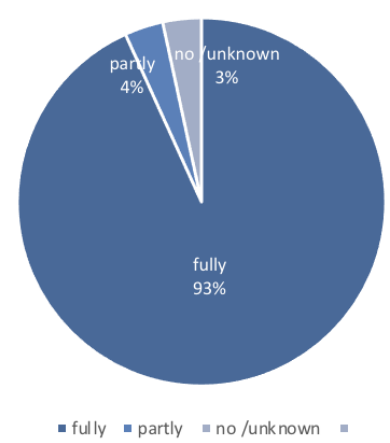

Figure 30: Degree of Acceptance of the 59 architecture principles. 
that a group of people agree.

In all case studies, we found one or more architecture principles that were not described explicitly but that were used in the project as declarative statements guiding the design. In the NEST case, no architecture principles were explicitly defined, and with Epos only some of the principles were partially described. There was a full degree of acceptance of almost all principles in these three cases and many of these principles were complied with (see Figure 30).

Some principles were used implicitly or even unconsciously by some stakeholders, such as "rest points" in NEST and "harmonization" in Octopus. The directives had become obvious because they had been absorbed by the organization. If we assume that every organization has some joint directives, the question is whether those directives guide design and are necessary for implementing the essential requirements. Hence, an architecture principle can appear in social constructs between people making specific arrangements to direct the design.

2. Architecture principles are more than IT principles

In all three case studies, stakeholders-mostly, but not only, businesspeople-saw architecture as an IT topic. They did not see organizational or strategic principles as architecture principles. In the three case studies, the number of architecture principles related to application and technical infrastructure was 1.5 times the number of principles related to IS (35 and 24 respectively, see Figure 31). 
The IS-type of architecture

principle 3 especially can have, by definition, more effect on a project than applicationtype or technical infrastructuretype

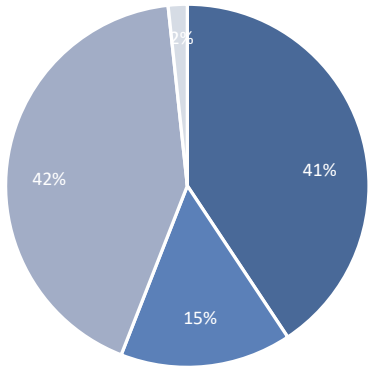

principles. The scope of the first type of principles is much more extensive. In combination with the fact that principles are also social constructs, all kinds of IS-type of principles may be used implicitly, making a possibly large contribution to IS project success.

3. Essential architecture principles

Architecture principles may contribute to IS project success, but do they contribute equally? We analyzed which principles were related the most to the essential requirements for each case study. For those principles, we compared their usage to the average score for usage of all principles in that case (see Table 20).

3 : in jargon people may use the term 'enterprise architecture principles' for information systems-type of architecture principles. 
Table 20: Architecture principles most related to essential requirements.

\begin{tabular}{|c|c|c|c|}
\hline Case & Principle & Req. & $\begin{array}{l}\text { Average } \\
\text { score (\%) }\end{array}$ \\
\hline \multirow[t]{4}{*}{ NEST } & & & 48 \\
\hline & $\begin{array}{l}\text { 3. Configuration of NEST in separate } \\
\text { files and tables }\end{array}$ & $1,3,4,5,11$ & 80 \\
\hline & 4. NEST is divided into rest points & $3,4,5,6,7$ & 51 \\
\hline & 5. Building is modular, using components & $3,5,11,12$ & 80 \\
\hline \multirow[t]{5}{*}{ Octopus } & & & 88 \\
\hline & $\begin{array}{l}\text { 1. The target application must provide } \\
\text { case information and documents to } \\
\text { the Administration of Justice }\end{array}$ & $1,3,4$ & 75 \\
\hline & $\begin{array}{l}\text { 4. The target application connects with } \\
\text { "Aansluitpunt Rechtspraak" }\end{array}$ & 3,7 & 70 \\
\hline & $\begin{array}{l}\text { 8. At least the currently available } \\
\text { application Services are necessary in } \\
\text { the target application }\end{array}$ & $1,2,4$ & 91 \\
\hline & 39. Process harmonization & $1,2,4$ & 74 \\
\hline \multirow{4}{*}{ Epos } & & & 75 \\
\hline & 1. Component-based development & $8,3,5,9,10$ & 88 \\
\hline & $\begin{array}{l}\text { 2. Harmonization of process, forms, and } \\
\text { apps }\end{array}$ & $8,1,2,4$ & 88 \\
\hline & 7. Microservices & $8,3,5,9,10$ & 85 \\
\hline
\end{tabular}

For each case, we were able to identify principles related to the essential requirements. In the NEST and Epos case studies, the usage of those principles was higher than average, and so could have more effect. Noticeably, the principles "divided into rest points" (NEST) and "process harmonization" (Octopus) scored relatively low for usage, yet those two principles were mentioned as important for the IS projects' success by stakeholders. Reasons for this usage score were a combination of the principles not 
being explicitly described and stakeholders lacking a completely clear idea of these principles.

Based on the results, we concluded that focusing on some, essential, architecture principles is more effective than using many principles: quality rather than quantity is important. However, the set of principles used needs to be representative to realize the essential requirements. Therefore, the set of principles needs to cover all relevant requirements of the IS. In addition, as mentioned in Chapter 2, a principle is only effective if it is part of a set. In most situations, we cannot link one particular principle to the contribution made to the realization of the requirements. In summary, it is important to use some architecture principles, in the right combination.

4. Generic principles

Generic principles, architecture principles that reoccur in different case studies, may also indicate some contribution to IS project success. The hypothesis is that a generic principle is more effective because architects re-use the principle repeatedly in different projects.

To test this hypothesis, we inventoried all the principles in our four cases ${ }^{4}$ that were comparable to some extent. We calculated the average usage of those comparable principles, with the idea that effective principles should have a higher usage score than average (see Table 21). We identified nine generic principles used in the case studies, with average scores that did not differ much from the overall average score of the individual principles, which was $70 \%$.

4 : we also used the list of principles of the TDi-case of chapter 2. 
Table 21: Generic, reoccurring architecture principles in different case studies and their use.

$\begin{array}{llc}\text { Principle } & \text { Used in case study } & \begin{array}{c}\text { Average } \\ \text { score (\%) }\end{array} \\ \text { Component-based development } & \text { NEST.5/Epos.1 } & 84 \\ \text { Modular system design } & \text { TDi.10/NEST.5 } & 73 \\ \text { Data: store once, use many times } & \text { TDi.11/Octopus.9, } & 76 \\ & \text { 16/Epos.5 } & \\ \text { Use standards } & \text { TDi.13/Octopus.19, 26 } & 73 \\ \text { Reuse before buy before build } & \text { TDi.14,35/NEST.7/Oct } & 80 \\ & \text { opus.15, 32/Epos.3 } & \\ \text { ADW (Amsterdamse Digitale Werkruimte) } & \text { Octopus.12, 29 } & 100 \\ \text { Business is leading } & \text { Octopus.13/Epos.10 } & 79 \\ \text { KISS (Keep It Simple, Stupid) } & \text { Octopus.27/Epos.9 } & 68 \\ \text { Harmonization } & \text { Octopus.39/Epos.2 } & 81 \\ & & 70 \\ \text { Overall score of the individual principles } & & \\ \text { (total of 95) } & & \end{array}$

The identified generic principles were not excessively addressed in the list of essential principles, as described in Section 4.3. As a result, based on the results of these case studies, generic principles seem not to be an indicator for a positive or negative contribution to IS project success.

5. Previous attempts

In both the NEST and Epos case studies, there were previous attempts to implement a new IS. In the NEST case, CBS tried to implement a statistics system with the principle "implement all statistics in one generic tool." At $\mathrm{NZa}$, they used the architecture principle "configuring" the system in the MeNZa projects, the predecessors of Epos.

In both cases, the project teams learned from previous attempts. With NEST, they switched to a custombuild approach and with Epos they switched to the 
"modelling" principle. Stakeholders in both case studies addressed the link between the use of the principles on one hand and the project's success on the other. Although there is no other evidence, we suggest this as a possible indicator of both negative and positive contributions of architecture principles to IS project success.

\subsection{Limitations, conclusions, and next steps}

\section{Limitations}

First, despite collecting data from various sources, it is difficult to determine whether all relevant data have been found: is it possible to "know the unknown"? This is a typical characteristic of academic research and beyond our capacity to solve.

Second, to determine the contribution of architecture principles, we chose a scope in time and system. Some architecture principles, though, might have the objective of improving the IT operations of the system for the long term, such as implementing effortless maintenance in the Epos system. These kinds of objectives can only be measured over a longer period. Furthermore, especially in the Octopus case, a group of architecture principles was related to the entire information supply of the City Hall of Amsterdam, including the technical infrastructure. While the Octopus system had to comply with these principles, the effect could only be measured in a wider scope and time frame.

In the research approach, we considered using the focus group to validate the answer to the first subsidiary question. The focus group experts highlighted the difficulty of evaluating the large amount of data, when not substantively involved in the 
particular cases. Therefore, we decided to target the second research question. This was successful in challenging facts and providing new insights into the research data collected.

The last limitation is related to the measuring of IS project success. In the NEST and Epos case, there were several attempts to implement the system. If we incorporated the results of those attempts into the IS project success measurement, we would receive another outcome. Therefore, measuring the success of an IS project is relative, and comparing those results between case studies is not straightforward.

\section{Conclusions}

In Figure 32, we plotted the outcome of the three projects with the average scores for both the use of principles and IS project success. One case ended in the 'a possible positive contribution' area, the second one ended just in the 'no or limited contribution' area and the NEST case ended in between. Despite these scores, and knowing the positioning of those areas is indicative, we concluded that in all cases architecture principles contributed to some extent positively to the success of the project. In the research data of all cases, we found enough evidence to draw this conclusion for each of these three cases.

In addition, we determined that not all architecture principles contributed equally to project success. Some principles were more closely related to the essential requirements than others: "the essential principles." These principles were also used more than average.

We even had a first indication of the negative impact of principles. In earlier attempts of NEST and Epos, the projects used other principles that might have made a negative 
contribution to the projects' success. In addition, the opposing principles were important in implementing the essential requirements.

Therefore, the answer to the first subsidiary question, "Does the use of architecture principles make a contribution to IS project success in a specific case?", is a positive one.

As there might be other, more significant, factors that contribute to the success of IS projects, we answered the second question "Are there indicators of contribution to IS project success by the use of architecture principles, across the different cases?"

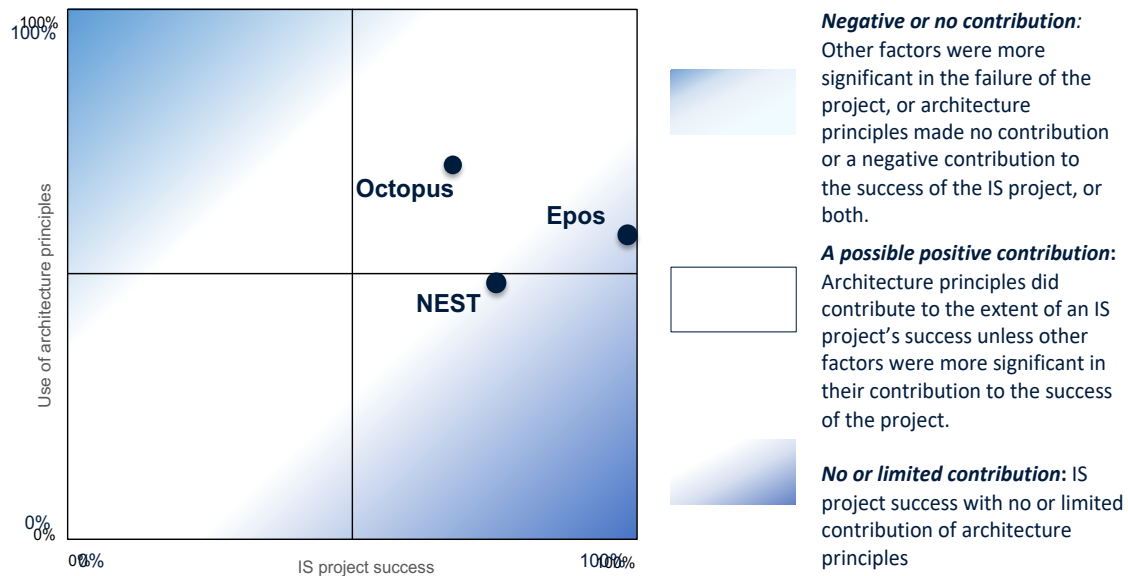

Figure 32: Use of architecture principles and IS project success for the three case studies.

Besides the indicators "previous attempts" and "essential principles," discussed above, we found two indicators of contribution of architecture principles to IS project success. As architecture principles can be seen as the "social constructs" of people who make specific arrangements to direct the design, 
many more principles are used than are normally apparent. Especially when we know that architecture principles are "more than IT," all kinds of IS-type principles may be used implicitly, possibly making a significant contribution to IS project success.

The indicator "case sensitive" addresses the fact that generic principles, architecture principles that reoccur in different case studies, seem not to be an indicator for a positive or negative contribution to IS project success.

Based on the three case studies, we conclude that the use of architecture principles does contribute-in these cases-to some extent positively to IS project success. Obviously, this is by no means a generalization, but only the observation that we could not falsify our theory with the three case studies. There may still be a case among Dutch governmental organizations that will prove otherwise. Therefore, with Popper in mind, for now the theory endures.

\section{Next steps}

In Chapter 1, we noted that investigating the use of architecture principles in practice is in the early phases of research and that the subject of the research is context-related. Therefore, we deliberately chose the case-study approach, with only a limited number of case studies from Dutch governmental organizations. It is hard to generalize the answers to the research questions to other industries, types or sizes of projects, and so on. As a next step, this research enables new opportunities to study this subject with other categories of projects.

We have investigated the contribution of architecture principles in three in-depth case studies, so we are now able to answer the overall research question of this research and 
evaluate our research approach. We also have to incorporate the findings of the case studies into the final version of the measurement instruments, such as adding the "classification" characteristic with the "scope" and "type" attribute to the individual principle, so that it can be used in new case studies. 


\section{LIMITATIONS, CONCLUSIONS, AND FURTHER RESEARCH}

In this chapter, we consider the limitations linked to the research methodology used and answer the main research question. We address opportunities for further research and describe the scientific and social impact.

\subsection{Introduction}

Although we are living in a digitized world, introducing new Information Systems (ISs) seems to be quite difficult. According to industry-based studies, like Standish Group, PMI, and Gartner, IS project failure rates are still high. In Dutch governmental organizations, there was, as an example, in 2020 an overrun of the initial costs with $37 \%$ (1,855 million euros). Therefore, success in implementing requirements in IS projects is not a certainty.

The aim of architecture is to focus on the essential requirements, to ensure that the objectives of an IS will be achieved [9]-[11]. Therefore, what is the relationship between architecture principles on the one hand and IS project success on the other?

Before we started our research, there was no scientifically based, empirical evidence of any contribution of architecture principles to the successful implementation of IS requirements [33]. Therefore, we asked the question "Are architecture principles effective in practice?" In other words, do they make a-hopefully positive-contribution to IS project success?

In Section 5.2, we describe the methodology used, including related limitations. In the next section, we summarize all the conclusions of our research. In Section 5.4 we describe 
opportunities for further research and we end this chapter with the scientific and social impact of this research.

\subsection{Methodology and limitations}

Theory claims that architecture principles contribute positively to IS project success by guiding the design and implementation of IS requirements [1]. With Popper [37] in mind, we challenged this theory through case studies. To falsify this theory, we measured both the use of architecture principles and IS project success for each case study and placed the outcome in a matrix (see Figure 36). Three outcomes were possible, taking into account that other success factors, such as sponsorship and team or architecture controls like models or frameworks [28], may also play a role in IS project success [6]:

1. Negative or no contribution: Other factors were more significant in the failure of the project, or architecture principles made no contribution or a negative contribution to the success of the IS project, or both.

2. A possible positive contribution: Architecture principles did contribute to the extent of an IS project's success unless other factors were more significant in their contribution to the success of the project.

3. No or limited contribution: The IS project was a success with no or limited contribution from architecture principles.

And, because in practice the use of architecture principles or the IS project success will almost never be fully present or totally absent, we measured the individual case studies on a scale of 0 to $100 \%$ and placed the outcomes in a matrix. Although the visualization of the outcome in a matrix helps in 
drawing conclusions, we were aware of the fact that the positioning of the areas is only indicative (See Chapter 1).

In this research, we have chosen the case study as our primary approach, although we also used literature studies to develop the measurement instruments. There are, in general, two reasons for using the case-study approach: empirical research of architecture principles is in an early phase, and the subject of the research is context-related [41]-[43].

By choosing the case-study approach, we had to accept some limitations, as addressed in Section 1.4. Given the fact that we chose to conduct context-related research using case studies, we were able to conduct only three case studies. Falsifying the theory with only three case studies is only a beginning. We eliminated the limitation to be biased as much as possible, by developing a measurement method with different kind of research protocols.

Another limitation of this research method is the scope of the case studies. Each case study forced us to choose a scope, both of time and system. A different scope might lead to different outcomes. We therefore need to be aware that measuring is relative and comparing the results between case studies is not straightforward.

In general, a typical characteristic of academic research is the fact that research takes place from a specific point of view. Therefore, it is difficult to determine whether all relevant data have been found. Especially when there are no other empirical research results to compare with. This is obviously beyond our capacity to solve, but we invite other researchers to challenge our results. 


\subsection{Conclusions}

To investigate the effectiveness of the use of architecture principles, we asked ourselves the question "do architecture principles contribute to IS project success?" To answer this overarching question, we disentangled it into three research questions (see Figure 33).

Measuring the principles

To determine to what extent architecture principles contribute to IS project success, we had to look for a way to measure them in practice. Therefore, our first research question was "how may architecture principles be defined, described and measured in practice?"

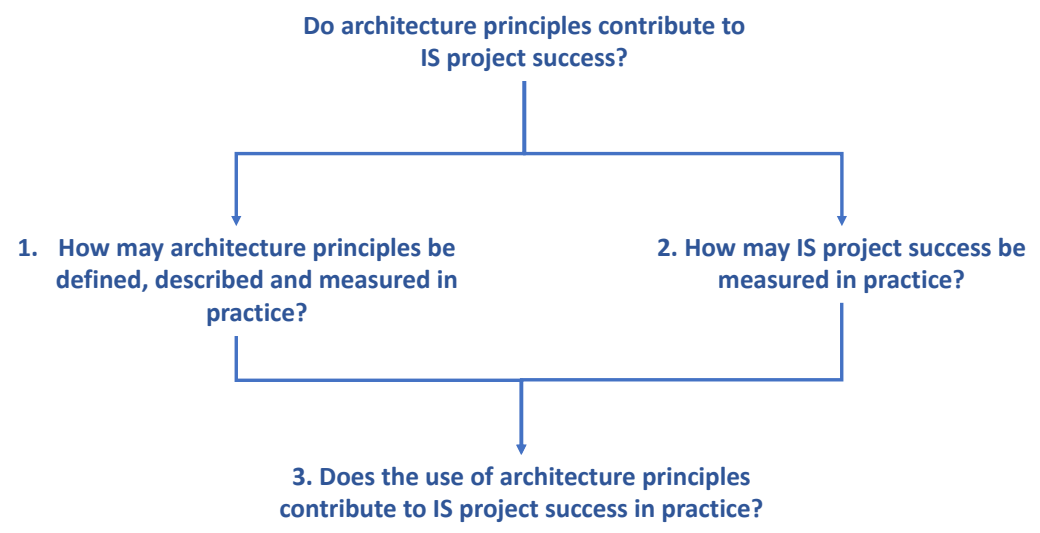

Figure 33: Structure of research questions.

In the literature, we found 16 different definitions of architecture principles. Using the $\mathrm{WH}$-questions we decomposed and analyzed the definitions (see Table 4, Section 2.4). With this 
analysis, we concluded that there is consensus in the literature about the definition of an architecture principle, although some definitions were incomplete or excessive, without capturing the essence. Based on this analysis, we strengthened the definition:

"An architecture principle is a declarative statement based on, at least, business and IT strategy. It normatively describes a property of the design of an information system that is necessary to ensure that the information system meets its essential requirements."

It is known that a principle is only effective if it is part of a set [20], [38], [63], [74], [80]. Therefore, analyzing the contributions of individual architecture principles without looking at the set of principles is unproductive. Therefore, we defined the architecture principle set as

"a group of architecture principles defined and presented as a collection based on a similar type or scope of architecture principles."

We first described both architecture principles and sets using a framework, including their relationships with the entities in their environment. We also used characteristics and attributes to describe the architecture principle and set in more detail (see Figure 34 and Appendix B). Second, we defined a three-step method to collect, analyze, and measure architecture principles qualitatively and quantitatively. Initially, we tested the measurement instrument in a real-life situation and strengthened the description of both architecture principles and sets with three other case studies. 


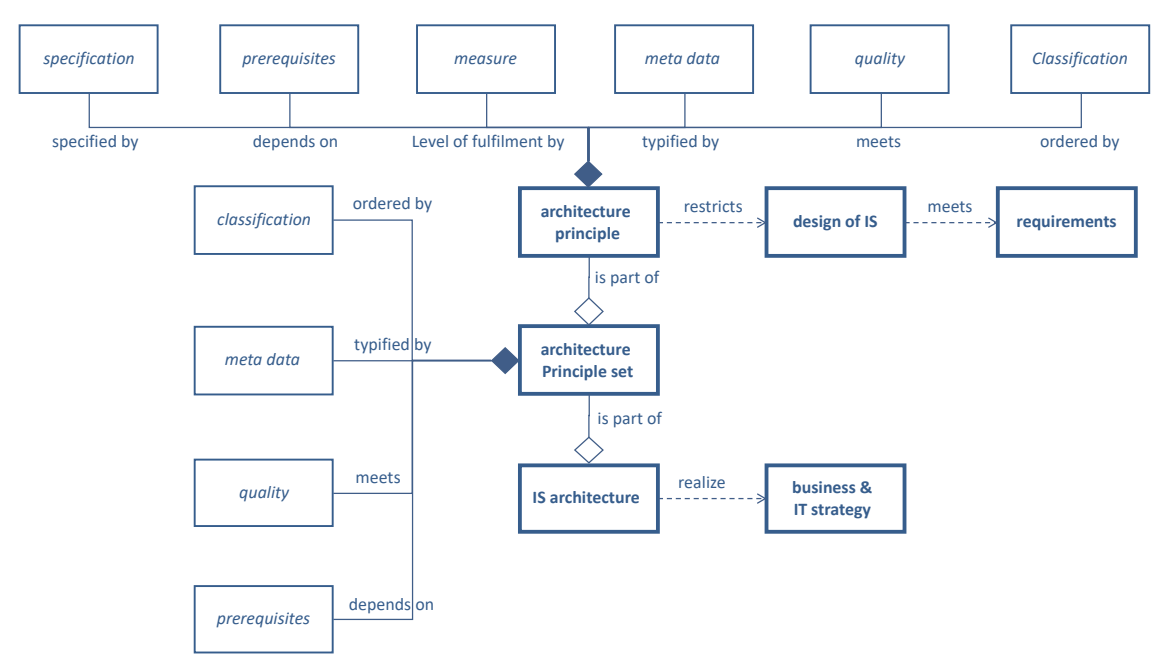

Figure 34: Framework for describing the architecture principle and architecture principle set.

Measuring IS project success

The second step in our research was to answer the question "how may IS project success be measured in practice?" To measure IS project success, we defined IS project success as a combination of Project Management Success (PMS) and Project Product Success (PPS). PMS focuses on the process of the project, while PPS relates to the outcome of the project. This is becoming a common line, given recent literature.

We described both PMS and PPS using three characteristics each. Each characteristic is described completely and coherently with a set of attributes (see Figure 35). We used this framework as the measurement model. We reused the three-step method used to measure the architecture principles to measure IS project success qualitatively and 
quantitatively. We used the measurement instrument for three case studies.

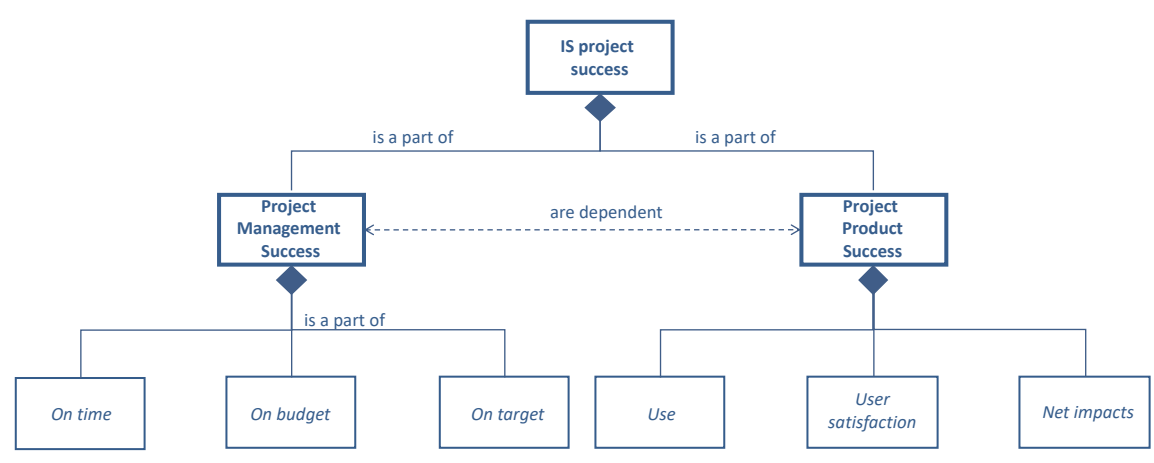

Figure 35: Description of IS project success (adaption of the Van der Westhuizen en Fitzgerald-model [87]).

Do architecture principles contribute to IS project success?

Having measurement instruments for both the use of architecture principles and IS project success, we were able to research the contribution of architecture principles in practice.

We investigated three case studies, and we plotted the outcome of those measurements into a matrix (see Figure 36). One case ended in the 'a possible positive contribution' area and another one ended just in the 'no or limited contribution' area. The NEST case ended in between. With that, we were aware of the fact that the positioning of the areas is only indicative, because a non-linear correlation would probably shift the areas into a different position.

The use of architecture principles scored lower in the Epos and NEST case, because the architecture principles were used more implicitly. In the detailed analysis of all research data we found relationships between architecture principles on the one 
hand and implemented essential requirements on the other. Those implemented essential requirements were important in the IS project success of the specific cases. So, in all three individual cases we concluded that architecture principles contributed positively to the IS project success, although we could not determine to what extent the contribution might have been.
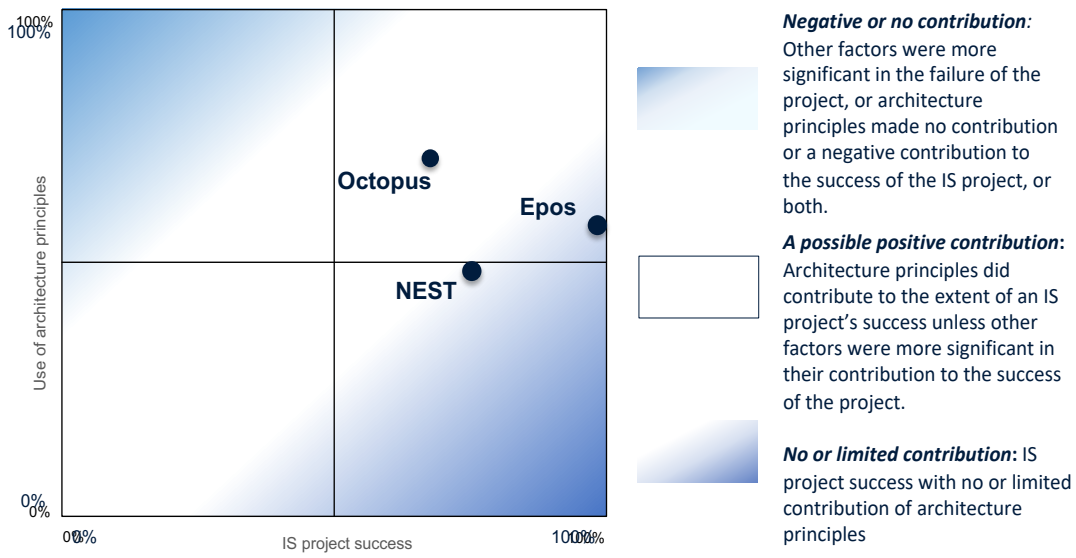

Figure 36: Use of architecture principles and IS project success for the three case studies.

Although we argued that, in these three individual cases, architecture principles contributed to some extent positively to IS project success, we searched for other indicators of contribution as well. Looking across the different case studies we found three indicators that may indicate a contribution to IS project success.

First, we found in each case some "essential architecture principles" that were related to more of the essential requirements and for which the usage was above average. Most of those essential requirements were implemented, and if not, 
other reasons than the non-compliance with the architecture principles could be identified for being not implemented.

Second, architecture principles can be seen as "social constructs" of people who make specific arrangements to direct the design. Therefore, many more principles might be used in projects than is immediately apparent. This is particularly true because we know that architecture principles are much more than merely an IT topic. So, architecture principles might have more impact than we are aware of.

Last, we also have a first indication of the negative impact of principles, due to the use of opposing principles in former non-successful projects. Because we did not investigate previous attempts in detail, it is just a first indication.

Besides the indicators of contribution across the three case studies, we also have seen indications of added value of enterprise architecture regarding IS project success in Chapter 1. Slot, Kurek and Chaos [6], [34], [36] are reporting findings regarding a positive effect of enterprise of specific criteria of IS project success. And, because architecture principles are also 'social constructs', there might be a link to the 'people issue' as most important success factor as addressed in Chaos [6].

To our knowledge, the results of this thesis describe the very first empirical study into the relationship between architecture principles and IS project success. We conducted an in-depth study in three real-life projects in the Dutch government. To be able to do this, we developed measurement instruments, and we conducted an elaborate literature review. Despite all the caveats we have to take into account (see 5.2), we conclude, based on the results of the case studies, that there are indications that architecture principles do contribute positively to the IS project success in Dutch governmental organizations. 


\subsection{Further research}

Here we discuss four research opportunities that are adjacent to the central theme of measuring the contribution of architecture principles to IS project success.

\section{Enlarge the sample size of the measurements}

It would be interesting to enlarge the number of test samples by conducting more case studies. Uludağ and Proper also suggest conducting more research on the use of architecture principles [67]. If there are cases with $100 \%$ IS project success and almost no use of architecture principles, we can refute-or at least rephrase-the theory: there is no reason to use architecture principles. Therefore, when looking for more case studies, it would be best to search for that kind of project. However, as we have seen in Section 5.3, architecture principles are social constructs, which are not always completely visible to stakeholders. Sometimes it may seem that no architecture principles have been used, while unconsciously they might have had a high impact.

In addition, in conducting more case studies it would also be interesting to search for other project categories. In this research, we focused on Dutch governmental organizations with medium-sized, custom-built, and finished IS projects. What is the impact of architecture principles in small or large projects, in other cultures, or in "off-the-shelf" implementations? In any event, conducting more case studies will also help to improve the measurement models and discover possible correlations between characteristics. In conducting more case studies, the use of automated data collection or the use of artificial intelligence might help to collect data in a context-related research setting. 


\section{Use of architecture principles}

First, in this research, we looked at the use of architecture principles using a black-box approach, only studying the effect after the launch of the IS. Further research could focus on the use of principles during the project's life cycle. For example, to investigate the link between architecture principles and the design [66] or to look for possible correlations between the use of different architecture controls. It would also be interesting to know when to start applying architecture principles in a project and to determine how long the effect of the architecture principles is sustained after the IS was implemented.

Second, it would also be interesting to investigate the possible impact of using the wrong architecture principles. As human beings, we are mostly focused on doing the right things, while we know that we sometimes make the wrong decisions. At the start of a project, we might choose the wrong set of principles. Does using the wrong architecture principles have a negative effect on the IS project success?

Third, because architecture principles are social constructs, research from a sociological perspective will also have added value. What have scientific studies revealed about the use of principles in society, for example, the use of principles for a sustainable society [124], and how can this be translated into using architecture principles?

Interdependencies between project management success and project product success

Besides research on architecture principle, it might also be interesting to conduct research into IS project success. As we have defined IS project success be the combination of PMS and 
PPS, what are the interdependencies between these dimensions? One dimension might be more important than the other, characteristics of both dimensions might influence each other, and success factors might positively influence some dimensions more than others. So, which characteristics are most important for determining IS project success? This presents some interesting research opportunities to consider.

\section{Research field of IT}

Without empirical evidence, we would like in closing to reflect on the research field of IT. First, we experienced the process of quantifying qualitative data into quantitative data. By quantifying the data, we were able to sharpen the subjects of research and have a better discussion regarding the use of architecture principles. Furthermore, with quantified data it is easier to visualize trends over time, such as Moore's law [125].

We would like to end this research with an appeal to make the research data Findable, Accessible, Interoperable and Reusable (FAIR) [126]. The FAIR data principles enable the reuse of research data by both individuals and machines. It is one of the steps toward open science, including in the IT research field.

\subsection{Scientific and social impact}

The aim of this research was to investigate the effectiveness of architecture principles. As described in section 5.3, we concluded that there are indications that architecture principles do contribute positively to the IS project success in Dutch 
governmental organizations. This outcome is expected to have both scientific and social impact.

The outcome of this research should direct the scientific research of enterprise architecture to the use of architecture principles. In which way can the use of architecture principles contribute to more successful IS projects, knowing that architecture principles are also a 'social construct' and some essential architecture principles might make a difference? Scientific research regarding Enterprise Architecture should be more than a "mathematical exercise".

Second, the fact that architecture principles are much more than merely an IT topic, implicates that the field of enterprise architecture covers more research fields than IT only. In that sense, you could even argue that there is no distinct separation of "IT" on the one hand and "Business" on the other. This implication will have both high scientific and social impact.

In 2020 there were 82 large IS projects running in the central Dutch governmental organizations, with a total budget of 2,547 million euro [127]. With an overrun of $37 \%$ in budget in 2020 , a delay in time of $37 \%$ in 2018 , improving the IS project success is necessary. The use of architecture principles might contribute to the current IS project success within the Dutch governmental organizations.

All kinds of stakeholders, like business owners, $\mathrm{ClO}$, project managers and architects, should be aware of the possible added value of architecture principles. These stakeholders have a key responsibility in implementing IS projects successfully. As addressed in section 5.4, the measurement instruments are useful in managing IS projects. Valorization of these research results should take place informally via social media, associations and other social networks. More formal adoption of the research results should 
take place via official entities within the Dutch government, such as 'ClO Rijk', BIT and 'Manifestgroep'. 


\section{REFERENCES}

[1] M. A. C. Borgers, "Do IT architecture principles contribute to IT system's requirements realisation ?," in DCEIS 2016 - Doctoral Consortium on Enterprise Information Systems, 2016, p. pages 3-8.

[2] F. Buytendijk, "Introducing digital connectivism: A new philosophy for the digital society," Gartner, Inc, no. May 10, pp. 1-17, 2018.

[3] F. Buytendijk, C. Howard, and L. Mcmullen, "Gartner Report: Last Call for \#DigitalSociety ... Departing Now!," 2019.

[4] G. Westerman, D. Bonnet, and A. McAffer, Leading Digital Turning Technology into Business Transformation. Harvard Business Press, 2014.

[5] R. van Est, E. de Bakker, J. van den Broek, J. Deuten, and P. Diederen, "Waardevol digitaliseren - Hoe lokale bestuurders vanuit publiek perspectief mee kunnen doen aan het 'technologiespel,"' Den Haag, 2018.

[6] The Standish Group, CHAOS 2020: Beyond Infinity. The Standish Group International, Inc., 2020.

[7] E. Stegman, J. K. Guevara, and L. Hall, "Gartner report: IT Key Metrics Data 2010 : Key Applications Measures: Project Measures," 2010.

[8] J. L. Eveleens and C. Verhoef, "The Rise and Fall of the Chaos Report Figures," IEEE Softw., vol. 27, no. 1, pp. 30-36, 2010.

[9] P. Kakebeeke and S. Olsthoorn, "Grote ICT-projecten overheid zeker $€ 1$ mrd duurder," Het Financieele Dagblad, p. 1, 02-Jul-2018.

[10] T. Elias, "Conclusions and recommendations of the Dutch temporary committee on government ICT projects." 2014.

[11] N. Groen, The never-ending project : understanding e-government project escalation. Mosae verbo, Maastricht, 2015.

[12] K. El Emam and G. A. Koru, "A replicated survey of IT software project failures," IEEE Softw., vol. 25, no. 5, pp. 84-90, 2008.

[13] J. Johnson and H. Mulder, "CHAOS Chronicles, focusing on failures and possible improvements in IT projects," 10th Int. Multi-

Conference Soc. Cybern. Informatics IMSCI 2016, no. July, 2016.

[14] B. Flyvbjerg and A. Budzier, "New research shows surprisingly high numbers of out-of-control tech projects-ones that can sink entire companies and careers," Harv. Bus. Rev., vol. 89, no. 9, pp. 23-25, 2011.

[15] D. L. Hughes, N. P. Rana, and A. C. Simintiras, "The changing landscape of IS project failure: an examination of the key factors," $J$. 
Enterp. Inf. Manag., vol. 30, no. 1, pp. 142-165, 2017.

[16] Y. K. Dwivedi et al., "Research on information systems failures and successes: Status update and future directions," Inf. Syst. Front., vol. 17, no. 1, pp. 143-157, 2015.

[17] N. P. Hughes, D.I., Dwivedi, Y.K., Simintiras, A.C. and Rana, Success and Failure of IS/IT Projects. Springer, London., 2015.

[18] B. O'Hara, Margaret; Watson, Richard; Cavan, "Managing the three levels of change," Inf. Syst. Manag., vol. 16, no. 3, pp. 63-70, 1999.

[19] M. Looijen, Information Systems - Management, Control and Maintance. Kluwer BedrijfsInformatie, 1998.

[20] D. Greefhorst and E. Proper, Architecture Principles - The Cornerstones of Enterprise Architecture. Springer Berlin Heidelberg, 2011.

[21] IEEE, "IEEE Standard Glossary of Software Engineering Terminology," pp. 1-84, Dec. 1990.

[22] R. Winter, P. Rohner, and C. Kiselev, "Mission Impossible? Exploring the Limits of Managing Large IT Projects and Ways to Cross the Line," Proc. 52nd Hawaii Int. Conf. Syst. Sci., 2019.

[23] PMI, "Success Rates Rise: Transforming the high cost of low performance," Pulse Prof. - 9th Glob. Proj. Manag. Surv., pp. 1-32, 2017.

[24] The Open Group, TOGAF® Version 9.1. Van Haren Publishing, 2011.

[25] Department of Defense, "Department of Defense Chief Information Officer Desk Reference," Chief Inf. Off. Desk Ref., vol. I, no. August, 2006.

[26] J.L.G. Dietz, Architecture - Builiging stategy into design. 2008.

[27] J. L. G. Dietz, Architecture - Building strategy into design. Academic Service, 2008.

[28] M. Op 't Land, H.A. Proper, M. Waage, J. Cloo, and C. Steghuis, Enterprise architecture: creating value by informed governance. Springer Berlin Heidelberg, 2009.

[29] M. K. Haki and C. Legner, "Enterprise Architecture Principles in Research and Practice: Insights from an Exploratory Analysis," Ecis, no. 2013, pp. 1-12, 2013.

[30] R. Winter and S. Aier, "How are enterprise architecture design principles used?," Proc. - IEEE Int. Enterp. Distrib. Object Comput. Work. EDOC, no. September 2016, pp. 314-321, 2011.

[31] D. Greefhorst, E. Proper, and G. Plataniotis, "The Dutch State of the Practice of Architecture Principles," J. Enterp. Archit., p. 6, 2013. 
[32] M. Borgers and F. Harmsen, "Strengthen the architecture principle definition and its characteristics: A survey encompassing 27 years of architecture principle literature," in ICEIS 2018 - Proceedings of the 20th International Conference on Enterprise Information Systems, 2018, vol. 2.

[33] M. Borgers and F. Harmsen, "Case Report of Identifying and Measuring IT Architecture Principles in the Dutch Tax Agency," 2016 IEEE 18th Conf. Bus. Informatics, no. November, pp. 100110, 2016.

[34] R. Slot, "A method for valuing Architecture-Based Business Transformation and Measuring the value of Solutions Architecture," PhD thesis, University Utrecht. 2010.

[35] M. van den Berg, Improving IT decisions with enterprise architecture. Amsterdam: ProefschriftMaken, Phd thesis, University of Amsterdam. 2019.

[36] E. Kurek, J. Johnson, and H. Mulder, "Measuring the value of enterprise architecture on IT projects with CHAOS research," WMSCI 2017 - 21st World Multi-Conference Syst. Cybern. Informatics, Proc., vol. 1, no. April, pp. 30-35, 2017.

[37] K. Popper, The Logic of Scientific Discovery. New York: Basic Books, 1959.

[38] D. Stelzer, "Enterprise architecture principles: literature review and research directions," Proc. 2009 Int. Conf. Serv. Comput., pp. 1221, 2009.

[39] H. A. Proper and D. Greefhorst, "The Role of Principles in Enterprise Architecture," Proc. 5th Work. Trends Enterp. Archit. Res. TEAR 2010, Delft, Netherlands, vol. 70, pp. 57-70, 2010.

[40] C. Fischer, R. Winter, and S. Aier, "What Is an Enterprise Architecture Principle?," Comput. Inf. Sci. 2010, no. leee 2000, pp. 193-205, 2010.

[41] J. Steenhuis and E. De Bruijn, "Building theories from case study research: the progressive case study," J. Chem. Inf. Model., vol. 53, no. 9, pp. 1689-1699, 2004.

[42] K. M. Eisenhardt, "Building Theories from Case Study Research.," Acad. Manag. Rev., vol. 14, no. 4, pp. 532-550, 1989.

[43] R. Yin, Case Study Research: Design and Methods. Beverly Hills: Sage Publications, 1984.

[44] E. Babbie, The Practice of Social Research. Cengage Learning, Inc, 2015.

[45] S. G. Sutton and V. Arnold, "Focus group methods: Using 
interactive and nominal groups to explore emerging technologydriven phenomena in accounting and information systems," Int. J. Account. Inf. Syst., vol. 14, no. 2, pp. 81-88, 2013.

[46] M. Borgers and F. Harmsen, "Managing architecture principles and their sets in practice," in CEIS 2019 - Proceedings of the 21th International Conference on Enterprise Information Systems, 2019.

[47] M. Borgers and F. Harmsen, An Architecture Principle Measurement Instrument Tested in Real-Life, vol. 378 LNBIP. Springer International Publishing, 2020.

[48] M. K. Haki and C. Legner, "New avenues for theoretical contributions in enterprise architecture principles - A literature review," Lect. Notes Bus. Inf. Process., vol. 131 LNBIP, pp. 182 197, 2012.

[49] "Oxford Dictionaries - Dictionary, Thesaurus, \& Grammar." [Online] Available: http://www.oxforddictionaries.com/. [Accessed: 21-Dec2015].

[50] J. Webster and R. T. Watson, "Analyzing the Past to Prepare for the Future: Writing a Literature Review.," MIS Q., vol. 26, no. 2, pp. xiiixxiii, 2002.

[51] W. Chrisholm, L. T. Milic, and J. A. C. Greppin, Interrogativity. John Benjamins Publishing, 1982.

[52] S. Aier, C. Fisher, and R. Winter, "Construction and Evaluation of a Meta-Model for Enterprise Architecture Design Principles," 10th Int. Conf. Wirtschaftsinformatik, 16th-18th Febr. 2011, Zurich, Switz., pp. 637-644, 2011.

[53] M. Eisenhardt, "Building Theories from Case Research," Acad. Manag. Rev., vol. 14, no. 4, pp. 532-550, 1989.

[54] R. K. Yin, "The case study crisis: Some answers," Adm. Sci. Q., vol. 26, no. 1, pp. 58-65, 1981.

[55] A. L. Strauss, Qualitative analysis for social scientist. Cambridge: Cambridge University Press, 1987.

[56] M. Miles and A. M. Huberman, "Drawing valid meaning from qualitative data: Toward a shared craft," Educ. Res., vol. 13, no. 5, 1984.

[57] C. Gersick, "Time And Transition in Work Teams: Towards a New Model Of Group Development.," Acedamy Manag. J., vol. 31, pp. 941, 1988.

[58] S. G. Harris and R. I. Sutton, "Functions of parting ceremonies in dying organizations.," Acad. Manag. J., vol. 29, no. 1, pp. 5-30, Mar. 1986. 
[59] K. Eisenhardt and L. J. Bourgeois, "Politics of strategic decision making in high velocity environments: Toward a mid-range theory," Acad. Manag. J., vol. 31, pp. 737-770, 1988.

[60] D. Marosin, S. Ghanavati, and D. Van Der Linden, "A principlebased goal-oriented requirements language (GRL) for Enterprise Architecture," CEUR Workshop Proc., vol. 1157, 2014.

[61] J. Hoogervorst, "Enterprise architecture: Enabling integration, agility and change," Int. J. Coop. Inf. Syst., vol. 13, no. 03, pp. 213-233, 2004.

[62] M. Esmaeil Zadeh, G. Millar, and E. Lewis, "Mapping the Enterprise Architecture principles in TOGAF to the cybernetic concepts - An exploratory study," Proc. Annu. Hawaii Int. Conf. Syst. Sci., pp. 4270-4276, 2011.

[63] A. Lindström, "On the Syntax and Semantics of Architectural Principles," in Proceedings of the 39th Hawaii International Conference on System Sciences, 2006, vol. 00, no. C, pp. 1-10.

[64] M. O. Land and H. Proper, "Impact of Principles on Enterprise Engineering," Ecis, no. 2007, pp. 1965-1976, 2007.

[65] P. van Bommel, P. M. Buitenhuis, S. J. B. A. Proper, and E. H. A. Hoppenbrouwers, "Architecture principles - A regulative perspective on enterprise architecture," Enterp. Model. Inf. Syst. Archit. concepts Appl. ; Proc. 2nd Int. Work. Enterp. Model. Inf. Syst. Archit. St. Goar, Ger. Oct. 8 - 9, no. June 2014, pp. 47-60, 2007.

[66] D. Marosin and S. Ghanavati, "A semi-formal evaluation of architecture design based on architecture principles," CEUR Workshop Proc., vol. 1829, pp. 25-30, 2017.

[67] Ö. Uludağ, H. A. Proper, and F. Matthes, "Investigating the establishment of architecture principles for supporting large-scale agile transformations," Proc. - 2019 IEEE 23rd Int. Enterp. Distrib. Object Comput. Conf. EDOC 2019, no. October, pp. 41-50, 2019.

[68] M. Paauwe, "Understanding Architecture Principles as Working Mechanisms," in Advances in Enterprise Engineering XII 8th Enterprise Engineering Working Conference, EEWC 2018, 2019, pp. 55-65.

[69] M. Paauwe, "Understanding architecture principles as working mechanisms," Lect. Notes Bus. Inf. Process., vol. 334, pp. 55-65, 2019.

[70] K. Haki and C. Legner, "The Mechanics of Enterprise Architecture Principles," J. Assoc. Inf. Syst., no. October, 2020.

[71] G. L. Richardson, B. M. Jackson, and G. W. Dickson, "A Principles- 
Based Enterprise Architecture: Lessons from Texaco and Star Enterprise," MIS Q., vol. 14 (4), pp. 385-403, 1990.

[72] F. J. Armour, S. H. Kaisler, and S. Y. Liu, "A Big-Picture Look at Enterprise Architecture," IEEE IT Prof., pp. 35-42, 1999.

[73] D. Chen and F. Lillehagen, "Enterprise Architectures - Review on Concepts, Principles and Approaches," in Proceedings of the 10th International Conference on Concurrent Engineering, 2004, pp. 1211-1216.

[74] D. Marosin, M. van Zee, and S. Ghanavati, "Formalizing and modeling enterprise architecture (EA) principles with goal-oriented requirements language (GRL)," Lect. Notes Comput. Sci. (including Subser. Lect. Notes Artif. Intell. Lect. Notes Bioinformatics), vol. 9694, pp. 205-220, 2016.

[75] K. Sandkuhl, D. Simon, M. Wißotzki, and C. Starke, "The nature and a process for development of enterprise architecture principles," Lect. Notes Bus. Inf. Process., vol. 208, no. c, pp. 260 272, 2015.

[76] T. Lumor, E. Chew, and A. Q. Gill, "Exploring the Role of Enterprise Architecture in IS-enabled OT: An EA Principles Perspective," in Enterprise Distributed Object Computing Workshop, 2016.

[77] J. Hoogervorst, "Enterprise governance and enterprise engineering," Enterp. Eng. Ser., no. 2017 \& 2018, p. 428, 2018.

[78] P. van Bommel, S. Hoppenbrouwers, E. Proper, and T. P. van Der Weide, "Giving Meaning to Enterprise Architectures," 2006.

[79] J. L. G. Dietz and J. B. F. Mulder, Enterprise Ontology - A HumanCentric Approach to Understanding the Essence of Organisation. Springer, 2020.

[80] D. Marosin and S. Ghanavati, "Measuring and managing the design restriction of enterprise architecture (EA) principles on EA models," 8th Int. Work. Requir. Eng. Law, RELAW 2015 - Proc., pp. 37-46, 2015.

[81] J. A. Zachman, "A Framework for Information Systems Architecture," IBM Syst. J. 26, No., vol. 3, no. 3, pp. 276-292, 1987.

[82] J. van't Wout, M. Waage, H. Hartman, M. Stahlecker, and A. Hofman, The Integrated Architecture Framework Explained - Why, What, Springer. Springer Berlin Heidelberg, 2010.

[83] S. Buckl, F. Matthes, and S. Roth, "A Conceptual Framework for Enterprise Architecture Design,” Trends Enterp. Archit. Res., pp. 44-56, 2010.

[84] D. Baccarni, "The logical framework method for defining project 
success," Proj. Manag. J., vol. 30, no. 4, pp. 25-32, 1999.

[85] de Wit, "Measurement of project success," Int. J. Proj. Manag., vol. 6, no. 3, pp. 164-170, 1988.

[86] A. A. Shojaie, M. Shadalooie, K. Khalili-Damghani, and M. R. Pakzad, "Development of a conceptual model of project management information systems for investigating its effective factors impacting the success of project using structural equation model," Int. J. Life Sci. Pharma Res., vol. Special is, no. 1, pp. 1729, 2016.

[87] D. van der Westhuizen and E. P. Fitzgerald, "Defining and measuring project success," in European Conference on IS Management, Leadership and Governance, 2005, pp. 157-163.

[88] G. Thomas and W. Fernández, "Success in IT projects: A matter of definition?," Int. J. Proj. Manag., vol. 26, no. 7, pp. 733-742, 2008.

[89] C. U. Press, "Cambridge English Dictionary," 2020. [Online]. Available: https://dictionary.cambridge.org.

[90] J. K. Pinto and D. P. Slevin, "Critical success factors across the project life cycle," Proj. Manag. J., pp. 67-75, 1988.

[91] U. A. Altahtooh and M. W. Emsley, "IT Projects : Classifying Risk Factors and Identifying Project Outcomes," J. Ind. Intell. Inf., vol. 3, no. 3, pp. 246-252, 2015.

[92] C. P. Prabhakar, "What is Project Success : A Literature Review," Int. J. Bus. Manag. Bus. Manag., vol. 3, no. 9, pp. 3-10, 2008.

[93] G. P. Sudhakar, "Understanding the meaning of 'project success,"” Binus Bus. Rev., vol. 7, no. August, pp. 163-169, 2016.

[94] W. J. Pinkerton, Project Management: Achieving Project Bottomline Succes. McGraw-Hill, New York, 2003.

[95] P. Rook, "Controlling software development projects," Softw. Eng. J., vol. 1, no. 1, pp. 7-16, 1986.

[96] L. Weitz, "How to implement projects properly," Softw. Mag., vol. 9, no. 13 , pp. 60-69, 1989.

[97] A. Taylor, "Software Project Management: Setting the Context.," Comp Bull. Brit Comp Soc., 2000.

[98] H. H. Bodicha, "How to Measure the Effect of Project Risk Management Process on the Success of Construction Projects: A Critical Literature Review.," Int. J. Bus. Manag., vol. 3, no. 12, pp. 99-112, 2015.

[99] de Bakker, Boonstra, and Wortmann, "Does risk management contribute to IT project success?," Int. Juornal Proj. Manag., pp. 123, 2010. 
[100] W.H. DeLone and E.R. McLean, Information Systems Success Measurement. now Publishing Inc., 2016.

[101] W.H. DeLone and E.R. McLean, "The DeLone and McLean model of information systems success: A ten-year updated," J. Manag. Inf. Syst., vol. 19, no. 4, pp. 9-30, 2003.

[102] P. A. Ramos and C. M. Mota, "Exploratory Study Regarding How Cultural Perspectives Can Influence the Perception of Project Success in Brazilian Companies.," vol. 26, no. 1, pp. 105-114, 2016.

[103] M. J. Cuellar, E. R. McLean, and R. D. Johnson, "The measurement of information system use," no. May 2014, p. 164, 2006.

[104] R. Agarwal and J. Prasad, "The role of innovation characteristics and percieved volunatariness in the acceptance of information technology," Decis. Sci., vol. 28, pp. 557-580, 1997.

[105] B. Ives, M. H. Olson, and J. J. Baroudi, "The measurement of user information satisfaction," Commun. ACM, vol. 26, no. 10, pp. 785793, 1983.

[106] R. Vaezi, A. Mills, W. Chin, and H. Zafar, "User satisfaction research in information systems: Historical roots and approaches," Commun. Assoc. Inf. Syst., vol. 38, no. 1, pp. 501-532, 2016.

[107] C. Parisi and P. Rossi, "Strategic Performance Mesurement of Research and Development: A Case Study," Int. J. Bus. Manag., vol. 3, no. 12, pp. 322-330, 2015.

[108] M. Scott, W. DeLone, and W. Golden, "IT Quality and Egovernment Net Benefits: A Citizen Perspective," Eur. Conf. Inf. Syst. 2011 Proc., pp. 1117-1128, 2011.

[109] K. T. Yeo, "Critical failure factors in information system projects," Int. J. Proj. Manag., vol. 20, no. 3, pp. 241-246, 2002.

[110] C. Sauer, A. Gemio, and B. Horner Reich, "The Impact of Size and Volatility on IT project Performance," Commun. ACM, vol. 50, no. 11, pp. 79-84, 2007.

[111] H. William, "The DeLone and McLean Model of Information Systems Success : A Ten-Year Update," vol. 19, pp. 9-30, 2003.

[112] J. Johnson, Creating CHAOS: A Syllabus. The Standish Group International, Inc., 2017.

[113] IEEE, Standard Glossary of Software Engineer- ing Terminology. IEEE Standard 610.12-1990. 1990.

[114] J. Cleland-Huang, "Quality requirements and their role in successful products," Proc. - 15th IEEE Int. Requir. Eng. Conf. RE 2007, p. 361, 2007. 
[115] D. Straub, M. Limayem, and E. Karahanna-Evaristo, "Measuring System Usage: Implications for IS Theory Testing," Manage. Sci., vol. 41, no. 8, pp. 1328-1342, 1995.

[116] W. J. Doll and G. Torkzadeh, "Developing a multidimensional measure of system-use in an organizational context," vol. 33, 1998.

[117] S. A. Brown, V. Venkatesh, and S. Goyal, "Expectation Confirmation in Information Systems Research: A Test of Six Competing Models," MIS Q. Manag. Inf. Syst., vol. 38, no. 3, pp. 729-756, 2014.

[118] W. J. Doll, X. Deng, T. S. Raghunathan, G. Torkzadeh, and W. Xia, "The meaning and measurement of user satisfaction: A multigroup invariance analysis of the end-user computing satisfaction instrument," J. Manag. Inf. Syst., vol. 21, no. 1, pp. 227-262, 2004.

[119] R. Vaezi, "User Satisfaction with Information Systems: A Complete Model of User Satisfaction," University of Houston, 2013.

[120] M. Martinsons, R. Davison, and D. Tse, "The balanced scorecard: A foundation for the strategic management of information systems," Decis. Support Syst., vol. 25, no. 1, pp. 71-88, 1999.

[121] R. Mirani and A. L. Lederer, "An instrument for assessing the organizational benefits of IS projects," Decis. Sci., vol. 29, no. 4, pp. 803-838, 1998.

[122] M. Scott, W. Delone, and W. Golden, "Measuring eGovernment success: A public value approach," Eur. J. Inf. Syst., vol. 25, no. 3, pp. 187-208, 2016.

[123] Wikipedia, "Situation, task, action, result," 2020. [Online]. Available: https://en.wikipedia.org/wiki/Situation,_task,_action,_result.

[124] T. C. Lindsey, "Sustainable principles: Common values for achieving sustainability," Journal of Cleaner Production, vol. 19, no. 5. pp. 561-565, 2011.

[125] G. Moore, "Moore's Law, Electronics," Electronics, vol. 38, no. 8, p. 114, 1965.

[126] M. D. Wilkinson et al., "Comment: The FAIR Guiding Principles for scientific data management and stewardship," Sci. Data, vol. 3, pp. 1-9, 2016.

[127] Dutch-government, "Rijks ICT-Dashboard," 2020. [Online]. Available: https://www.rijksictdashboard.nl. [Accessed: 31-Oct2020].

[128] E. Gamma, R. Helm, R. Johnson, and J. Vlissides, Design Patterns: Elements of Reusable Object-Oriented Software. Addison-Wesley, 1995. 
[129] European Committee of Standardization, "What is a standard," 2020. [Online]. Available:

https://www.cen.eu/work/endev/whatisen/pages/default.aspx.

[Accessed: 12-Nov-2020]. 


\section{SAMENVATTING}

De wereld digitaliseert steeds verder, maar het blijft lastig om een informatiesysteem (IS) te realiseren dat aan de gestelde eisen voldoet. Volgens diverse praktijkonderzoeken falen dergelijke projecten tussen de 5 en $19 \%$. Binnen de Nederlandse overheid kwamen, met een uitloop van $37 \%$ van de initiële projectkosten, alleen al de geschatte extra kosten uit op 1,9 miljard euro. Hieruit blijkt dat het succesvol implementeren van een informatiesysteem dat aan de gestelde eisen voldoet, niet een vanzelfsprekendheid is.

Architectuur concentreert zich juist op deze eisen, om te zorgen dat het informatiesysteem haar doel bereikt. Daarmee komt meteen de vraag naar boven of architectuur, en daarmee het gebruik van architectuurprincipes, wel een toegevoegde waarde heeft. Zijn architectuurprincipes in de praktijk wel effectief?

De theorie geeft aan dat het gebruik van architectuurprincipes een positieve bijdrage levert aan het succes van IS projecten. We wilden deze theorie falsificeren en hebben daarom drie casestudies uitgevoerd om de bijdrage van principes aan het succes van IS projecten te onderzoeken. Om zowel het gebruik van architectuurprincipes als het succes van IS projecten te meten, hebben we twee meetinstrumenten ontwikkeld.

We hebben bij drie Nederlandse overheidsorganisaties een casestudie uitgevoerd. Per casus hebben we alle onderzoeksgegevens geanalyseerd en de uitkomsten in een matrix geplaatst. Op basis van de analyses hebben we bij elke casus vastgesteld dat de architectuurprincipes positief hebben bijgedragen aan het succes van het betreffende IS project. Omdat ook andere factoren een belangrijkere rol kunnen hebben gespeeld bij het succesvol realiseren van het IS project, 
hebben we niet kunnen vaststellen in welke mate deze principes hebben bijgedragen aan het succes.

We hebben, door de drie casestudies te vergelijken, ook gezocht naar andere indicatoren voor de bijdrage van architectuurprincipes aan het succes van IS projecten. Daarbij vonden we drie indicatoren die mogelijk aangeven dat principes bijdragen aan het succes van IS projecten.

Ten eerste vonden we in elke casus enkele "essentiële architectuurprincipes". Zo'n essentieel principe kon worden gerelateerd aan meerdere geïmplementeerde essentiële eisen. Daarbij was het gebruik van deze principes boven gemiddeld. We zagen daarnaast dat architectuurprincipes gezien kunnen worden als "sociale constructies": mensen die met elkaar bepaalde afspraken maken om richting te geven aan het ontwerp van het systeem. Mogelijk zijn in IS projecten vaker dergelijke afspraken gemaakt dan dat we bewust van zijn en hebben die ook meer impact dan dat we zien. Als laatste hebben we ook een eerste indicatie gezien van een negatieve bijdrage van principes. Bij eerdere - niet succesvolle - pogingen om tot een informatiesysteem te komen, werden bij twee cases een tegenovergesteld principe gebruikt.

Naast de drie indicatoren over de drie cases heen, hebben we ook in de literatuur aanwijzingen gevonden van de toegevoegde waarde van enterprise architectuur in relatie tot succes van IS projecten.

Zover wij weten, beschrijven we in dit proefschrift de resultaten van het eerste empirische onderzoek naar de relatie tussen architectuurprincipes en het succes van IS projecten. Alle randvoorwaarden in beschouwing nemend, concluderen we op basis van de casestudies dat er indicaties zijn dat architectuurprincipes een positieve bijdrage leveren aan het succes van IS projecten bij Nederlandse overheidsorganisaties. 


\title{
APPENDICES
}

\section{A: Overview of architecture principle definitions by different authors}

\author{
Table 22. Overview of architecture principle definitions by different \\ authors.
}

Nr. Definition of architecture principle

1 "Principles are an organization's basic

Author YoP

philosophies that guide the development of the

G.L. Richardson, et al.

1990

architecture... Principles provide guidelines and rationales for the constant examination and reevaluation of technology plans."

2 "... simple, direct statements of how an enterprise wants to use IT. These statements establish a context for architecture design decisions by translating business criteria into language and specifications that technology managers can understand and use. Architecture principles put boundaries around decisions about system architecture."

3 "... collectively the design principles are identified

J. Hoogervorst as enterprise architecture."

4 "Architecture principles are rules to use when elaborating enterprise architectures."

5 "Architecture principles define the underlying general rules and guidelines for the use and deployment of all IT resources and assets across the enterprise...."

6 "Principles are general rules and guidelines,

D. Chen, et al.

Ä. Lindström intended to be enduring and seldom amended, that inform and support the way in which an organization sets about fulfilling its mission"

7 "Enterprise architecture principles are fundamental propositions that guide the description, construction, and evaluation of enterprise architectures."

8 "An EA principle constrains and guides the design of the EA and may in turn provide justification for decision-making throughout an EA. In general, principles are self-restraint and not externally obliged, .... by law in terms of compliances."

9 "An EA principle is based on business strategy and IT strategy. Principles can be attributed to

Aier, et al. different layers. An EA principle is described in a 
principle statement saying what to improve. For each principle, a rationale is formulated explaining why the principle is meant to help reaching a predefined goal. For each principle, concrete implications or key actions are described explaining how to implement the principle.

Measurement is a key issue of EA principles. For every principle, it should be defined how to determine its fulfilment."

10 "Architectural principles are statements that express how your enterprise needs to design and deploy information systems across the enterprise to connect, share and structure information."

11 "A qualitative statement of intent that should be met by the architecture. Has at least a supporting rationale and a measure of importance."

12 "a declarative statement that normatively prescribes a property of the design of an artifact, which is necessary to ensure the artifact meets its essential requirements."

13 "EA principles can be attributed to different architectural layers, should be based on business and IT strategies, and refer to the construction of an organization. Each EA principle should be described in a principle statement along with a rationale that explains why this principle is helpful in attaining a predetermined goal, as well as implications that describe how to implement this principle. Finally, metrics could be identified for each principle to measure its fulfilment."

14 "an enterprise-specific and abstract, yet simple collection of statements, which generally provide a framework for decision making and thus support the transformation process of an enterprise from a current to a target EA."

15 "In EA, principles have been defined as guidelines and rationales for the design and evolution of technology plans. In other words, EA principles can be seen as "rules of conduct" and can be made more precise and operational by formalization."

16 "...the principle of a concept (a concept principle) is the enforced way a concept works, producing results. " 


\section{B: Architecture principle framework}

\section{Table 23. Characteristics and attributes of architecture principles.}

\begin{tabular}{|c|c|c|c|}
\hline \multirow{4}{*}{$\begin{array}{l}\text { Characteristic } \\
\text { Specification }\end{array}$} & Attribute & Definition & Add-on \\
\hline & Statement & Statement & \\
\hline & Rationale & $\begin{array}{l}\text { Highlights the business benefits } \\
\text { of adhering to the principle }\end{array}$ & \\
\hline & Implications & $\begin{array}{l}\text { Highlights the requirements for } \\
\text { carrying out the principle }\end{array}$ & \\
\hline \multirow[t]{3}{*}{ Measure } & & $\begin{array}{l}\text { Level of the fulfilment of the } \\
\text { statement }\end{array}$ & \\
\hline & $\begin{array}{l}\text { Degree of } \\
\text { acceptance }\end{array}$ & $\begin{array}{l}\text { level of acceptance of the } \\
\text { principle by all of its users }\end{array}$ & After TDi case \\
\hline & Level of fulfilment & $\begin{array}{l}\text { the level of fulfilment of the } \\
\text { principle }\end{array}$ & After TDi case \\
\hline \multicolumn{4}{|l|}{ Prerequisites } \\
\hline & Precondition & $\begin{array}{l}\text { Preconditions and requirements } \\
\text { to be fulfilled before the } \\
\text { principle can be applied }\end{array}$ & \\
\hline & Key action & $\begin{array}{l}\text { Guidelines for implementing the } \\
\text { principle, giving the } \\
\text { preconditions }\end{array}$ & \\
\hline & $\begin{array}{l}\text { Preconditions } \\
\text { fulfilled }\end{array}$ & $\begin{array}{l}\text { Level of fulfilment of the } \\
\text { preconditions defined }\end{array}$ & After TDi case \\
\hline Meta data & Several & $\begin{array}{l}\text { Specifications to be able to } \\
\text { govern the principle, like } \\
\text { version number, owner, status, } \\
\text { visualization, etc. }\end{array}$ & \\
\hline \multicolumn{4}{|l|}{ Quality } \\
\hline & Specific & $\begin{array}{l}\text { The user can understand its } \\
\text { intention and its effects to use it } \\
\text { in his work }\end{array}$ & \\
\hline & Measurable & $\begin{array}{l}\text { Possible to determine whether } \\
\text { or not a given behavior is in line } \\
\text { with architecture principle }\end{array}$ & \\
\hline & Achievable & $\begin{array}{l}\text { The implications of it can all be } \\
\text { performed by or adhered to by } \\
\text { all those affected }\end{array}$ & \\
\hline & Relevant & $\begin{array}{l}\text { The principle should lead to a } \\
\text { improvement of the system }\end{array}$ & \\
\hline
\end{tabular}


Time framed

Classification

Type

Scope meeting the essential

requirement

Principle should be stable in

context and time

After Octopus case

The principle is related to one

of the architecture layers.

Organizational level of use of the principle.

Table 24. Characteristics of architecture principle set.

$\begin{array}{lll}\begin{array}{l}\text { Characteristic } \\ \text { Classification }\end{array} & \text { Attribute } & \text { Definition } \\ & \text { Type } & \begin{array}{l}\text { The principles in the set are } \\ \text { related to one of the } \\ \text { architecture layers. } \\ \text { Organizational level of use of } \\ \text { the principle. }\end{array}\end{array}$

Prerequisites

Precondition

Basic assumptions

Meta data

Quality

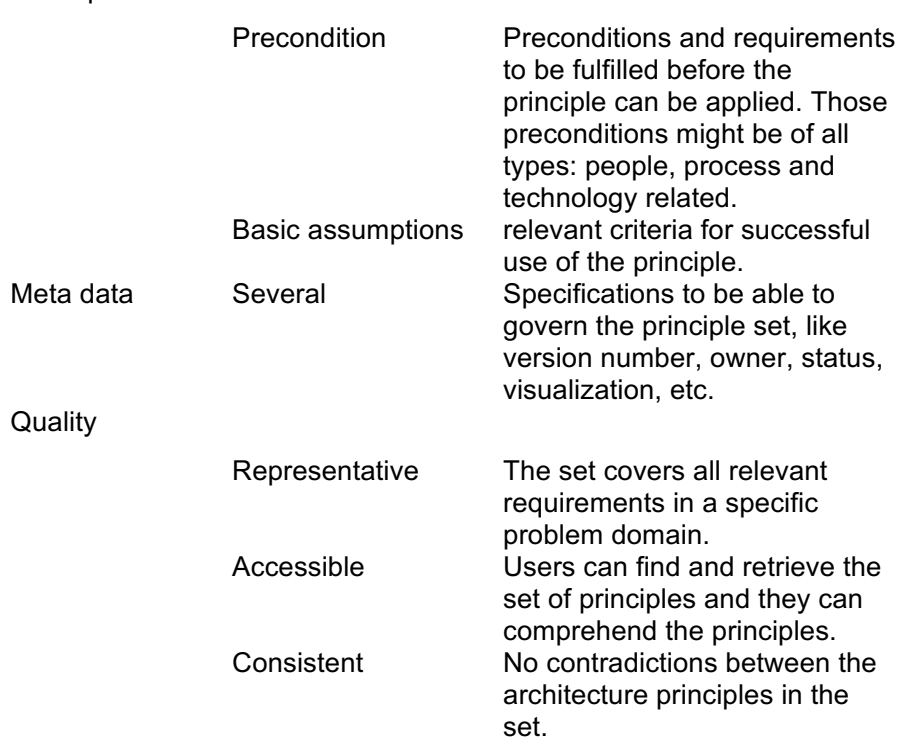

Add-on

After TDi case 
Table 25. Possible values for the attributes of the classification characteristic.

Attribute

Type: The principles in the set are

related to one of the architecture layers.

Scope: Level of use of the principle.
$0 \quad$ Infrastructure

1 Application

2 Information system

\section{Score Value}

0 Part of the target organisation.

1 Full target organisation.

2 More than the target organisation.

\section{C: Measurement method}

Survey before interview

This online survey was sent to all interviewees before the interview. Translated from Dutch. We used a five-point Likert scale, because a larger scale is not effective.

\section{Maastricht University}

\section{Aim of this research}

Maastricht University is doing scientific research within the Dutch government regarding the use of architecture principles in IS projects: are architecture principles effective? To answer this question, we investigate both the use of architecture principles and the IS project success. One of the projects in scope is [project name]. The objective of this survey is to collect upfront basic information regarding the [project name] project and related architecture principles. The outcome of this survey is used to prepare the interview and to be able to focus on specific items during the interview. Therefore, we kindly ask you to fill in this survey. 


\section{Instructions}

Please fill in your name and role within the project. After that, please answer the questions. The survey is a combination of open and multiple-choice questions. If more answers are possible, it is indicated explicitly. If you do not know the answer regarding a question, you can fill in 'no opinion'. Filling in the survey will take 10 minutes at most.

What is your name:

What is your role in the project?

\section{Success of the project}

This part of the survey is about the success of the [project name] project. When we talk about the [project name] project we focus on the period between the start of the project at [date] and the ending at [date].

[project name] is the system of [organization] executing the functions of [...]. Before system [project name] those functions were done by [...].

1. Was the project successful?

- Completely

○ Partly

- Not 
2. The project was implemented on time.

○ Totally disagree

- Disagree

○ Neither disagree, nor agree

o Agree

○ Totally agree

Because:

3. The project was implemented on budget.

$\circ \quad$ Totally disagree

- Disagree

- Neither disagree, nor agree

- Agree

○ Totally agree

Because:

4. The (essential) requirements for [project name] were implemented.

$\circ \quad$ Totally disagree

- Disagree

○ Neither disagree, nor agree

○ Agree

○ Totally agree

Because: 
5. The [project name] system is being used well.

- Totally disagree

- Disagree

$\circ \quad$ Neither disagree, nor agree

$\circ \quad$ Agree

$\circ \quad$ Totally agree

Because:

6. You, as stakeholder, are satisfied with the [project name] system.

$\circ \quad$ Totally disagree

- Disagree

○ Neither disagree, nor agree

- Agree

$\circ \quad$ Totally agree

Because:

7. The system, according to you, had added value.

- Totally disagree

- Disagree

- Neither disagree, nor agree

$\circ \quad$ Agree

$\circ \quad$ Totally agree

Because: 


\section{Use of architecture principles}

This part of the survey is about the use of architecture principles. Architecture principles are statements being used during the project to give direction to the solution. Those directives cover both the solution and the development process.

8. Are architecture principles being used in the [project name] project?

○ Yes

○ No

I I do not know

If the answer is 'No' or 'I do not know', go to question 18.

9. Which architecture principles are being used in the [project name] project?

When more than 8 architecture principles being used, fill in the open text field with the other principles.

- Principle 1

- Principle 2

- Principle $\mathrm{x}$

10. What was the objective of use the architecture principles in this project (more answers possible)?

$\square \quad$ They gave direction to the development process of the [project name] system

$\square$ They restrict the number of possible solutions of the [project name] system

$\square$ They enabled the [project name] system getting the right functionality

$\square$ They kept focusing on the objectives of the [project name] system 
11. Which of the used architecture principles were described well?

Well described $\quad \begin{array}{rr}\text { Rather well } \\ \text { described }\end{array} \quad \begin{array}{r}\text { Not good } \\ \text { described }\end{array} \quad$ No opinion

Principle 1

Principle 2

$\circ$

○

○

○

Etc.

12. Which of the used architecture principles were complied with?

$\begin{array}{cccc}\begin{array}{c}\text { Well complied } \\ \text { with }\end{array} & \begin{array}{c}\text { Rather well } \\ \text { complied with }\end{array} & \begin{array}{c}\text { Not complied } \\ \text { with }\end{array} & \text { No opinion }\end{array}$

Principle 1

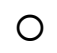

O

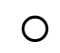

O

Principle 2

○

O

O

O

Etc.

13. Which of the used architecture principles did have a high quality?

High quality Average quality Low quality No opinion

Principle 1

O

O

O

O

Principle 2

O

O

O

O

Etc. 
14. Were prerequisites defined for the (individual or a set of) architecture principles to be able to comply with? Could you write down those prerequisites and address whether those prerequisites are fulfilled during the project?

15. Who was using the architecture principles during the project (more answers possible)?

$\square \quad$ Business owner

$\square \quad$ Project leader

$\square \quad$ Architect

Designer

$\square \quad$ Developer

$\square \quad$ Tester

$\square \quad$ End-user

$\square \quad$ Unknown

16. Who was the administrator of the architecture principles (more answers possible)?

$\square \quad$ Business owner

$\square \quad$ Project leader

$\square \quad$ Architect

$\square \quad$ Designer

$\square \quad$ Developer

$\square \quad$ Tester

$\square \quad$ End-user

$\square \quad$ Unknown

17. The architecture principles were related to (more answers possible)

$\square \quad$ Information system

$\square \quad$ Application

$\square \quad$ Technical infrastructure

$\square \quad$ No opinion 
18. Any other remarks can be written down here:

We want to thank you for filling in the survey.

Michiel Borgers

Survey for measuring 'Use' and 'User satisfaction'

This online survey was sent to the end-user of the system. Translated from Dutch.

\section{Maastricht University}

\section{Aim of this research}

[Organization] is participating in scientific research regarding successful IS projects. One of the projects in scope is [project name]. To investigate the success of [project name] we want to measure the daily use of [project name]. Therefore, we kindly ask you to fill in this survey.

\section{Instructions}

The survey is anonymous. Also, all possible answers cannot be redirected to individuals. The survey is a multiple-choice questionnaire, with only one answer possible. Filling in the survey will take 5 minutes at most.

[system name] is supporting your business tasks regarding [business activities]. 
1. How many functions of [system name] are you using in your day-to-day work?

- No functions

- Small number of functions

$\circ \quad$ Half of the functions

- Most functions

- All functions

2. In doing [business activities] you try to use as many functions of the [system name] as possible.

$\circ \quad$ Totally disagree

- Disagree

$\circ \quad$ Neither disagree, nor agree

$\circ \quad$ Agree

- Totally agree

$\circ \quad$ No opinion

3. In using the functions of [system name], you use the functions as meant to be.

$\circ \quad$ Totally disagree

- Disagree

- Neither disagree, nor agree

$\circ \quad$ Agree

- Totally agree

- No opinion

4. You are only using the [system name]-system if necessary, not in all situations.

$\circ \quad$ Totally disagree

- Disagree

- Neither disagree, nor agree

- Agree

○ Totally agree

$\circ \quad$ No opinion 
5. The functions of [system name] helps you in doing your work regarding [business activities].

- Totally disagree

- Disagree

○ Neither disagree, nor agree

$\circ \quad$ Agree

- Totally agree

$\circ \quad$ No opinion

6. The different functions of [system name] are easy to use.

- Totally disagree

- Disagree

- Neither disagree, nor agree

$\circ \quad$ Agree

$\circ \quad$ Totally agree

$\circ \quad$ No opinion

During the use of the [system name]-system, you might need training, to ask for change requests, to get incidents solved, or other forms of support.

7. Do you get the right level of support regarding the needs from functional management and/or the IT-department?

- Totally disagree

- Disagree

$\circ \quad$ Neither disagree, nor agree

$\circ \quad$ Agree

$\circ \quad$ Totally agree

$\circ \quad$ No opinion

8. If you get support from functional management and/or the ITdepartment regarding [system name], are you satisfied by the level of support?

- Totally disagree

- Disagree

- Neither disagree, nor agree

- Agree

- Totally agree

$\circ \quad$ No opinion 
Any other remarks regarding the use of [system name] can be written down here:

We want to thank you for filling in the survey. We will process the results of the survey in our research. The final report of this research will be available via [name contact person].

Michiel Borgers

Spreadsheet for checking the architecture principle definition

Table 26. Table for checking architecture principle are according the architecture principle definition.

$\begin{array}{llcccc}\text { Nr. } & \text { Principle name } & \begin{array}{c}\text { Principle } \\ \text { (Yes / No) }\end{array} & \begin{array}{c}\text { Declarative } \\ \text { statement }\end{array} & \begin{array}{c}\text { Based on } \\ \text { B / IT- } \\ \text { strategy }\end{array} & \text { Etc. } \\ 1 & \text { [ name ] } & \text { [yes } / \text { no ] } & \text { [finding] } & \text { [finding] } & \text { [finding] } \\ 2 & \text { [name ] } & \text { [yes } / \text { no ] } & \text { [finding] } & \text { [finding] } & \text { [finding] }\end{array}$

Etc.

Table 27. Table for recording the findings and scores for the individual architecture principles. For the recording of the architecture principle set a similar table has been used.

\begin{tabular}{|c|c|c|c|c|}
\hline \multirow[b]{2}{*}{ Score } & \multirow[b]{2}{*}{$\begin{array}{l}\text { Substantiating } \\
\text { expert opinion }\end{array}$} & \multicolumn{2}{|c|}{$\begin{array}{l}\text { Per Architecture } \\
\text { Principle }\end{array}$} & \multirow[b]{2}{*}{ Source 1} \\
\hline & & Characteristic & Attribute & \\
\hline \multirow[t]{4}{*}[0/50/100\%]{} & [ facts ] & Specification & & \\
\hline & & & Statement & [specific findings] \\
\hline & & & Rationale & [specific findings] \\
\hline & & & Implication & [specific findings] \\
\hline
\end{tabular}


Etc.

Table 28. Table for recording the findings and scores for Project Management Success (PMS). For the recording of Project Product Success, a similar table has been used.

Score

Substantiating expert opinion

Characteristic Attribute Source 1

[0/50/100\%] [ facts ] On time

$\begin{array}{lll} & \text { Initial timeline } & \text { [specific findings] } \\ & \text { Change requests } & \text { [specific findings] } \\ \text { Octual timeline } & \text { [specific findings] } \\ \text { On budget } & & \text { [specific findings] }\end{array}$

Etc.

\section{D: Case study results of NEST}

\section{NEST}

The main objectives of the project were (page 8 -of the PID):

- To secure the continuity of the information system for energy statistics and, with that, the continuity of the energy statistics process;

- To mitigate the risks of errors and inconsistencies between energy figures.

The NEST- system had to meet twelve essential requirements (page 11 of the BAD):

1. Considerable reduction of error prone, manual tasks;

2. More efficient data transfer to customers;

3. Eliminating of double data management; 
4. Introduction of missing data management in parts of the process;

5. Some level of flexibility in the process and in the system, especially with changes in variables and classifications;

6. Flexible and efficient process flow through a flexible system;

7. Standardization of the work process, with a better hand-over to other employees;

8. High level of consistency between energy statistics;

9. Better fit with customers' demands for output;

10. Standardization of definitions and coding;

11. A new, modern, energy system, built using the latest technology standards;

12. Lower labor-intensive maintenance of the energy system.

Architecture principles

- Specification: The 'statement' and the 'rationale' were present for all 9 architecture principles. The 'implications', though, were incomplete, inconsistent between different sources, or lacking at six principles. This in a context where the principles were not documented, but only discussed between two or more project members (see Figure 37).

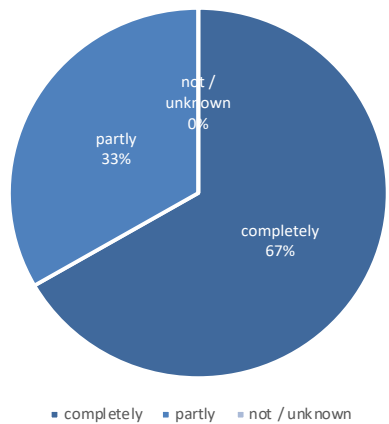

Figure 37: specification of NEST's architecture principles

In Figure 38 we present a snapshot of the measurement of the "On time" characteristic of IS project success of NEST. In this snapshot we show 1 of the 10 data sources we found regarding IS project success (in Dutch). 


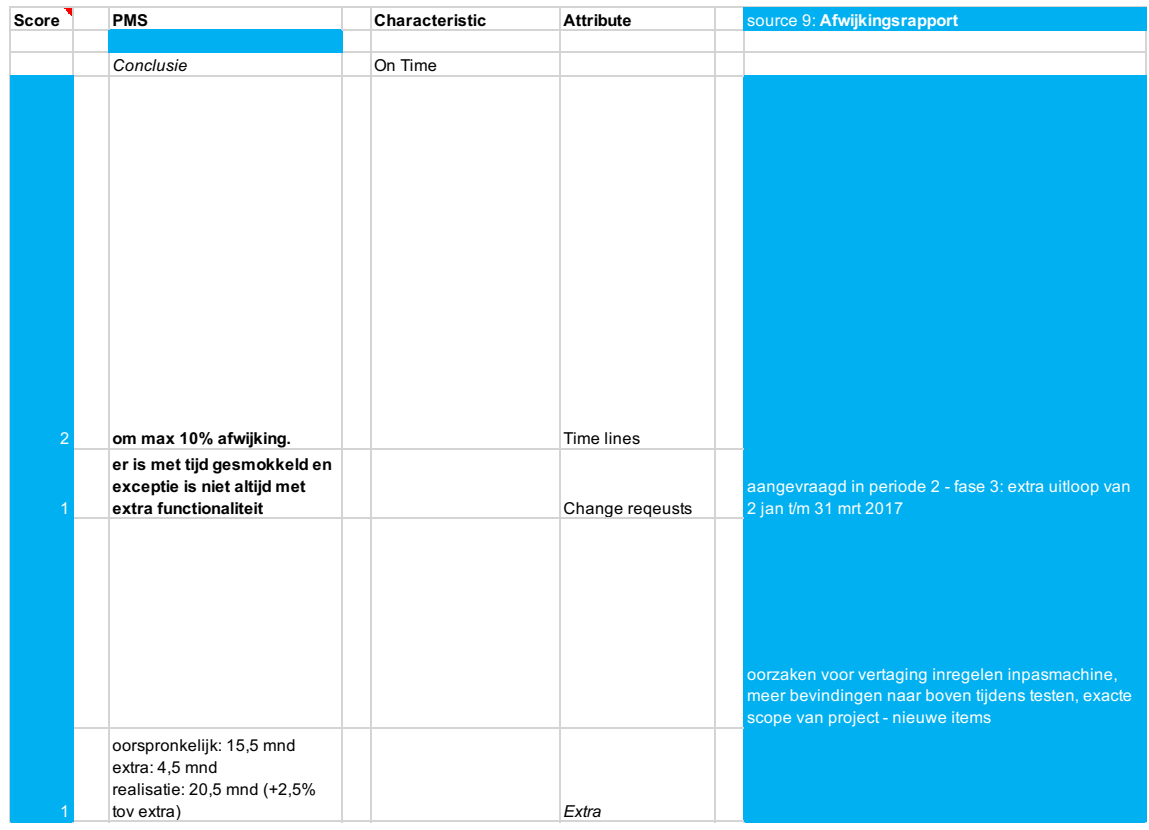

Figure 38: a snapshot of the measurement of "On time" of IS project success of NEST.

- Prerequisites: the project did not fulfil the prerequisites of two principles sufficiently: "Output requirements are leading in the design" and "Rest points". Because the project members were focused on the technical prerequisites only, they overlooked some non-technical prerequisites. There was a lack of support of the NEST-users to limit the amount of statistics. Secondly, there was no budget and time reserved for the disclosure of the NEST data for other CBS-processes.

In Figure 39 we present a snapshot of the measurement of the "Measure" characteristic of the architecture principle "Rest points." In this snapshot we show 1 of the 7 data sources we found for this principle (in Dutch). 


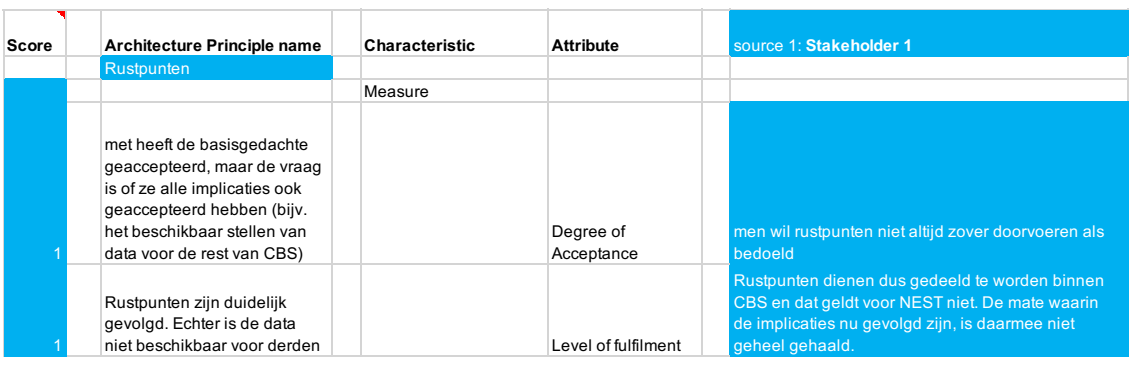

Figure 39: a snapshot of the measurement of "Measure" of the architecture principle "Rest points" of NEST.

- Measure: five architecture principles have been complied with completely, and two principles have been complied with only partly: "Output requirements" and "Rest points". For two principles we could not determine whether or not the principles have been followed, lacking the implications of those principles (see Figure 40).

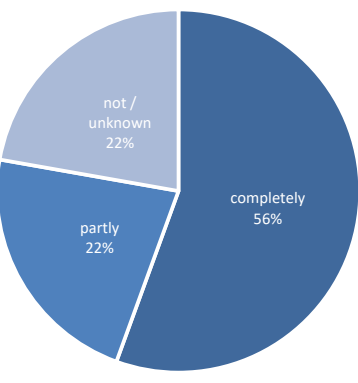

- completely - partly | not / unk nown

Figure 40: measure of NEST's architecture principles

- Meta data: the architecture principles were not documented explicitly. So, no meta data regarding the principles was in place. Some information related to the architecture principles can be found in the project documentation. Most of the information sharing took place via oral discussions.

In Figure 41 we present a snapshot of the definition check of all statements found, used in the NEST-project. In this snapshot we show 6 of the 14 statements of which 9 were architecture principles (in Dutch). 


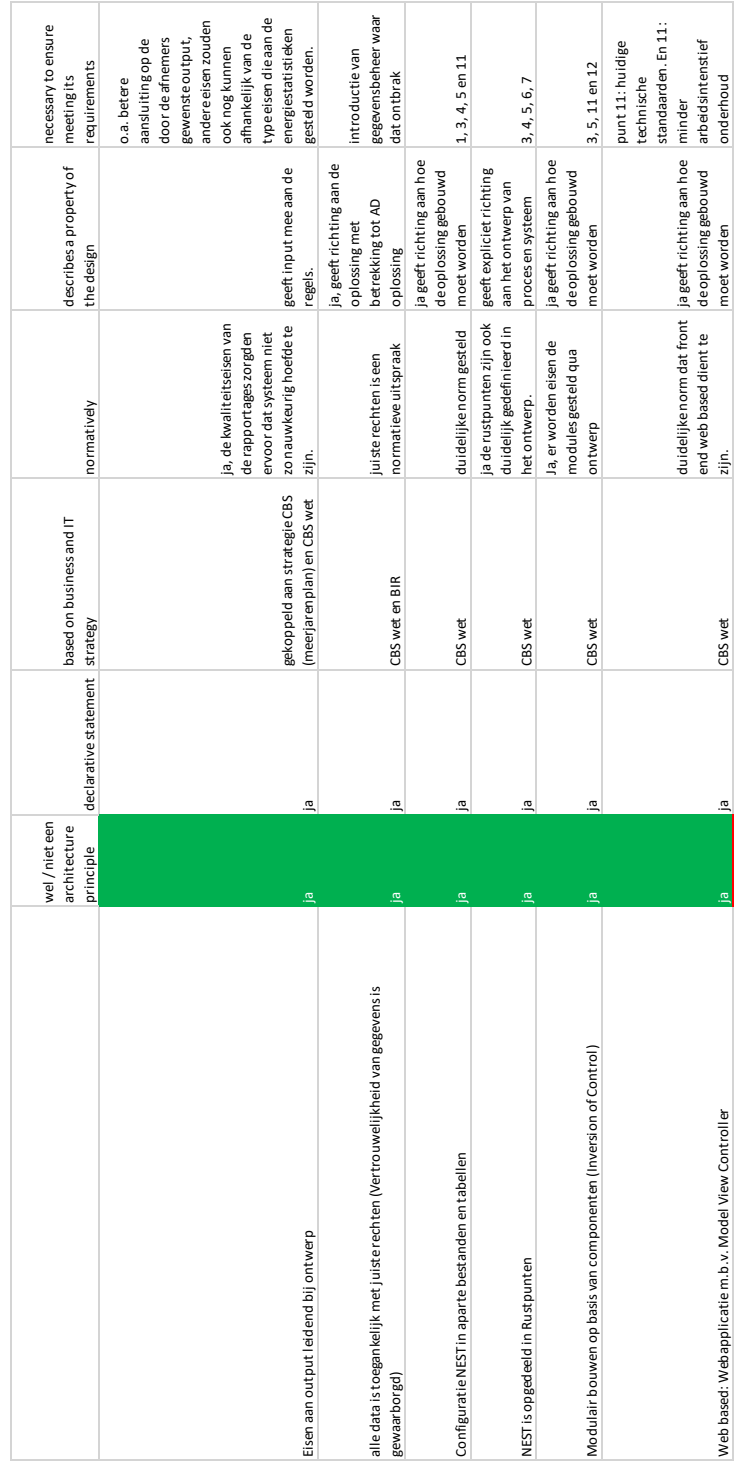

Figure 41: a snapshot of the definition check of the statements used in the NEST project. 
- Quality: five architecture principles were (almost) matching all quality attributes. The principles "Output requirements" and 'Web based' had decreasing quality on the attributes 'specific', 'measurable' or 'achievable'. The quality of the architecture principles "Published data points to observed data" and 'Logging of process steps' was low, because these principles were not specified in detail (see Figure 42).

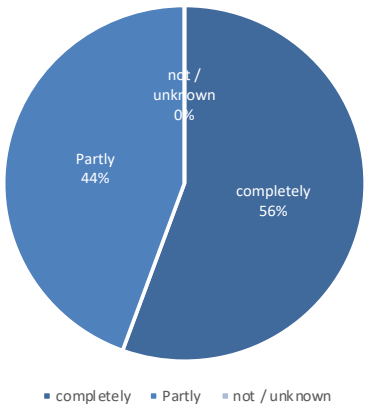

Figure 42: quality of NEST's architecture principles

- Classification: all principles, except for one, are generic principles to be used within CBS, and not specifically aligned to the NESTsystem. Six principles are focused on the application, while three principles are related to the information system.

- Quality of the set: the identified principles cover nine of the eleven essential requirements of the NEST-system and probably the other two as well. Because the implications of some principles are not that clear, we can't connect all essential requirements to the principles. Besides, the group of principles are not conflicting with each other. Even some principles are related to or strengthen each other. The use of "Rest points" is helpful to build a modular system and "Re-use of components" is only possible when the system is built modularly.

\section{Outcome of the user questionnaire}

All of the 16 users responded on the user questionnaire. The outcome of the respondents regarding the 'use' and 'user satisfaction' of Nest (in Dutch): 
1 - Hoeveel van de aanwezige functies in het NEST-systeem gebruikt $u$ voor het maken van de energiestatistieken?

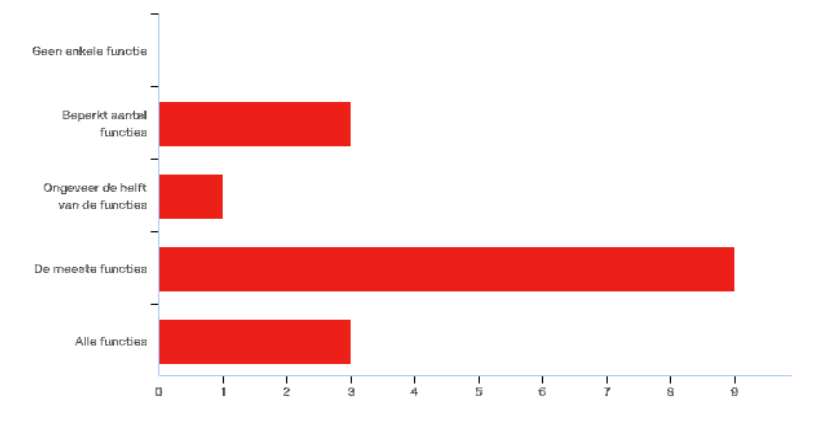

2 - Gebruikt u voor het maken van de energiestatistieken - alleen maar het NEST-systeem en/of daarnaast ook andere applicatie?

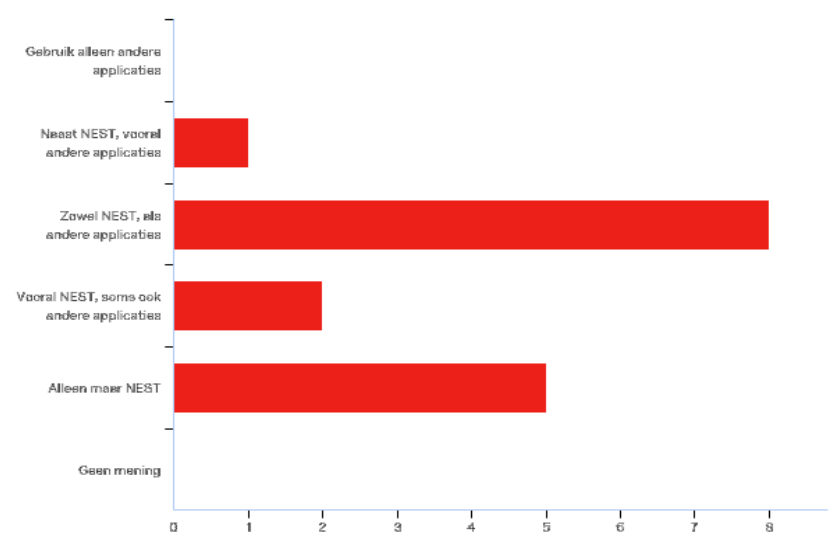

3 - Hoe vaak gebruikt $u$ het NEST-systeem voor het maken van uw statistieken?

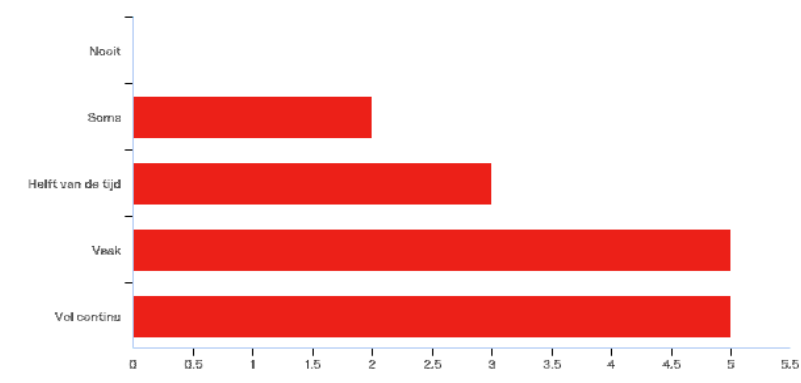


4 - Het NESTsysteem levert nauwkeurige statistieken op.

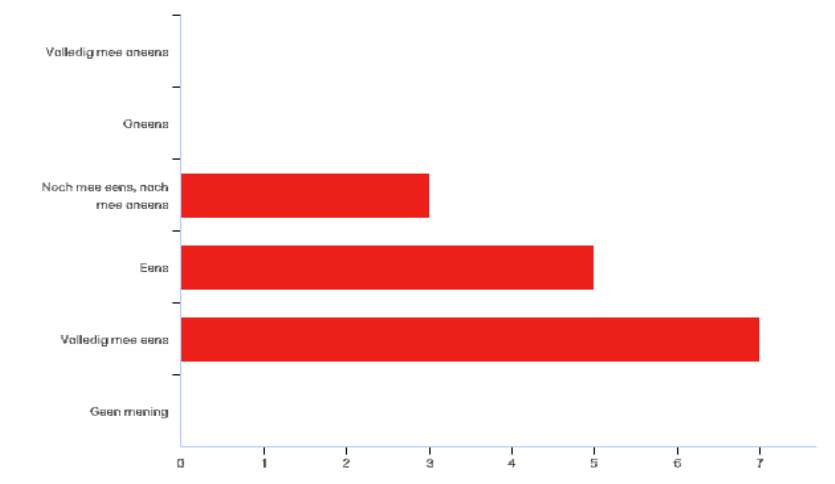

5 - U past (deel)resultaten uit het NESTsysteem handmatig aan om tot de juiste statistiek te komen.

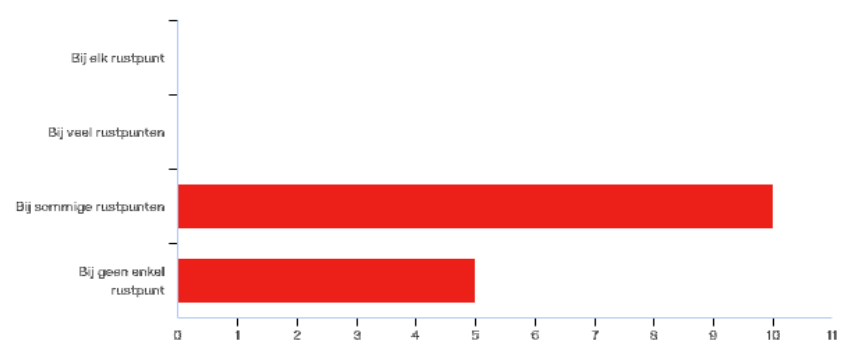

6 - $U$ vindt het fijn om het NESTsysteem te gebruiken.

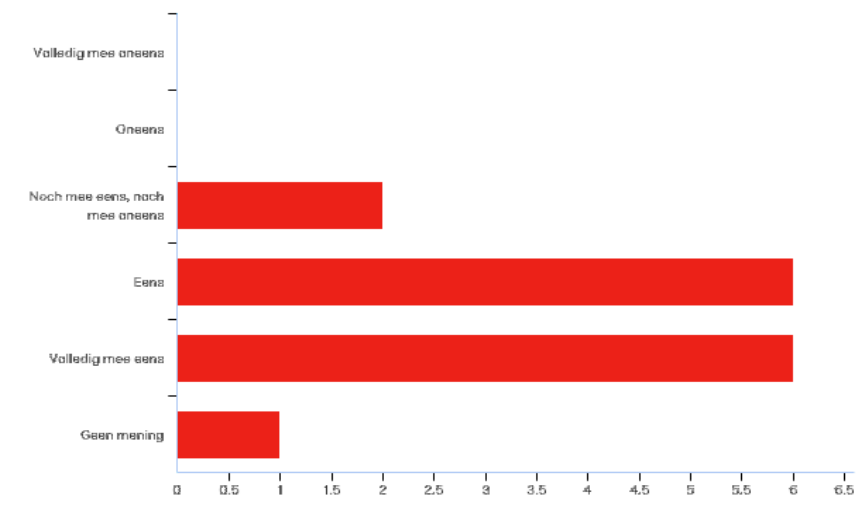




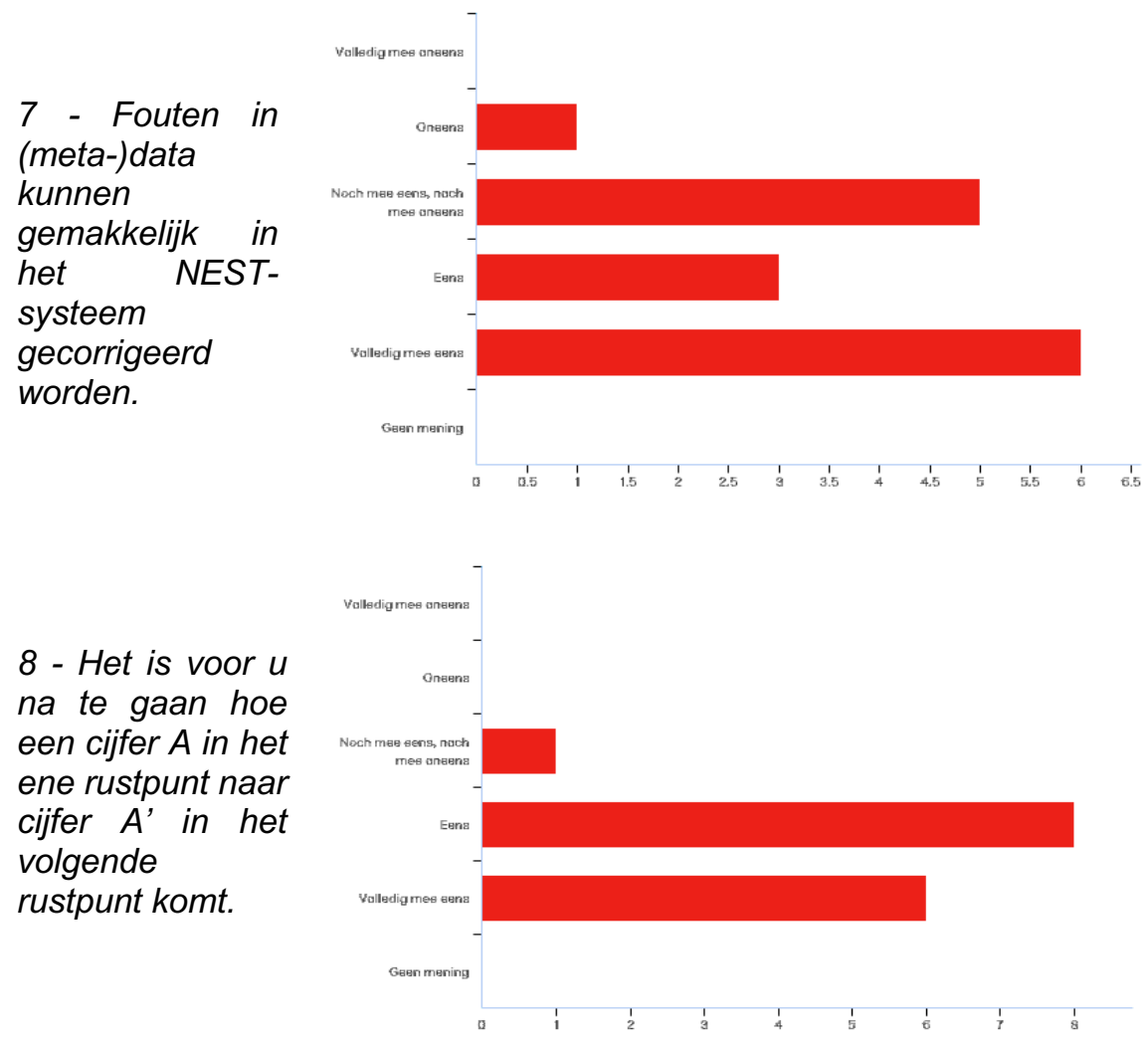


9 - Het NESTsysteem is geschikt voor het maken van de volgende energiestatistieken:

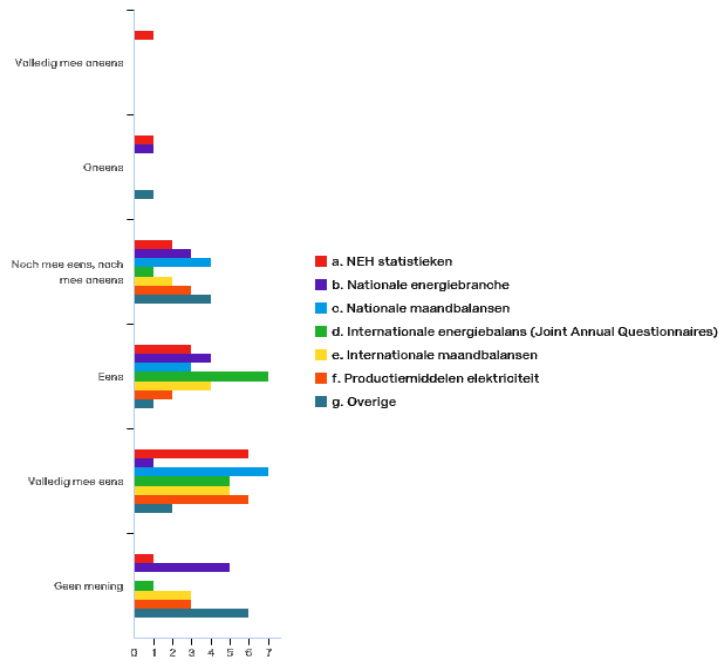

10 - Het NEST-systeem is gebruikersvriendelijk. Gebruiksvriendelijk betekent o.a. het aantal muisklikken, vastleggen en houden van mappen, volgorde periodes, begrijpelijke waarschuwingen bij verkeerd gebruik, etc.)

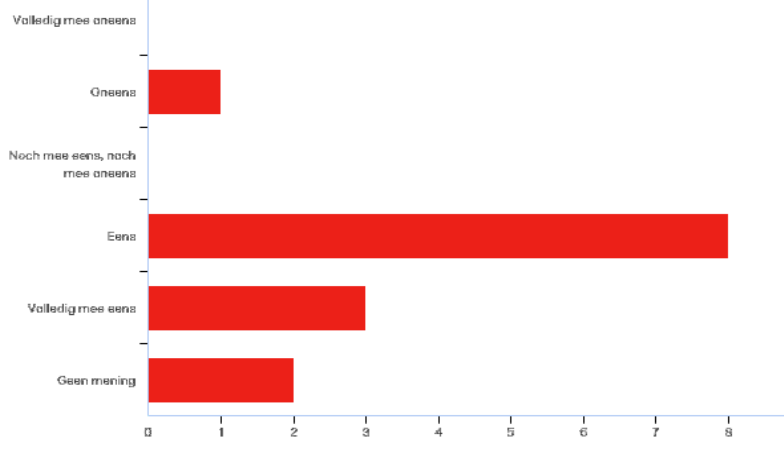


11 - Kan het NESTsysteem makkelijk aangepast worden? Bij aanpasbaarheid kunt $u$ denken aan het aanpassen van metadata, regels, toevoegen gegevensbronnen, etc.

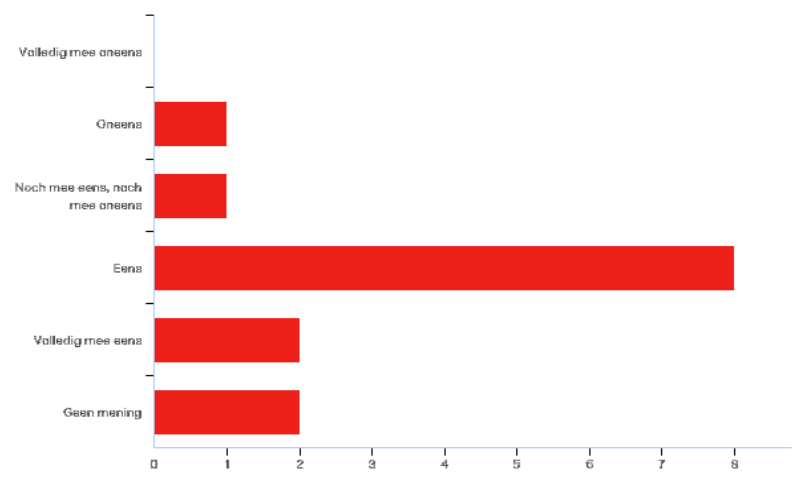

12 - Het NESTsysteem is logisch van opzet dat het voor u makkelijk is werkzaamheden van anderen over te nemen.

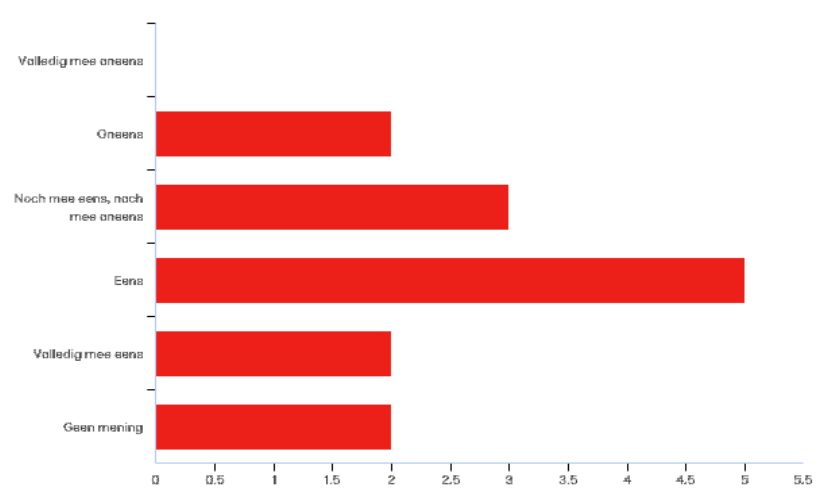

13 - De gebruikersondersteuning (support) bij incidenten is goed geregeld.

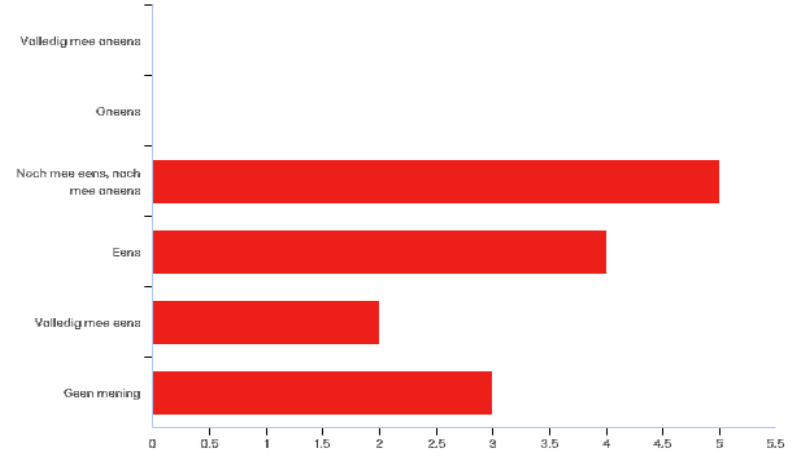


14 - Het NESTsysteem beschikbaar indien dat gewenst is. is

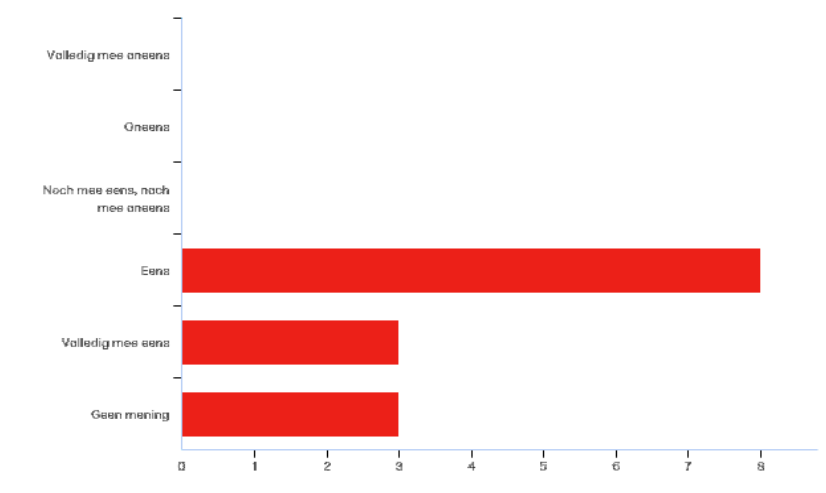

\begin{abstract}
15 - $D e$ performance van het NEST-systeem is goed. Onder performance verstaan we de reactietijd waarmee NEST-applicatie reageert op handelingen van gebruikers en de verwerkingstijd van berekeningen.
\end{abstract}

16 - De capaciteit van het NESTsysteem is voldoende om de gewenste gegevens te verwerken.
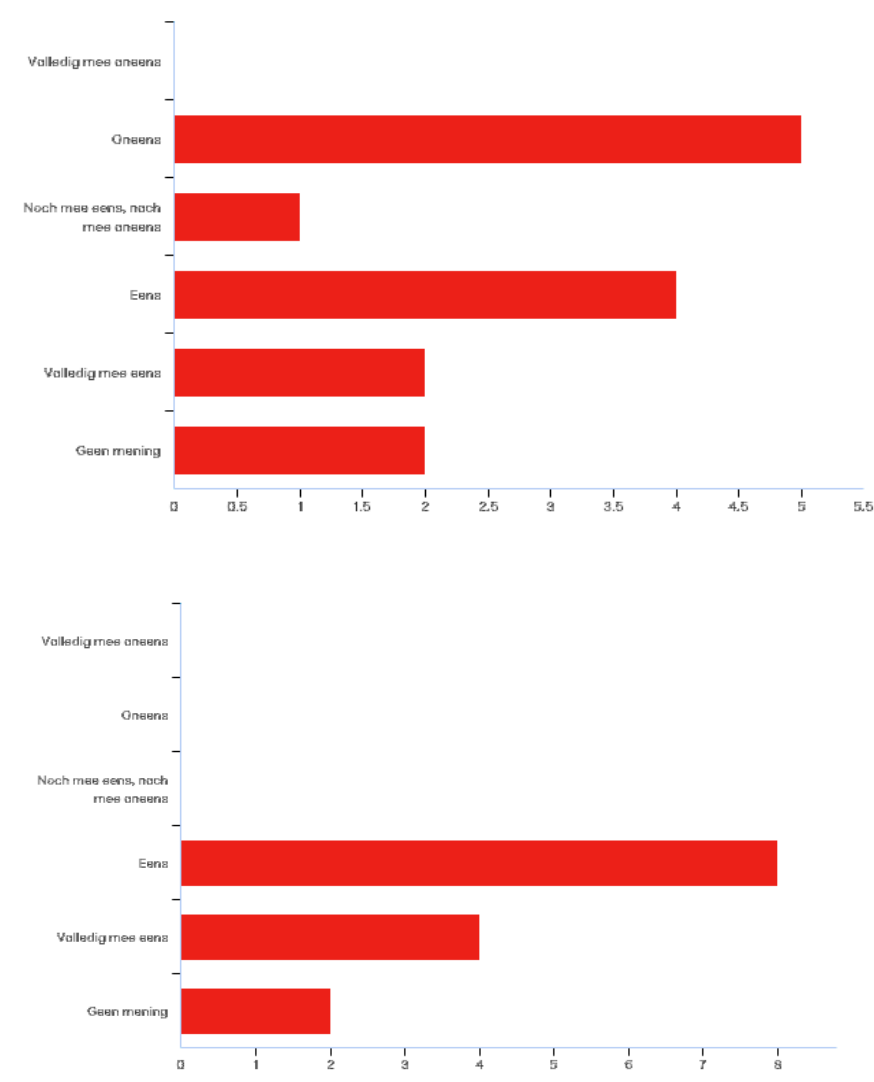
17 - De beveiliging

en de continuïteit

na calamiteit van

het NEST-systeem

is voldoende

geborgd.

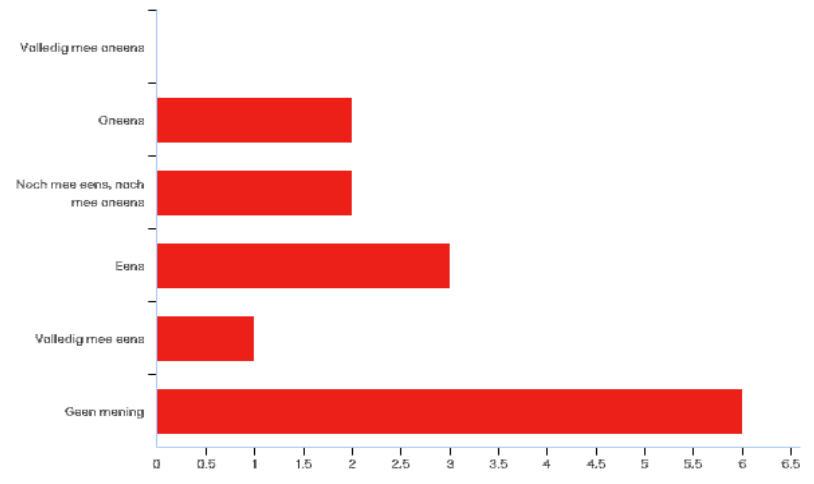

Received documents regarding NEST (in Dutch):

- Strategisch meerjaren programma 2014 - 2018

- CBS IV-architectuur

- SKIB-criteria checklist, handleiding en toelichting

- Afwijkingsrapport NEST periode 2 verlening

- BI001 architectuur ICT Masterplan business en informatiemodel 1.0

- IT001 ICT Masterplan conceptuele IT architectuur 1.4

- IT002 ICT Masterplan logische IT architectuur 1.3

- Lijst verantwoording exceptie Actueel

- SER 23 - Afwijkingsrapport NEST periode 2 verlenging

- SKIB rapport Energie

- VKUI SER23 NEST

- Vooronderzoek Energie

- Energie-vernieuwing PID versie 1.1 - projectnummer SER23

- Business Analyse Document Project NEST - versie 1.0 p2

- Technische documentatie NEST - 23-3-2017

- CBS IV-architectuur 1.1.p2 - 12 juli 2019

- Testverslag GebruikersAcceptatieTests NEST fase 3-5

- User satisfaction meting - januari en maart 2017

- Nieuwbouw Energie-statistieken (NEST) - SER23 faseplan Periode 2 versie 1.0 
All documents, interview recordings and minutes, survey outcome are stored at: Borgers, 2021, "Are Architecture Principles Effective?", https://doi.org/10.34894/RY1MOO, DataverseNL. Because of confidentiality access is restricted and permission by the author is necessary.

\section{E: Case study results of Octopus}

The transition to the Octopus-system would be successful if the following objectives were achieved (page 6 of the PID):

- Automated and digitized communication with the administration of justice using one information system;

- Connection of Private Law with the 'Mijn Rechtspraak'-portal;

- Rationalized (temporary) information system with optimized processes for complaints, appeals and preliminary injunctions;

- Digital Information Management (using digital cases).

The Octopus-system had to meet eight essential requirements (page 7 of the PID). In brackets our findings regarding the implementation of the requirements.

1. One information system for all departments involved in the legal domain (implemented);

2. One standardized process for complaints, appeals and preliminary injunctions and implemented in one information system of the legal domain (implemented);

3. One "Aanspreekpunt Rechtspraak" connected to the information system (not implemented);

4. All departments involved in the legal domain are using the same information system with similar configuration, the connection with the administration of justice, "Aanspreekpunt Rechtspraak", and with digital case management at October 1 ${ }^{\text {st }}, 2017$ (partly implemented).

5. Risk based security and privacy measures are specified, implemented and managed in (the working with) the information 
system and in the process of data transfer between "de Rechtspraak" and the departments involved (partly implemented);

6. Users are trained to work according the new, standardized process and information system (implemented)

7. Private Law cases can be managed by using the online portal of 'Mijn Rechtspraak' (not implemented)

8. (European) tendering of the new target application (not implemented).

In Figure 43 we present a snapshot of the measurement of the "Use" characteristic of IS project success of Octopus. In this snapshot we show 1 of the 7 data sources we found regarding IS project success (in Dutch).

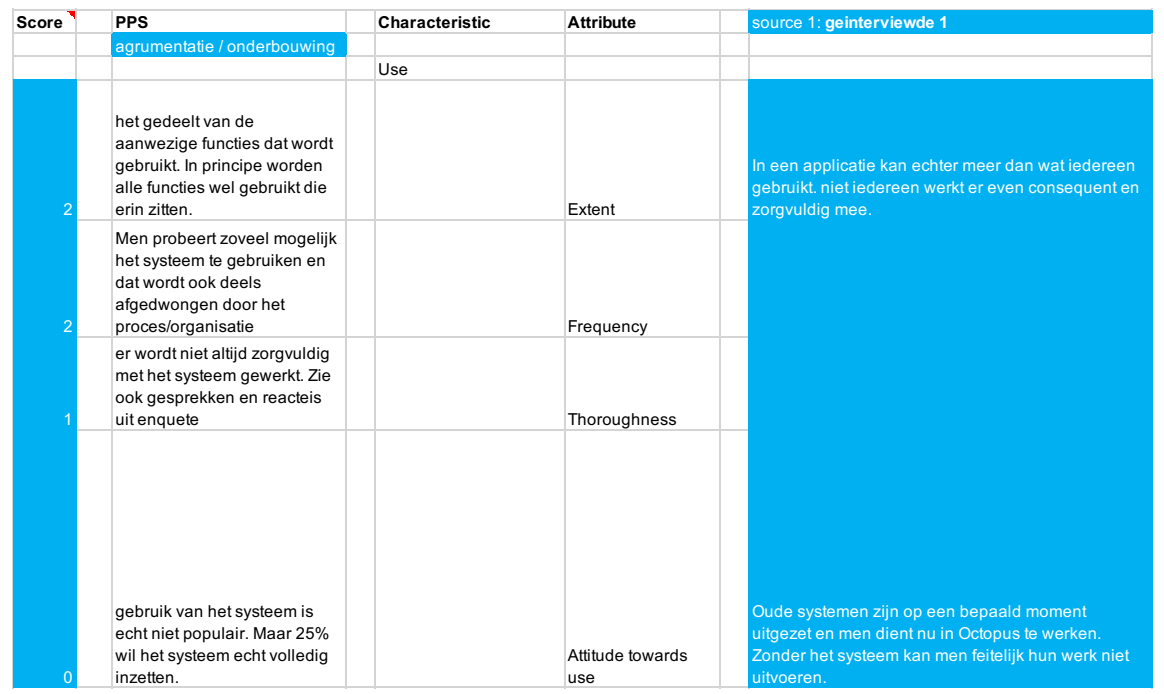

Figure 43: a snapshot of the measurement of "use" of IS project success of Octopus. 
Architecture principles

- Specification: the 'statement', 'rationale' and 'implications' were present for almost all principles. The principle "OIN" did not have a 'rational' and the principle "Application services" did not have implications. Besides one, all principles were documented in (architecture) documents, like "Project Start Architectuur", "Technische Architectuur", "Project Eind Architectuur" or specific project documentation. Only one principle was used implicitely: "Proces harmonization" (see Figure 44).

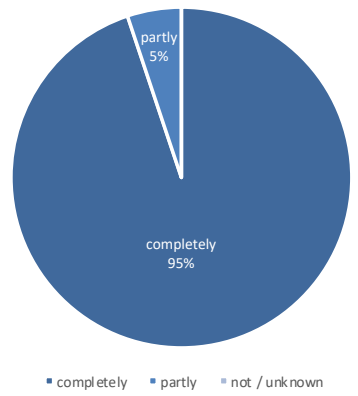

Figure 44: specification of Octopus's architecture principles

- Prerequisites: 26 percent of the architecture principles, all in the set of "Stadsbrede IVkaders", had explicitly defined preconditions. Those prerequisites were (partly) fulfilled. Almost no preconditions were defined for the other principles and were - at best - implicitly present during the implementation. E.g. to comply with the principle "Personal data will be extracted out of

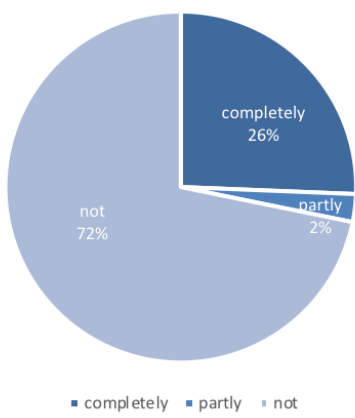

Figure 45: precondition defined for the Octopus's architecture principles the primarily source only" it was necessary to make a connection with the data source GBA. Though, no capacity was available to 
implement that connection, with the effect that the system could not fulfil the principle. Also, the implementation of the required AISlevel was not feasible, because of the current configuration of the technical infrastructure. And, although postponed by others, the lacking system of the administration of justice was the root cause of no compliance to some key principles.

In Figure 46 we present a snapshot of the measurement of the "Specification" characteristic of the architecture principle "Process Harmonization." In this snapshot we show 1 of the 7 data sources we found for this principle (in Dutch).

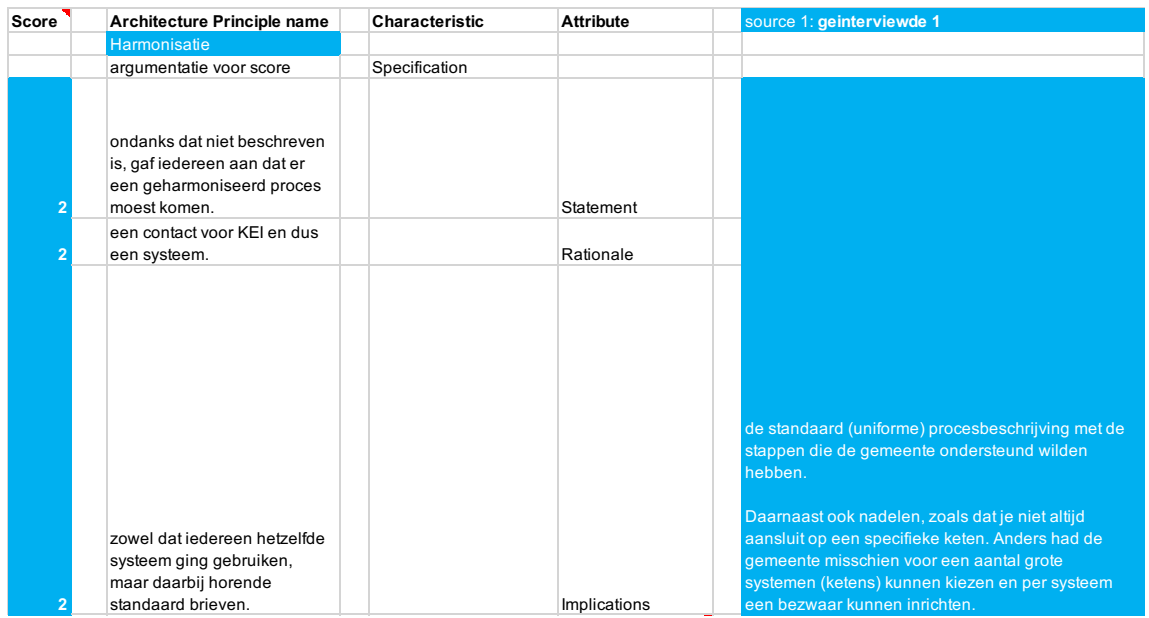

Figure 46: a snapshot of the measurement of "Specification" of the architecture principle "Process harmonization" of Octopus. 
In Figure 47 we present a snapshot of the definition check of all statements found, used in the Octopus-project. In this snapshot we show 7 of the 14 statements of which 9 were architecture principles (in Dutch).

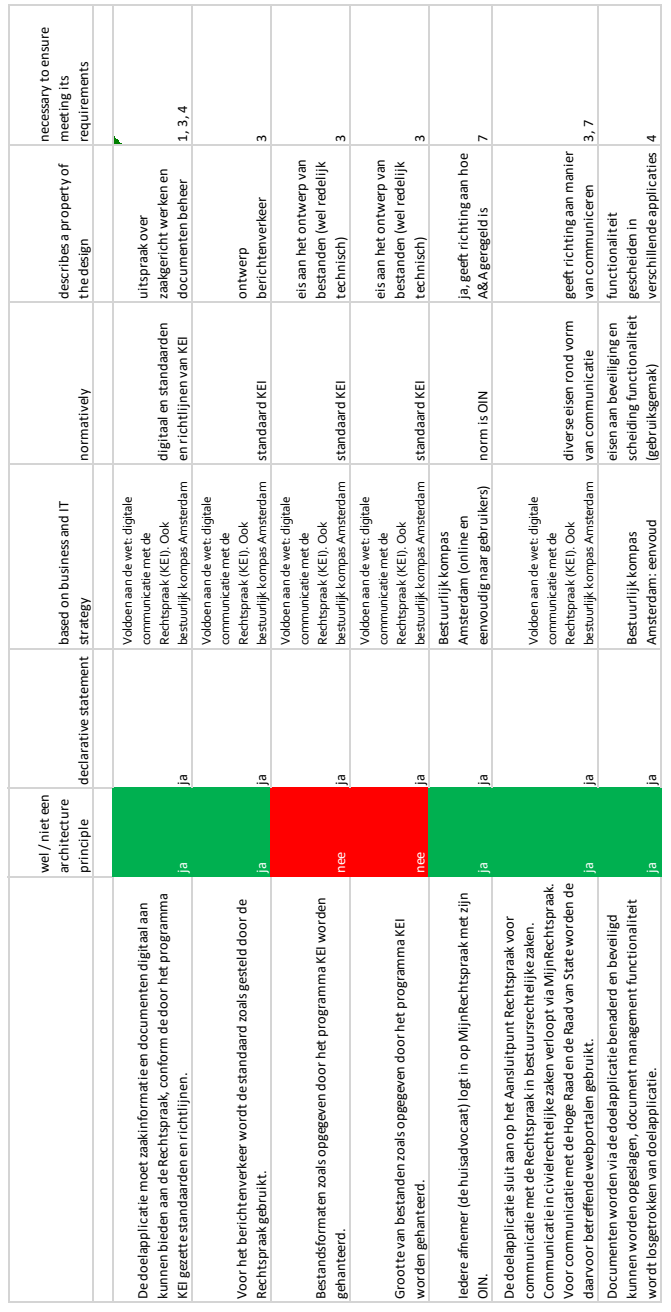

Figure 47: a snapshot of the definition check of the statements used in the Octopus project. 
- Measures: the Octopus-system does not comply with 21 percent of the principles, and with 20 percent only partly. Despite the support for all 39 principles, fulfillment of particular architecture principles was hard, because the missing prerequisites as described above.

- Meta data: except for one, all

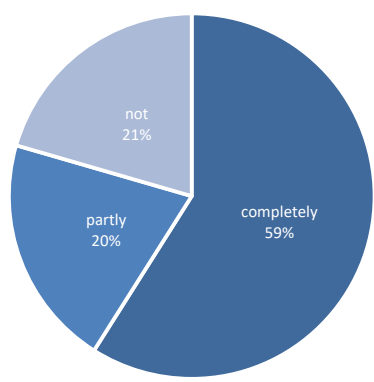

Figure 48: measure of the Octopus's architecture principles architecture principles were described in one or more (architecture) documents, such as "Project Start Architecture", "Project End Architecture", and "Technical Architecture Octopus". So, the management of the architecture principles, with all the meta data, was in place.

- Quality: 87 percent of the architecture principles met (almost) all quality attributes. Of the $13 \%$ percent of other principles had the most some shortcomings in the palpability ('specific') and related to that in the measurability or achievability of the principle. This can be applied to the principle "Process harmonization", because this principle was not described explicitly. But also other principles, like "Value proposition", Standardization of technology" and "KISS" were

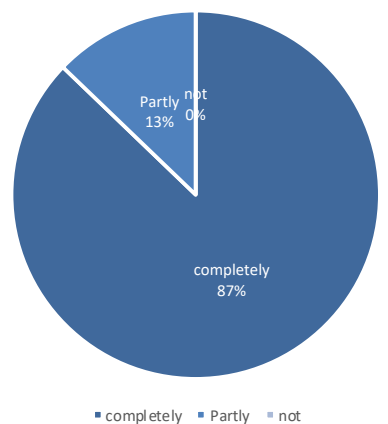

Figure 49: quality of the Octopus's architecture principles described to generic (see Figure 49). 
- Classification: all sets, except for the set "ICT principles", were concerning the information systems-layer. The "ICT principles'-set was focused on the application and technical infrastructure. Besides, the project "Digitization Legal Domain" was the scope for two sets, while the other two sets were defined for the entire organization of the City of Amsterdam.

- Prerequisites of the set: Except for the set "Process harmonization", no 'preconditions' or 'assumptions' were found for the other sets.

- Meta data of the set: the sets, including meta data, were described in different (architecture) documents.

- Quality of the set: two sets ("Proces harmonization" and "Stadsbrede IV-kaders") were representative for the objectives they wanted to achieve. The other two sets were only representative partially, because many principles of those sets were related to only a small number of essential requirements. In the set "Digitalisering Juridisch Domein" many principles were related to the first, third and fourth requirement. Only a few principles were related to some of the other requirements, and there was no match with requirement six and eight. The accessibility of the sets was well in place, because of the documentation and the discussions during the projects. Two sets had overlapping principles, like the "ADW"-principle, and in one set, there were some contradictions between principles. So, overall the quality of all sets was above average.

\section{Outcome of the user questionnaire}

Of the approximately 350 users of Octopus, 79 users responded on the user questionnaire. Because of the COVID-19 outbreak, a second reminder was of no use. 
The outcome of the respondents regarding the 'use' of Octopus (in Dutch):

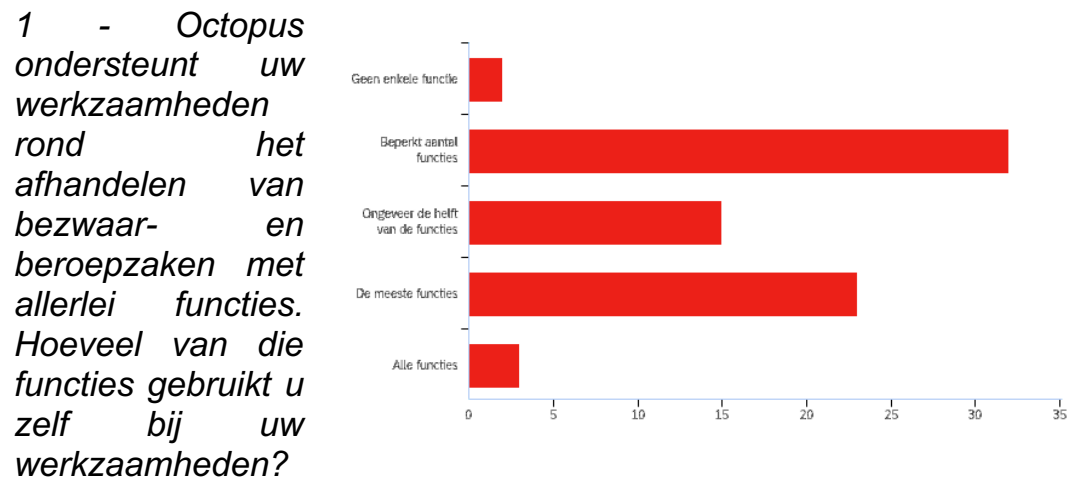

$\begin{array}{lr}2 & \text { Bij } \\ \text { verwerken } & \text { van } \\ \text { bezwaar- en } \\ \text { beroepzaken } \\ \text { probeert } u \\ \text { zoveel als } \\ \text { mogelijk de } \\ \text { functies van } \\ \text { het Octopus- } \\ \text { systeem te } \\ \text { gebruiken. }\end{array}$

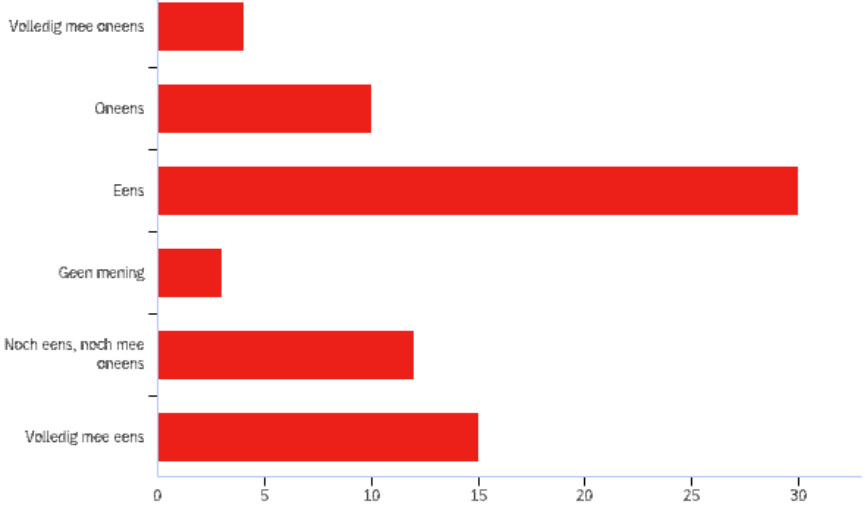



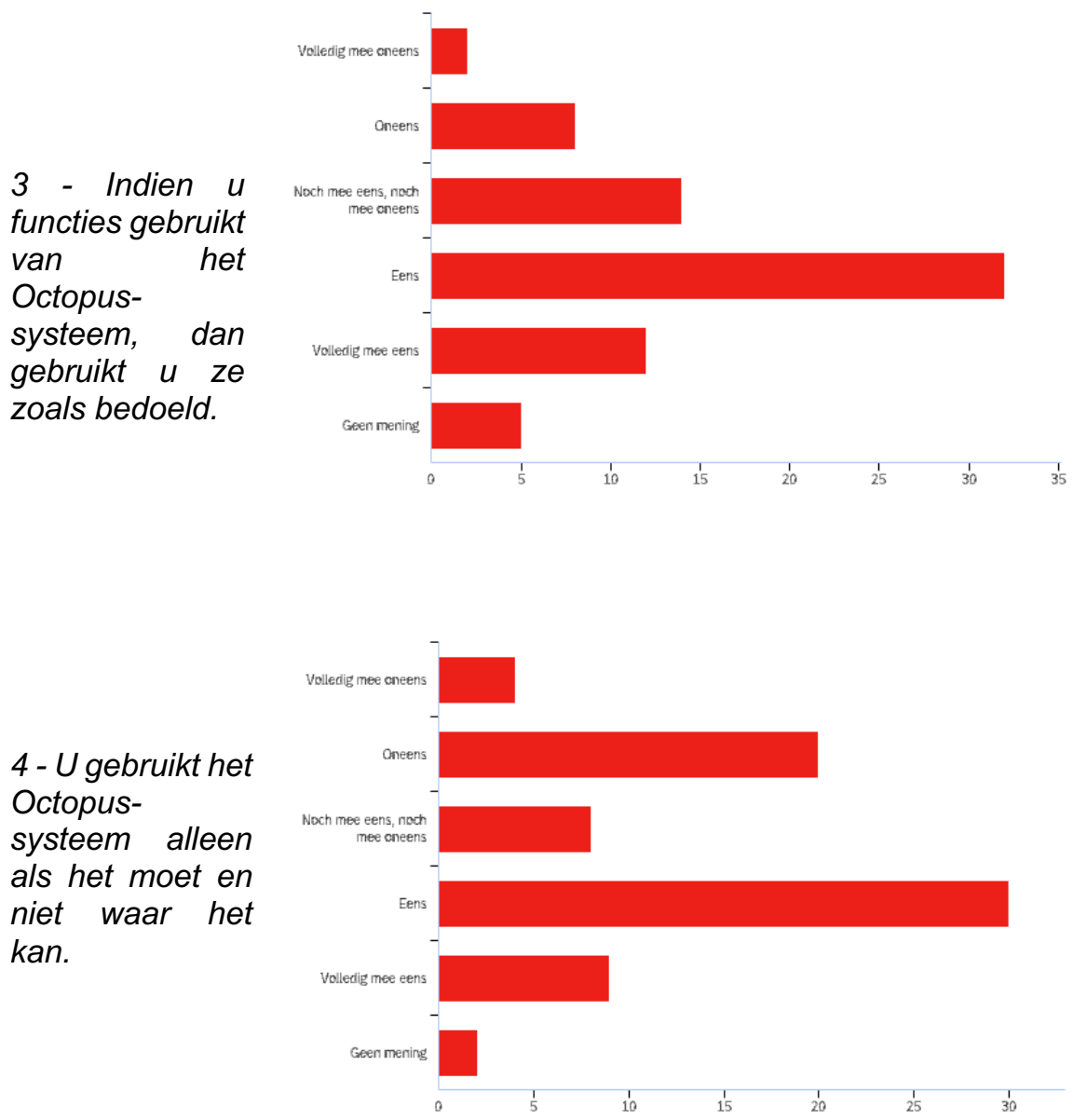

4 - U gebruikt het Octopus-

systeem alleen als het moet en niet waar het kan.

The outcome of the respondents regarding the 'user satisfaction' of Octopus (in Dutch): 
1 - De functies in het Octopussysteem helpen $u$ bij het doen van $u$ werk rond het behandelen van bezwaren en beroepen.

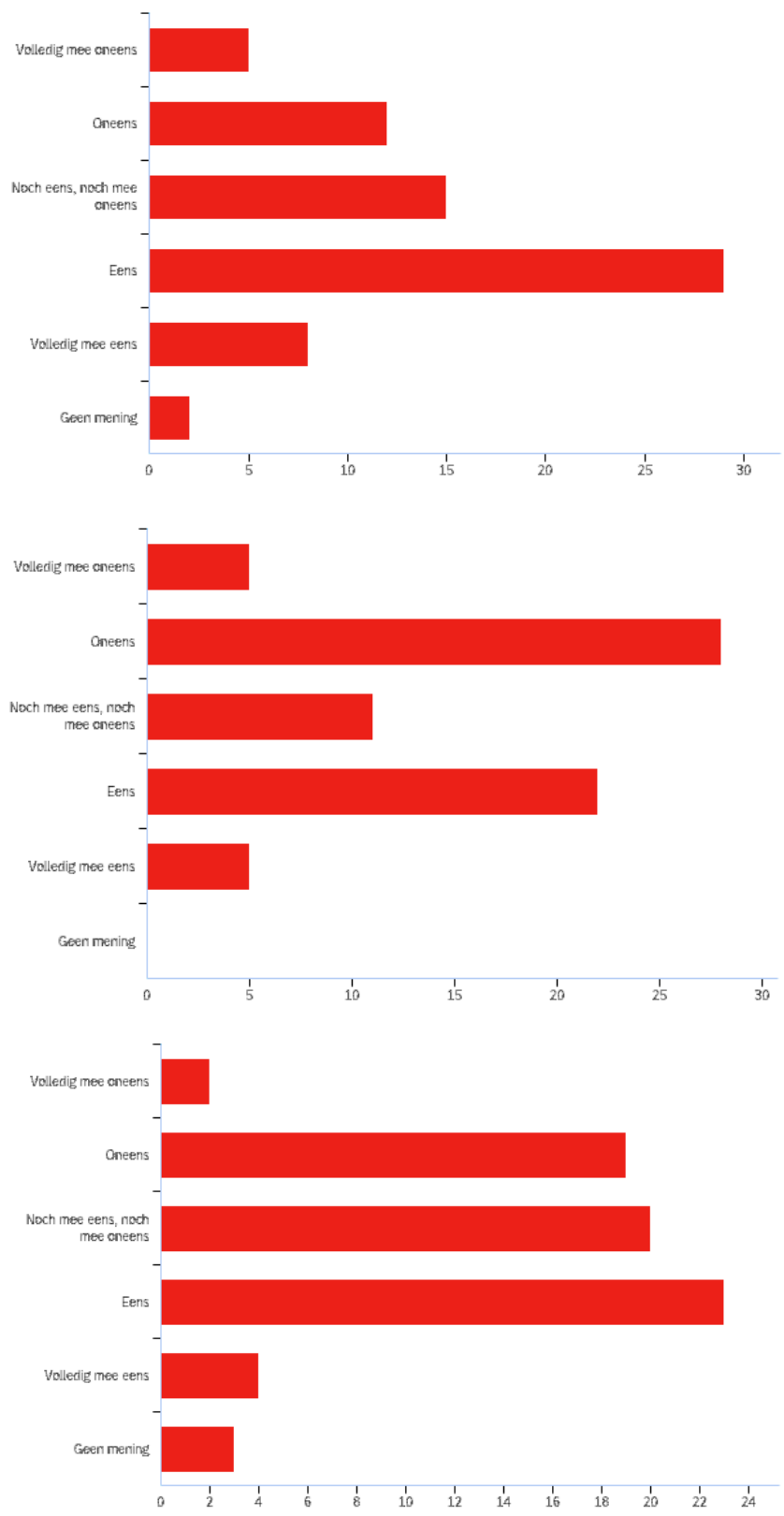

2 - U vindt het gemakkelijk om de verschillende functies van het Octopus-

systeem te gebruiken.

3 - Bij het gebruik van het Octopussysteem kunt $u$ behoefte hebben aan training, veranderingen aan het systeem, het oplossen van fouten in het systeem en 
andere vormen van dienstverlening. U krijgt voldoende ondersteuning m.b.t. bovengenoemde behoeftes vanuit functioneel beheer en/of ICT.
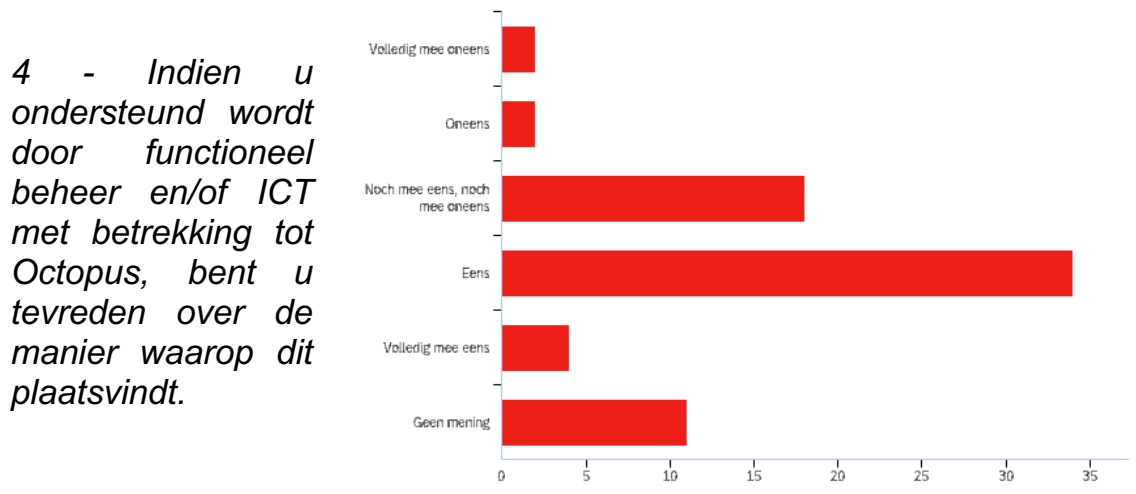

Received documents regarding Octopus (in Dutch):

- Business case KEl_v 01.07.16 v2

- Business case project digitalisering jur domein v0.3_verstuurd

- Projectvoorstel Digitalisering Juridisch domein v06

- PID Digitalisering Juridisch domein v1.0

- 2016-006-2.3_PSA Digitalisering juridisch domein 20161128

- TA Digitalisering Juridisch Domein_170712 9versie 0.94)

- TST_001 Master Test Plan OCTOPUS v0.3

- Statusupdate issues vrijgave advise 8 februari18 v01

- 2016-006-2.5 CAT advies Digitalisering juridisch domein

- Exceptierapport Uitstel project Sociaal_0.2

- Exceptierapport_KEl project_v0.2.

- Exceptierapport_aanbesteding Bezwaar en Beroep_v0.2

- Execptierapport_BRP koppeling_v0.2

- Reqruiements Octopus op procesniveau v0.5 OPM MdH

- Vastgestelde processchema's beroep etc RD 141116

- TA Discussiestuk Digitalisering Juridisch Domein_170317

- Agenda Stuurgroep project digitalisering juridisch domein 28 mei 2018

- Decharge project DJD tbv CAT 01 
- Eindrapportage_en_dechargeverklaring_DJD_0.2

- Einde projectarchitectuur 2018716

- Projectevaluatie_DJD_1_0

- Architectuur principes (ICT-principes)

- Stadsbrede IV-kaders 1.1

- Bestuurlijkkompas_gemeenteamsterdam_def

- 5 principes Amsterdam

- Strategisch meerjaren programma 2014 - 2018

All documents, interview recordings and minutes, survey outcome are stored at: Borgers, 2021, "Are Architecture Principles Effective?", https://doi.org/10.34894/RY1MOO, DataverseNL. Because of confidentiality access is restricted and permission by the author is necessary.

\section{F: Case study results of Epos}

The objective of the Epos-system is to implement a new, modern, and high-performance renewed version of MeNZa (MeNZa new), with similar and smarter user functionality and similar end products (among others PDF appointment).

The new Epos-system has to meet the following requirements:

1. A business card for the NZa, regarding the Look \& Feel and output (implemented)

2. Uniform process and lay-out (using style cards) (implemented)

3. Good performing (state-of-the-art, $\mathrm{mm} \mathrm{sec}$. response on clicking) (implemented)

4. Intuitively working system (implemented)

5. Scalable (also for the long term, regarding MijnNZa.nl) (implemented)

6. Comply with archiving requirements (implemented)

7. Comply with Security and Privacy requirements (implemented) 
8. Good and simple maintainable (partly implemented)

9. Flexible set up (implemented)

10. Shortening project lead time and testing time (implemented)

11. Future proof (implemented)

Architecture principles

- Specification: Despite lacking descriptions of the architecture principles itself, parts of principles were specified in documents and stakeholders could illuminate particular principles as well. Six of the architecture principles were well specified, the 'rational' and/or 'implications' were less clear for the others, such as "Business is leading", "Master data" and "KISS" (see Figure 50).

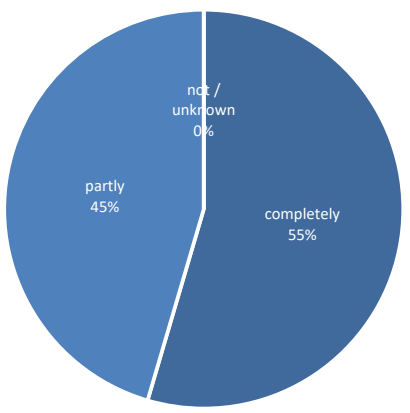

Figure 50: specification of the Epos's architecture principles

- Prerequisites: no prerequisites were defined, which is obvious when architecture principles are used implicitly only. The project met already some prerequisites at the start, such as expertise and technology for "Component Based Development". However, the prerequisites were not fulfilled for some other principles, like missing technology and/or knowledge to comply with "Re-use". 
- Measures: despite the support for all architecture principles, the Epos-system complied with nine principles and with two only partly. The fulfillment of the 'Reuse'principle was difficult, through which the re-use of complicated forms took more time of experts. For some developers the implications of KISS were not clear, with the effect that in the Epos-system was a less plain separation of

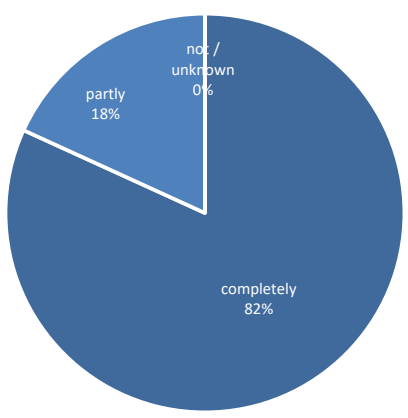

Figure 51: measure of the Epos's architecture principles presentation, business, and data-functions (see Figure 51).

- Meta data: although some parts of the architecture principles were described in project documents, no overview of principles was made. Therefore, no meta data related to one or more of the principles was in place. The principles "Component Based" and "Harmonization" were described in the documents "Besluitvorming Nieuwbouw MeNZa" and "Analyse Vernieuwing MeNZa 1.0".

- Quality: 8 of the architecture principles were (almost) matching all quality attributes $(82 \%)$ The other three principles had shortcoming on almost all attributes: 'Business is leading', 'KISS' and 'Agile' (see Figure 52).

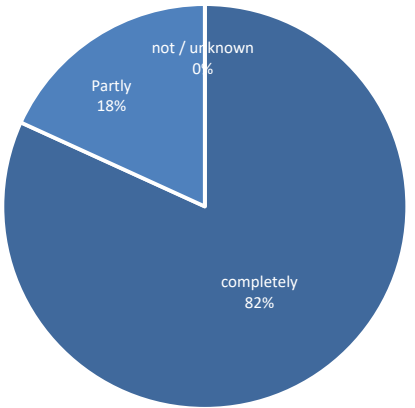

Figure 52: quality of the Epos's architecture principles 
In Figure 53 we present a snapshot of the measurement of the "On target" characteristic of IS project success of Epos. In this snapshot we show 1 of the 10 data sources we found regarding IS project success (in Dutch).

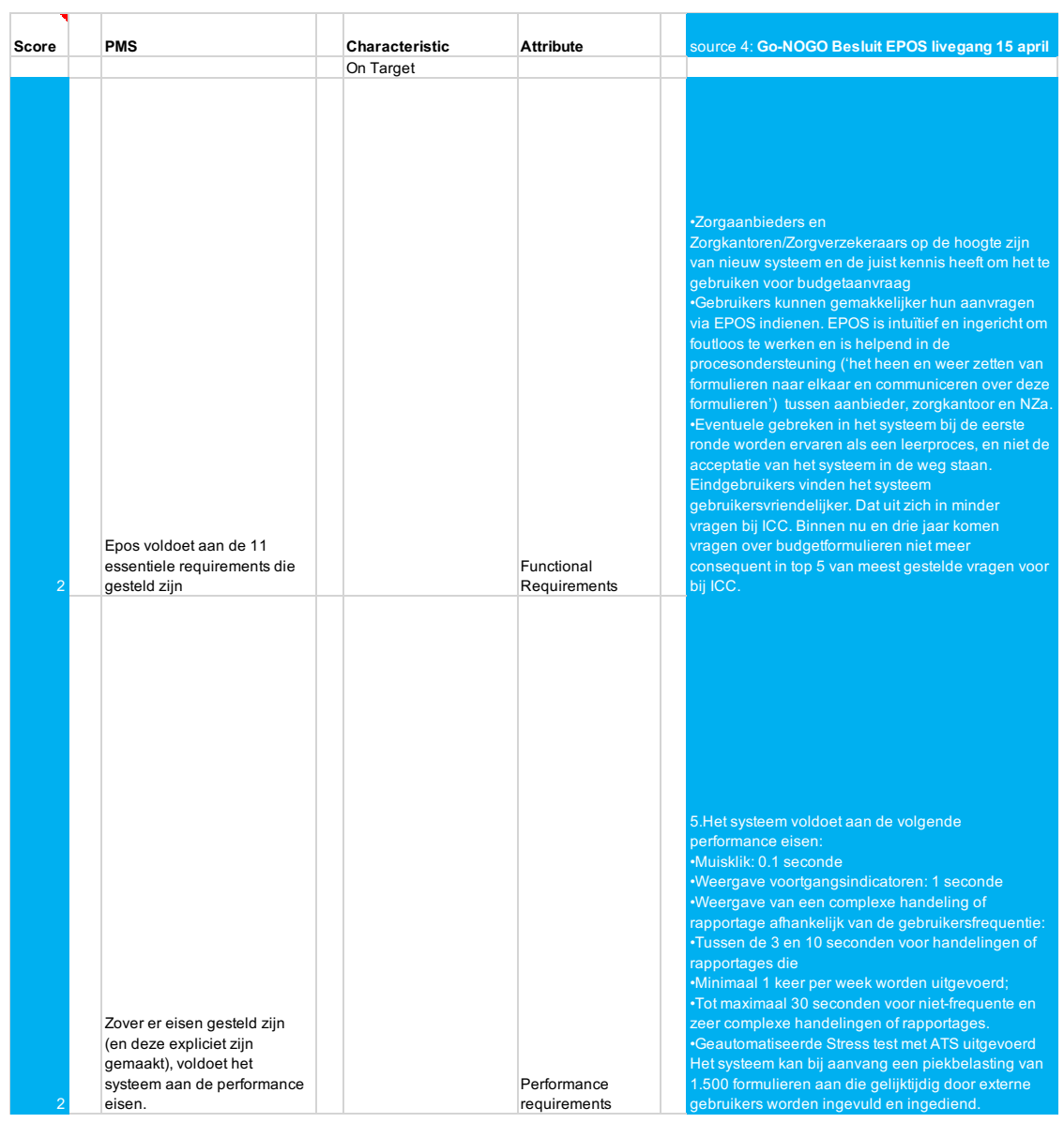

Figure 53: a snapshot of the measurement of "On target" of IS project success of Epos. 
In Figure 54 we present a snapshot of the definition check of all statements found, used in the Epos-project. In this snapshot we show 6 of the 11 statements of which all 11 were architecture principles (in Dutch).

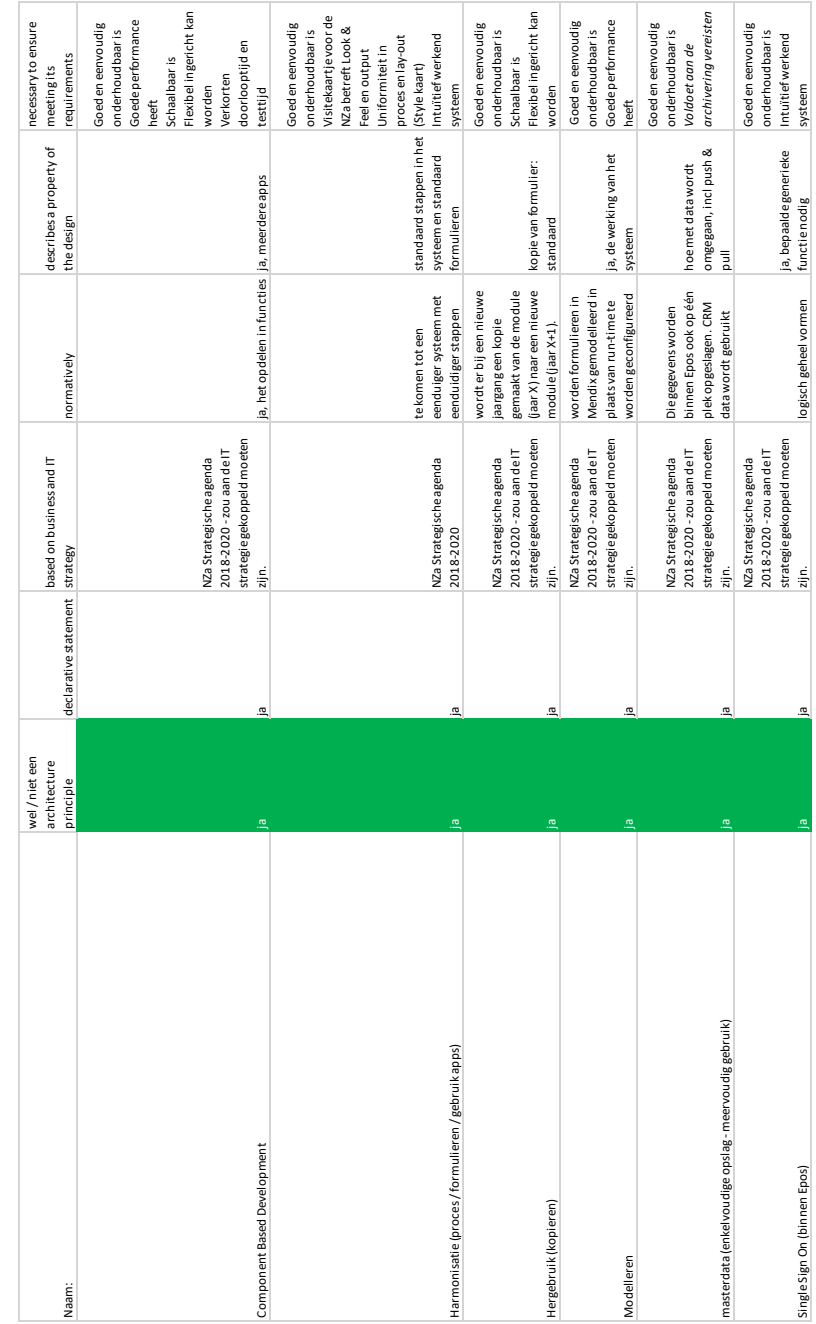

Figure 54: a snapshot of the definition check of the statements used in the Eposproject. 
In Figure 55 we present a snapshot of the measurement of the "Specification" characteristic of the architecture principle "Component Based." In this snapshot we show 1 of the 7 data sources we found for this principle (in Dutch).

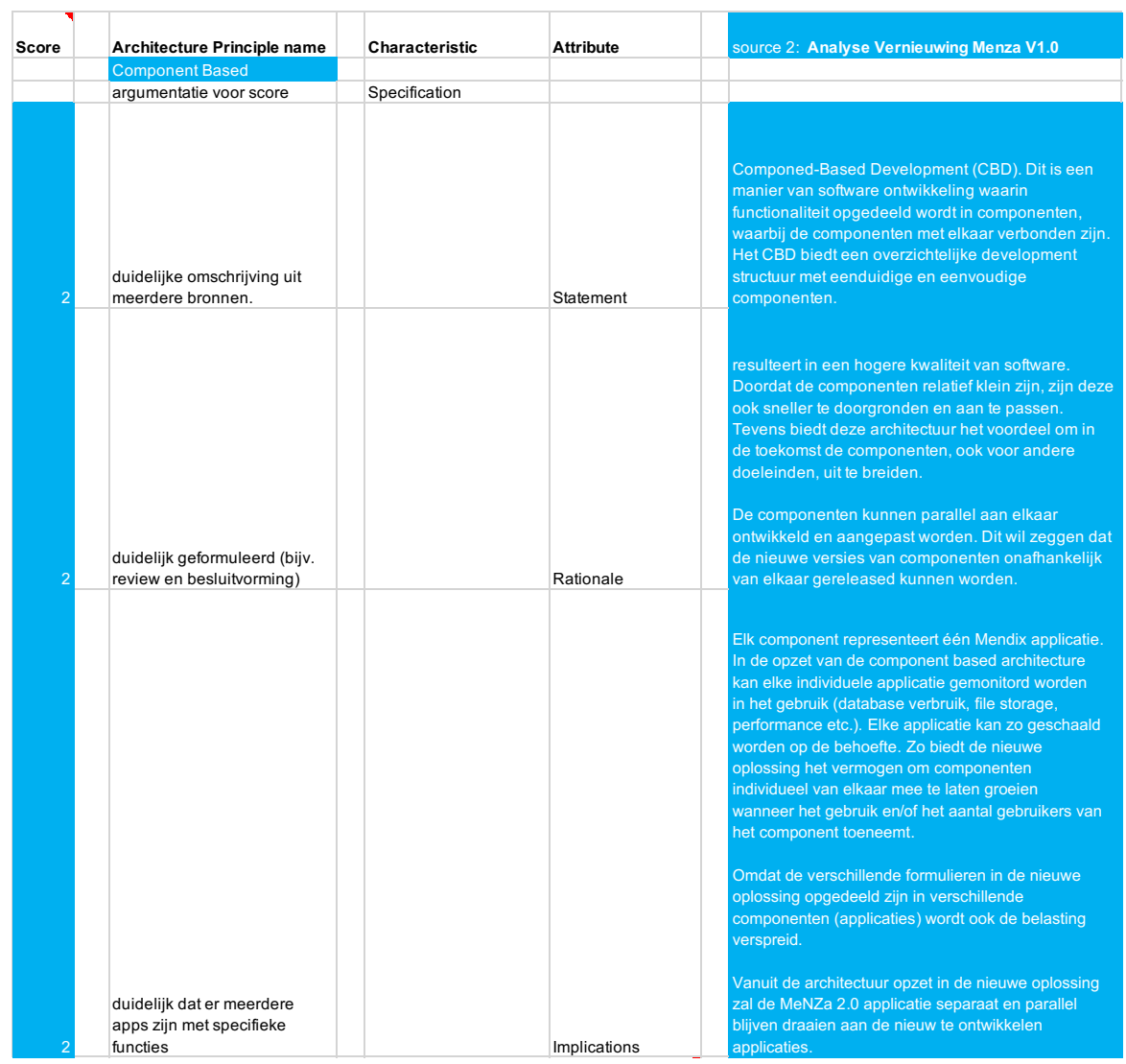

Figure 55: a snapshot of the measurement of "Specification" of the "Component Based" architecture principle of Epos.

- Classification: four principles were related to the entire information system, while the other seven principles were guiding the design of the application. Most of the principles were specifically used for 
implementing the Epos-system, while two principles had to apply to the entire NZa-organization: "Business is leading" and "Data minimalization".

- Quality of the set: the eleven principles were, almost, representative for implementing the essential requirements, covering the most of them. Almost all essential requirements could be related to one or more principles. There are no links between principles and the requirements "Comply with archiving requirements" and "Comply with Security and Privacy requirements". There is a dependency between the principle "Component Based" and "Microservices": the last is a refinement of the first principle. Project members discussed most of the principles during the project with the relevant stakeholders and some information could be found in project documentation as well. The principles were not inconsistent with each other; on the contrary, some pairs of principles were strengthening each other, like "Component Based" \& "Microservices" and "Business is leading" \& "Agile".

Received documents regarding Nest (in Dutch):

- 20170929 Brandbrief BB en Menza 2.0 SG

- 20181008 Communicatieplan EPOS

- Analyse Vernieuwing Menza_V1.0_27022018

- Besluitvorming Nieuwbouw MeNZa 31052018

- Epos architectuur review door Mendix

- Feed Back Analysefase NZa Organisatie

- GO-NO GO Besluit EPOS livegang 15 april

- NZa portaal Externe paneltest vaststelling 2018

- Planning EPOS

- Voorbeeld maandelijkse voortgang EPOS_Voortgangsrapportage 2018_12_14

- Voorbeeld Scrum board Jira EPOS

- NZa Strategische Agenda 2018-2020 
All documents, interview recordings and minutes, survey outcome are stored at: Borgers, 2021, "Are Architecture Principles Effective?", https://doi.org/10.34894/RY1MOO, DataverseNL. Because of confidentiality access is restricted and permission by the author is necessary.

\section{G: Overview of architecture principles used in the different cases}

Collection of all architecture principles used in the four cases used in this research, all translated from Dutch.

Table 29: The 36 architecture principles used within the TDi case.

\begin{tabular}{|c|c|c|c|}
\hline Nr. & Principle & Type of principle & Average score (\%) \\
\hline 1 & Organisational units do specialize & Information system & 67 \\
\hline 2 & Collaboration based on services & Information system & 70 \\
\hline 3 & $\begin{array}{l}\text { We share proven services within } \\
\text { the Dutch government }\end{array}$ & Information system & 70 \\
\hline 4 & $\begin{array}{l}\text { We communicate digitally with } \\
\text { citizen and companies, if possible }\end{array}$ & Information system & 66 \\
\hline 5 & $\begin{array}{l}\text { Data administration is done } \\
\text { digitally only }\end{array}$ & Information system & 67 \\
\hline 6 & $\begin{array}{l}\text { Digital workspaces offer } \\
\text { customized information }\end{array}$ & Information system & 64 \\
\hline 7 & $\begin{array}{l}\text { We connect with the activities of } \\
\text { citizens and companies }\end{array}$ & Information system & 65 \\
\hline 8 & $\begin{array}{l}\text { We develop knowledge about } \\
\text { laws and regulations and share } \\
\text { them }\end{array}$ & Information system & 65 \\
\hline 9 & $\begin{array}{l}\text { We strengthen the information } \\
\text { position of citizens and companies }\end{array}$ & Information system & 65 \\
\hline 10 & Design modularity carefully & $\begin{array}{l}\text { Application \& } \\
\text { Technical } \\
\text { infrastructure }\end{array}$ & 65 \\
\hline 11 & $\begin{array}{l}\text { Unique management and multiple } \\
\text { use of data }\end{array}$ & $\begin{array}{l}\text { Application \& } \\
\text { Technical } \\
\text { infrastructure }\end{array}$ & 67 \\
\hline
\end{tabular}



operations completely

Technical infrastructure

Application \&

Technical

infrastructure

14 Use services available (re-use,

Application \& before buy, before build)

Technical

infrastructure

Use ICT products as intended

Application \&

Technical

infrastructure

Deliver robust ICT services

Application \&

Technical

infrastructure

Take security risks consciously

Application \&

Technical

infrastructure

Solve problems at the source

Application \&

Technical

infrastructure

Employee centrally, tailor-made

Information system

66 information

20 Standard building blocks

21 Client-oriented payment and management of data

22 Establish source data

23 Exchange of information

24 Process characteristics

From object-oriented to subjectoriented

Information system

66

Information system

Information system

Information system $\quad 64$

26 Maximize compliant behaviour Integral production control

Information system

Data is used across contexts

Information system

67 alongside periodical transactions

30 The handling time of transactions

Information system matches the expectation of the customer positive and negative claims 

Customer Intimacy

34 Decoupling of risk detection and determining legal consequences Sensible reuse of process patterns and ICT facilities

Where possible, we shift
Information system

67

Information system

67

Information system

70

Information system functionality for transaction processing to the interaction process

\section{Table 30: the 9 architecture principles used within the Nest} case.

\begin{tabular}{|c|c|c|c|}
\hline Nr. & Principle & Type of principle & Average score (\%) \\
\hline 1 & $\begin{array}{l}\text { Output requirements are leading in } \\
\text { the design }\end{array}$ & Information system & 41 \\
\hline 2 & $\begin{array}{l}\text { Access of data based on access } \\
\text { rights }\end{array}$ & Application & 77 \\
\hline 3 & $\begin{array}{l}\text { Configuration of NEST in separate } \\
\text { files and tables }\end{array}$ & Information system & 80 \\
\hline 4 & Nest is divided in rest points & Application & 51 \\
\hline 5 & $\begin{array}{l}\text { Building modular, using } \\
\text { components (inversion of control) }\end{array}$ & Application & 80 \\
\hline 6 & $\begin{array}{l}\text { Web based application using the } \\
\text { model view controller }\end{array}$ & Application & 71 \\
\hline 7 & $\begin{array}{l}\text { Reuse of central components } \\
\text { (reuse - before buy - before build) }\end{array}$ & Application & 80 \\
\hline 8 & $\begin{array}{l}\text { Published data points to observed } \\
\text { data }\end{array}$ & Information system & 43 \\
\hline 9 & Logging of process steps & Application & 41 \\
\hline
\end{tabular}

Table 31: the 39 architecture principles used within the Octopus case.

Nr. Principle

1 The target application has to provide case information and documents to the administration of
Type of principle

Application

Average score (\%)

75 
justice, in accordance with the standards and guidelines op the KEI program.

2 The standard for message handling is used as defined by the administration of justice.

3 Each client (or their lawyer) logs into "MijnRechtspraak" using his OIN.

$4 \quad$ The target application connects with

Application

"Aansluitpunt Rechtspraak" for communication with the administration of justice in administrative law cases.

Communication for civil law cases "MijnRechtspraak" will be used. Communication with the Law Lords and Council of State the specific web portals will be used.

5 Documents can be retrieved and securely saved, using the target application. Functionality for the document management system is separated from the target application.

$6 \quad$ The target application is supporting case based way of working

7 Meta data will be added to the

Application documents via the target application

8 The current available application Application services are necessary in the target situation, at least

9 Personal data will be extracted out

Application of the primarily source only

10 The connection with the administration of justice has to be secure. Access management has to be in place by IT operations.

11 The target application and document solution have to be Application connected with other applications 
for information and document

sharing

12

The solution is available via ADW

only

13

Business is leading in information

supply

14

Information supply is designed with

guidelines and in coherence with all city hall functions

15

Information services will be shared and re-used

Data will be shared and re-used

Information services are secure and reliable are related to the necessity and benefits of it

Information is stored and processed based on European, Dutch and Open standards

20 The ICT department within the city hall is responsible for the governance of the IT-infrastructure Information services are governed by Amsterdam, and delivered by the market information supply

\section{Operational Excellence}

Supply / Demand

A full value proposition

Standardization of technology and process functionality the city hall of Amsterdam

Roll based access

Information system

Information system

100

Technical

infrastructure

Information system

Application

85

Application

88

Information system

Information system

Information system

Information system

80

Information system

Information system

Information system

Information system

Information system

Application \&

Technical

infrastructure

Application \&

Technical

infrastructure 
$31 \quad$ Risk based Information Security

$32(\mathrm{Re})$ use, before buy, before build

33 Amsterdam is a Majority Adopter of new technologies

$34 \quad$ One Suit before Best-Of-Breed

35 Clustering technology as low as in technology stack

$38 \quad$ Acceptation criteria

$$
\text { Independent of business processes }
$$

Virtualization as baseline

Process harmonization
Application \&

Technical

infrastructure

Application \&

80

Technical

infrastructure

Application \&

80

Technical

infrastructure

Application

70

Application \&

68

Technical

infrastructure

Application \&

80

Technical

infrastructure

Application \&

80

Technical

infrastructure

Application \&

Technical

infrastructure

Information 64 68 80

system

\section{0} 80 80 70 80 80

\section{Table 32: the 11 architecture principles used within the Epos case.}

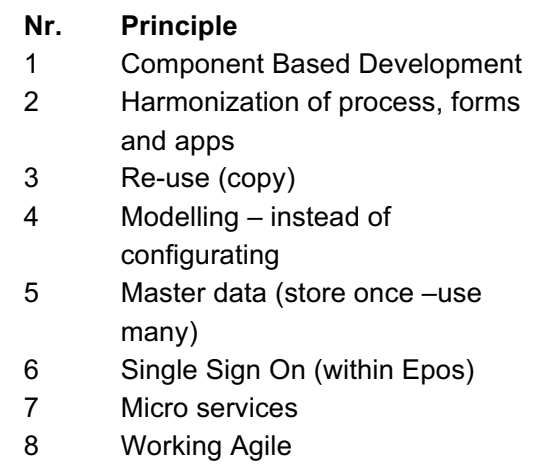

$\begin{array}{lc}\text { Type of principle } & \text { Average score (\%) } \\ \text { Application } & 68 \\ \text { Application } & 68 \\ & 62 \\ \text { Information system } & 70 \\ \text { Application } & \\ \text { Application } & 63 \\ \text { Application } & \\ \text { Application } & 51 \\ \text { Information system } & 65 \\ \end{array}$


9 KISS

10 Business is leading

11 Data minimalization
Application 37

Information system $\quad 38$

Information system $\quad 58$

\section{H: Procedure of the Focus Group Session}

We had a nominal Focus Group session with 7 participants, one observer and one researcher, on 29 May 2020. Because of the COVID-19 epidemic, the session was online. In the session we used a tool to ask questions to the participants and they could interact anonymously with a smart device.

During the session we asked the participants to answer the following questions:

I. Is there a (positive or negative) contribution of the use of architecture principles to IS project success in a specific case?

II. Can we discover factors in the different cases, which indicate if there is a (positive or negative) contribution of architecture principles to IS project success?

1. Preparation before session: All participants received one week before the session the concept reports of the individual cases, including the spreadsheets with the outcome of the qualitative and (light scale) quantitative analysis of the research data. They also received background information about the research project. 
2. Way of working question I:

1. Start Mentimeter.com and log on with code 922535
$\begin{aligned} \text { 2. We answer the first question per case: } \\ \text { - NEST - CBS } \\ \text { - Octopus - gemeente Amsterdam } \\ - \text { Epos - Nza }\end{aligned}$
3. We follow the questions of Mentimeter.
4. During the discussion in the group: please raise your hand

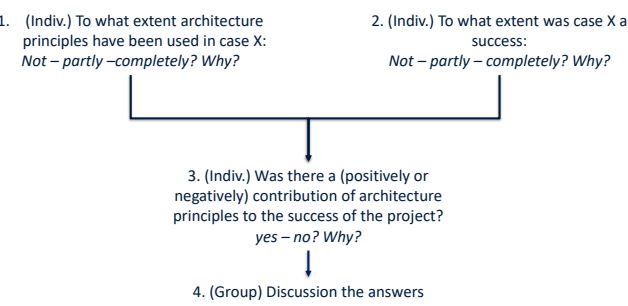

3. Way of working question II:

1. Start Mentimeter.com and log on with code 922535

2. Write down as many factors which might be indicators.

3. We address the facts one-by-one, most important one first

4. During the discussion in the group: please raise your hand

4. Reporting: minutes of the session were sent to all participants and comments were incorporated.

\section{I: Definitions of development process artefacts}

- Design principle: A normative principle on the design of an artifact. As such, it is a declarative statement that normatively restricts the design freedom [20].

- (Software) design pattern: is a general, solution to a commonly occurring problem within a given context in (software) design [128].

- (Technical) standard: A standard is a technical document designed to be used as a rule, guideline or definition. It is a consensus-built, repeatable way of doing something [129].

- Guide line: information intended to advise people on how something should be done or what something should be [89]. 


\section{CURRICULUM VITAE}

Michiel Borgers (1972, Rotterdam) graduated from the Emmaus College Rotterdam in 1991. He finished his study Computer Science at the TU Delft in 1997 and started his professional career in IT consulting. After advising organizations for 12 years, he became deputy director at the Dutch Tax and Customs Administration in 2008. Since 2017 is Michiel Borgers the $\mathrm{ClO}$ of Maastricht University.

In 2014 he started as parttime student PhD research at Maastricht University. Over the years he published 42 articles, of which 8 scientific papers. Michiel was visiting lecturer at several universities and colleges, and supervisor of several Master Science students. 
